\title{
ISOTOPE GEOCHEMISTRY OF GALLIUM IN HYDROTHERMAL SYSTEMS
}

by

\author{
Constance E. Payne
}

A thesis submitted to Victoria University of Wellington in partial fulfilment of the requirements for the degree of Master of Science

Victoria University of Wellington 


\section{ABSTRACT}

Little is known about the isotope geochemistry of gallium in natural systems (Groot, 2009), with most information being limited to very early studies of gallium isotopes in extra-terrestrial samples (Aston, 1935; De Laeter, 1972; Inghram et al., 1948; Machlan et al., 1986). This study is designed as a reconnaissance for gallium isotope geochemistry in hydrothermal systems of New Zealand. Gallium has two stable isotopes, ${ }^{69} \mathrm{Ga}$ and ${ }^{71} \mathrm{Ga}$, and only one oxidation state, $\mathrm{Ga}^{3+}$, in aqueous media (Kloo et al., 2002). This means that fractionation of gallium isotopes should not be effected by redox reactions. Therefore the physical processes that occur during phase changes of hydrothermal fluids (i.e. flashing of fluids to vapour phase and residual liquid phase) and mineralisation of hydrothermal precipitates (i.e. precipitation and ligand exchange) can be followed by studying the isotopes of gallium. A gallium anomaly is known to be associated with some hydrothermal processes as shown by the unusual, elevated concentrations (e.g. 290 ppm in sulfide samples of Waiotapu; this study) in several of the active geothermal systems in New Zealand.

The gallium isotope system has not yet been investigated since the revolution of high precision isotopic ratio measurements by Multi-Collector Inductively Coupled Plasma Mass Spectrometry (MC-ICPMS) and so a new analytical methodology needed to be established. Any isotopic analysis of multi-isotope elements must satisfy a number of requirements in order for results to be both reliable and meaningful. Most importantly, the analysis must represent the true isotopic composition of the sample. Ion-exchange chromatography is generally utilised to purify samples for analysis by MC-ICPMS and exclude potential mass interfering elements but care must also be taken to recover as close to $100 \%$ of the element of interest as possible, as column chromatography can often result in fractionation of isotopes (Albarède and Beard, 2004).

An ion exchange column chromatography methodology for the separation of gallium based on earlier work by Strelow and associates (Strelow, 1980a, b; Strelow and van der Walt, 1987; Strelow et al., 1974; van der Walt and Strelow, 1983) has been developed to ensure a quantitative and clean separation from the majority of elements commonly associated with hydrothermal precipitates and waters (i.e. As, $\mathrm{Sb}, \mathrm{Mo}, \mathrm{Hg}, \mathrm{W}, \mathrm{Tl}, \mathrm{Fe}$ and other transition metals). A protocol to measure the isotopes of $\mathrm{Ga}$ was developed by the adaptation of methods used for other stable isotope systems using the Nu Plasma MC-ICPMS at the School of Geography, Environment and Earth Sciences, Victoria University of Wellington, NZ.

Gallium isotopic ratios have been collected for a suite of samples representing the migration of hydrothermal fluids from deep fluids in geothermal reservoirs to the surface expression of hot spring waters and associated precipitates in hydrothermal systems. A range in $\delta^{71}$ GasRm994 values 
is observed in samples from Taupo Volcanic Zone geothermal fields from $-5.49 \%$ to $+2.65 \%$ in silica sinter, sulfide, mud and brine samples. Mineral samples from Tsumeb and Kipushi mines range from $-11.92 \%$ to $+2.58 \%$ o $\delta^{71}$ GasRm994. Two rock standards, BHVO-2 and JR-2 were also analysed for gallium isotopes with $\delta^{71}$ Gasrm994 values of $-0.92 \%_{0} \pm 0.12 \%$ and $-1.91 \%_{0} \pm 0.23 \%$ o respectively. 


\section{ACKNOWLEDGEMENTS}

I would like to thank my supervisor Terry Seward for giving me the opportunity to work on such an interesting and challenging project. I am very grateful for all your valuable insights, the constructive feedback, the ongoing support and encouragement. Thank you for sharing your experiences with me, knowing I am not the only student to collect all the data near the end has been a great comfort. To Monica Handler, thank you for all your assistance in the lab, and your feedback and patience. A big thank you to Sabrina Lange for making sure everything I could ever need was always there, and to Joe Heiss, whose assistance with preliminary work on the multicollector was invaluable. Thanks go to GNS and Mighty River Power for helping with access and collection of samples. To Joel Baker, thanks for helpful advice on running the MC and your comments on establishing a new isotope measurement protocol, and Marc-Alban Millet for your enthusiastic support at the early stages of this project and always being available when I needed you. Loretta, thanks for being my lab buddy and for holding my hand when taking over the reins for the MC, thank you for always being there to answer my many little questions.

The School of Geography, Environment and Earth Sciences at Victoria has been a great place to complete my Masters, and I'd like to thank all the staff for their support through all the ups and downs. To the wonderful group of post-graduate students in the department, thank you, your banter and distractions have made my time here memorable. To my amazing office mates during the course of my Masters, thank you for the conversation, and welcome distractions. In particular, Loretta and Jenni, thank you for making my time spent in the office so enjoyable, for putting up with me and the clutter that follows, and for providing much welcome and amusing conversation. To the team at Kenex, thank you for your understanding and flexibility and for the many opportunities you have given me throughout the duration of my Masters project.

I would like to acknowledge the financial support from Toihuarewa in the form of the Tu Horomata scholarship, and Nga Puhi in the form of the Masters Disbursement.

To Shyamal, I can't thank you enough for all your love and support. Thank you for your understanding and for putting up with me coming and going at all hours of the night while running columns and writing up. You will always be my rock that I will never truly understand. Thank you for challenging me, for loving me and for helping me, I couldn't have processed all my data so swiftly without you.

Lastly, to my friends and most importantly my family, thank you. I cannot express my appreciation for the support you have given me. Thank you for your patience, your unconditional love and your encouragement, without any of which I could not have completed this work. 


\section{TABLE OF CONTENTS}

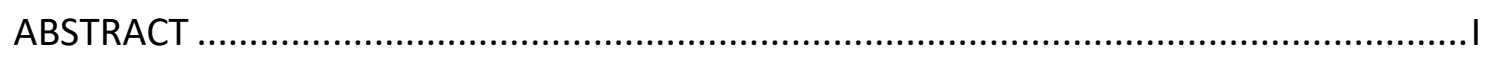

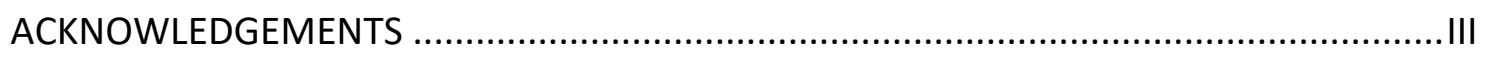

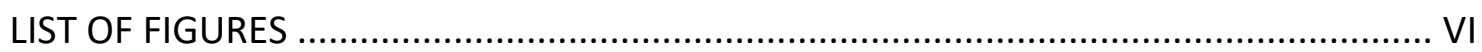

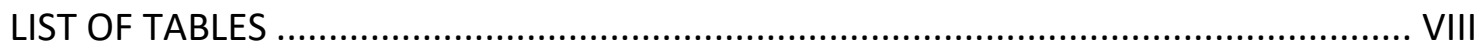

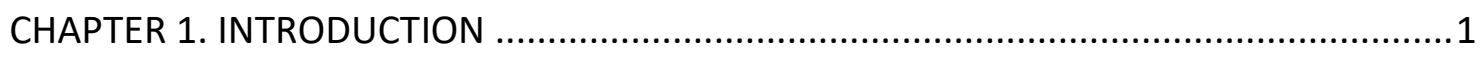

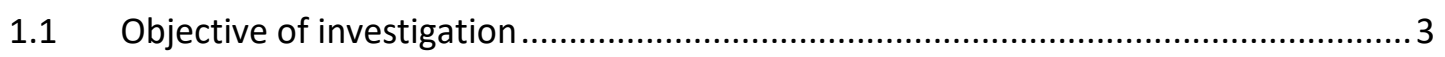

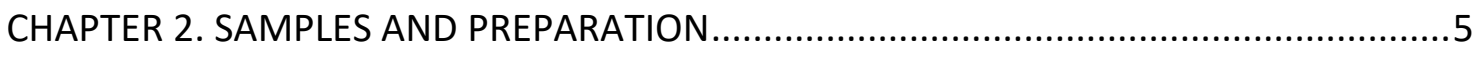

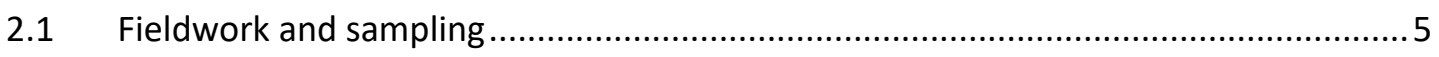

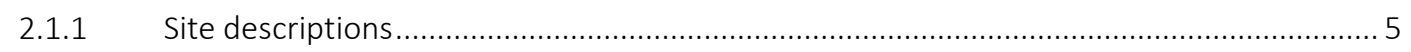

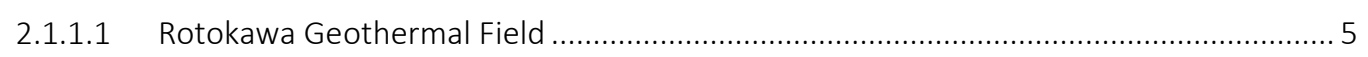

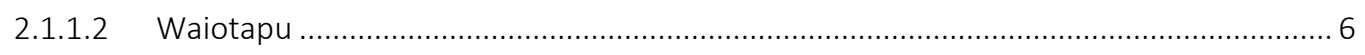

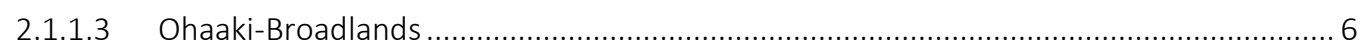

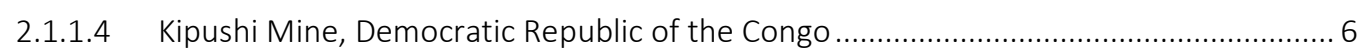

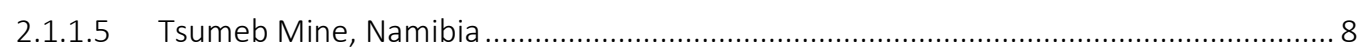

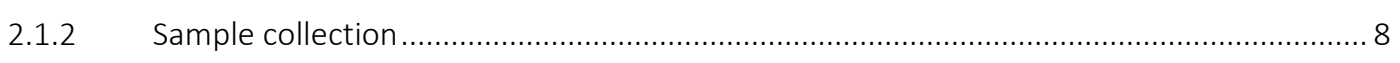

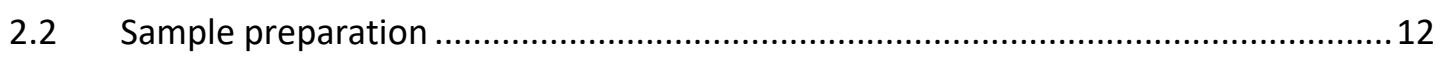

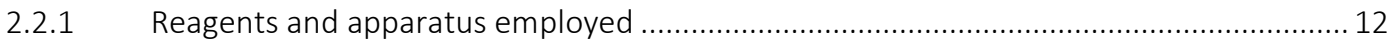

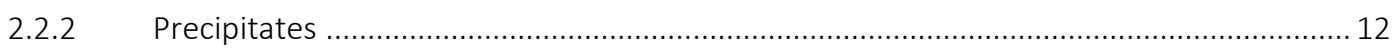

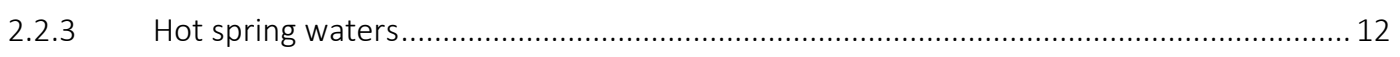

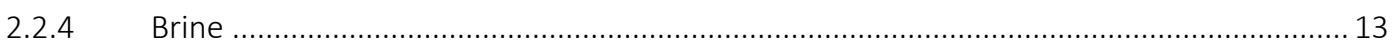

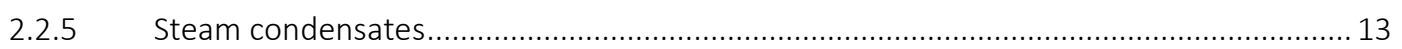

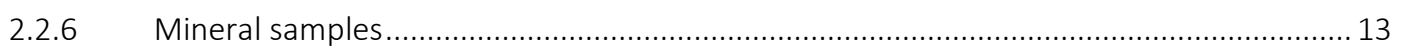

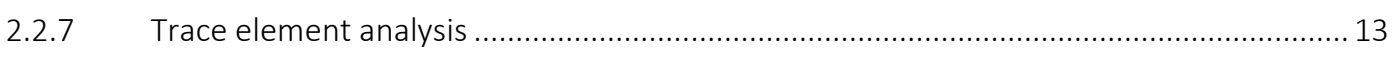

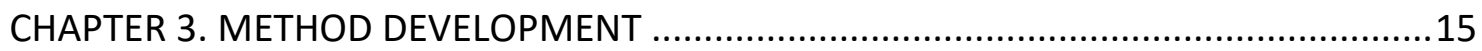

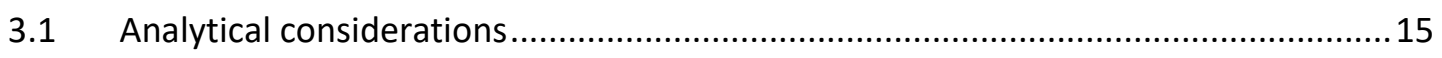

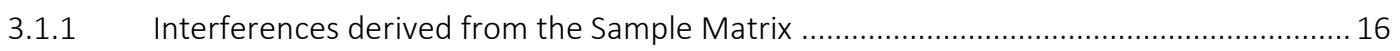

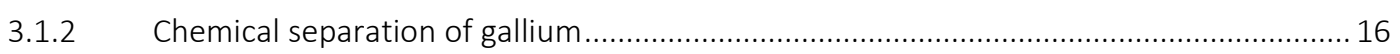

3.1.2.1 Anion Exchange Resins..................................................................................... 17

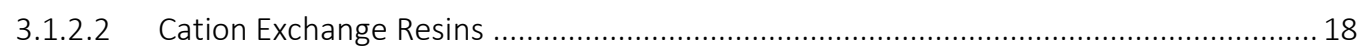

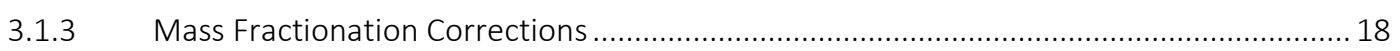

3.1.4 Simple Sample-Standard Bracketing Correction ............................................................. 20



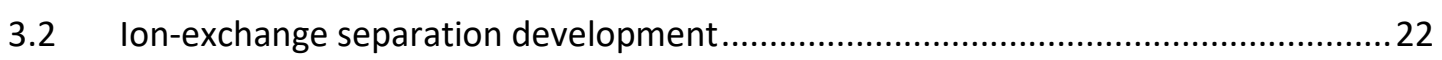

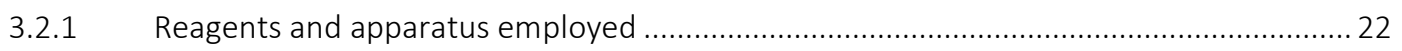

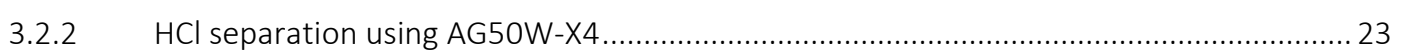

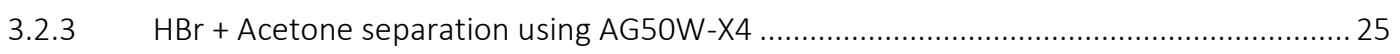

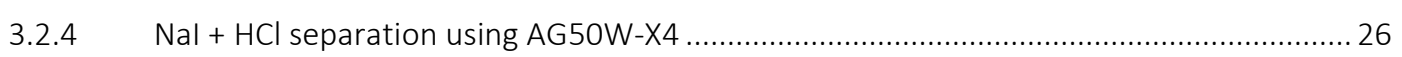

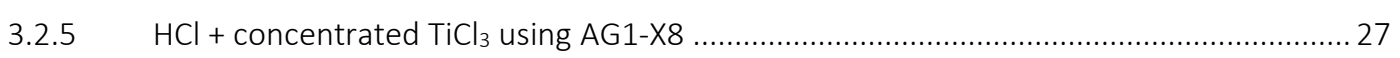




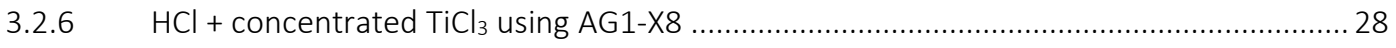

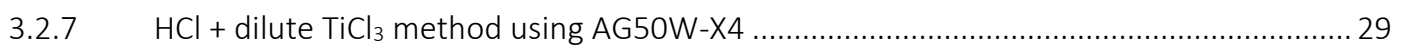

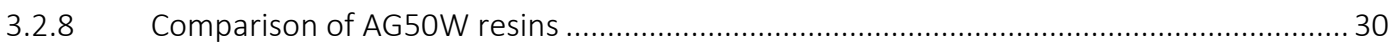

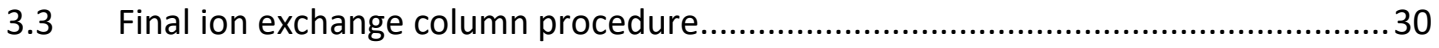

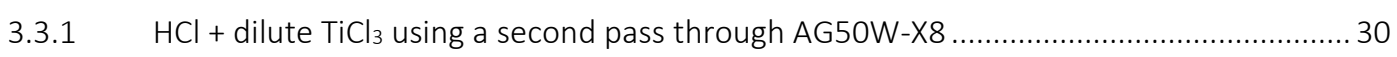

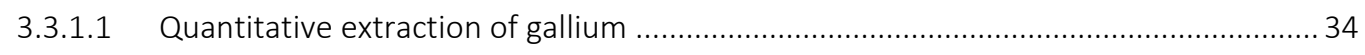

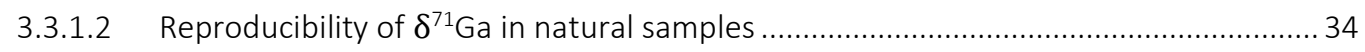

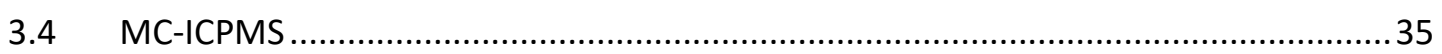

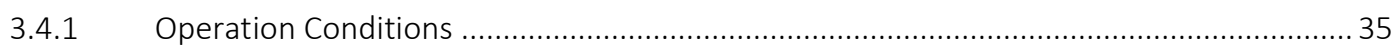

3.4.2 Mass fractionation correction .................................................................................. 36

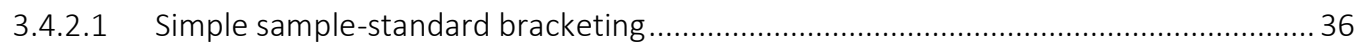

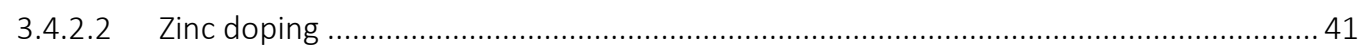

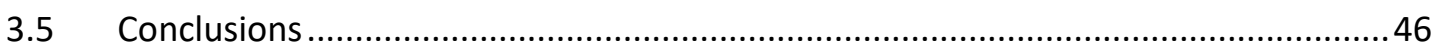

CHAPTER 4. RESULTS AND DISCUSSION ......................................................48

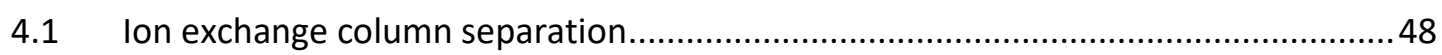

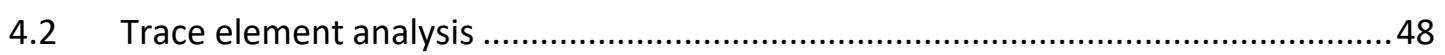

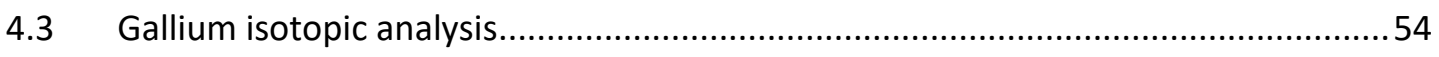

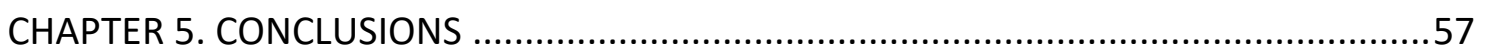

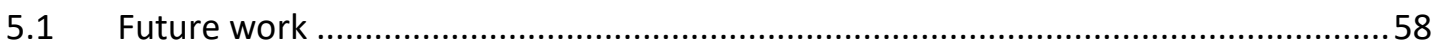

5.1.1 Gallium in the other phases of hydrothermal systems .............................................. 58

5.1.2 Speciation of gallium in hydrothermal fluids ............................................................. 59

5.1.3 Fine structure of gallium-sulfide/gallium-silica complexes ..............................................5 59

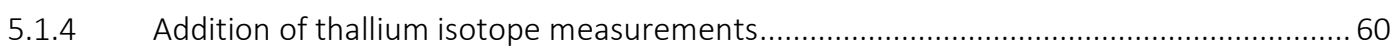

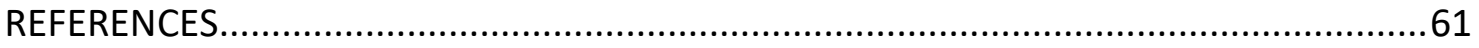

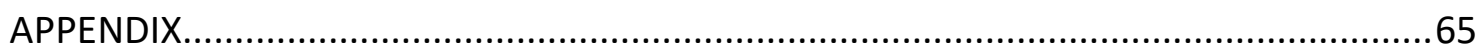




\section{LIST OF FIGURES}

Figure 2.1 Location of geothermal fields sampled for this study. Areas in brown indicate active hydrothermal zones. The map created using ESRI ArcGIS 10.4 utilising available basemaps.

Figure 2.2 Location of Tsumeb Mine, Tsumeb, Namibia and Kipushi Mine, Kipushi, Democratic Republic of the Congo. The map created using ESRI ArcGIS 10.4 utilising available basemaps.

Figure 3.1 Graphical representation of the simple sample-standard bracketing correction. This method corrects for drift and machine fractionation at the same time. The insert shows the drift between standards over the course of the analysis, can be approximated by the exponential law between standards.

Figure 3.2 Elution curve for $\mathrm{HCl}$ separation using $5.5 \mathrm{~cm}$ AG50W-X4, 100-200 mesh. gallium is separated from $\mathrm{Ag}, \mathrm{Cr}, \mathrm{Mn}, \mathrm{Mo}, \mathrm{Pt}, \mathrm{Sn}$, and V. Fe, Sb and TI display a second peak in $2.5 \mathrm{M} \mathrm{HCl}$. Zn, and As persist in the Gallium eluate.

Figure 3.3 Elution curve for $\mathrm{HBr}+$ Acetone using $5.5 \mathrm{~cm}$ AG50W-X4, 100-200 mesh. gallium is separated from $\mathrm{Ag}, \mathrm{Cu}, \mathrm{Sb}$ and $\mathrm{TI}$. $\mathrm{Cr}, \mathrm{Fe}, \mathrm{Mn}$ and $\mathrm{V}$ display a second peak in 2.5 $\mathrm{M} \mathrm{HCl}$. Zinc persists in the Gallium eluate.

Figure 3.4 Elution curve for $\mathrm{Nal}$ in $\mathrm{HCl}$ using $3.5 \mathrm{~cm}$ AG50W-X4, 100-200 mesh. gallium is separated from $\mathrm{Ag}, \mathrm{Cr}, \mathrm{Mn}, \mathrm{Mo}, \mathrm{Pt}, \mathrm{As}$, and V. Fe displays a second peak in $2.5 \mathrm{M}$ $\mathrm{HCl}$. Sb, Sn, and zinc persist in the Gallium eluate.

Figure 3.5 First pass through $11 \mathrm{~cm} \mathrm{AG50W-X8,100-200} \mathrm{mesh.} \mathrm{A} \mathrm{and} \mathrm{B} \mathrm{are} \mathrm{elements} \mathrm{eluted}$ in a blank column, i.e. no sample was loaded, $C$ and $D$ are elements eluted when the synthetic standard is loaded. In the order of alternating grey and white boxes: 0-10 ml. MQ water, $10-50 \mathrm{ml} 2.5 \mathrm{M} \mathrm{HCl}, 50-100 \mathrm{ml}, 8 \mathrm{M} \mathrm{HCl}, 100-110 \mathrm{ml} \mathrm{HCl}+$ $0.3 \% \mathrm{TiCl}_{3}, 110-115 \mathrm{ml}$ sample is loaded in $\mathrm{HCl}+0.3 \% \mathrm{TiCl}_{3}, 115-205 \mathrm{ml} \mathrm{HCl}+$ $0.3 \% \mathrm{TiCl}_{3}, 205-305 \mathrm{ml} 8 \mathrm{M} \mathrm{HCl}, 305-350 \mathrm{ml} 2.5 \mathrm{M} \mathrm{HCl}$ (Ga eluent). Gallium has been satisfactorily separated from $\mathrm{Sc}, \mathrm{V}, \mathrm{Cr}, \mathrm{Mn}, \mathrm{Co}, \mathrm{Ni}, \mathrm{Ag}, \mathrm{Pt}, \mathrm{Mo}, \mathrm{Sb}, \mathrm{Tl}, \mathrm{Bi}$ and $\mathrm{Sn}$. Small amounts of $\mathrm{Fe}, \mathrm{Zn}, \mathrm{W}, \mathrm{As}, \mathrm{Au}, \mathrm{Mg}, \mathrm{Al}$, and $\mathrm{Hg}$ remain. Errors are below $5 \%$ for all elements except $\mathrm{Au}, \mathrm{Mo}$ and $\mathrm{W}$ which are below $35 \%$.

Figure 3.6 Second pass through $11 \mathrm{~cm}$ AG50W-X8, 100-200 mesh. A and B are elements eluted in a blank column, $C$ and $D$ are elements eluted when the synthetic standard is loaded. In the order of alternating grey and white boxes: $0-5 \mathrm{ml}$ sample is loaded, 5-55 ml $8 \mathrm{M} \mathrm{HCl}, 55-100 \mathrm{ml} 2.5 \mathrm{M} \mathrm{HCl}$ (Ga eluent). Gallium has been satisfactorily separated from the remaining elements. Less than $5 \mathrm{ppb}$ persists of $\mathrm{Al}, \mathrm{Cu}, \mathrm{Mn}$, and Fe. Errors are below 3\% for all measureable elements except $\mathrm{Au}, \mathrm{Mo}$ and $\mathrm{W}$ which are below $40 \%$.

Figure 3.7 Repeat analyses on two rock standards: JR-2, rhyolite powder, Geological Survey of Japan; BHVO-2, basalt powder, United States Geological Survey. Three different portions of JR-2 powder were digested and processed separately for gallium isotope analysis and three aliquots of the same portion of digested BHVO-2 powder were taken and processed individually for gallium isotope analysis. Filled squares indicate individual analyses; open squares indicate the 
mean of the individual analyses (i.e. black squares) and the associated error bars reporting two times the standard deviation.

Figure 3.8 External reproducibility of the simple sample-standard bracketing method assessed by repeated measurements of CM gallium single element standard ( $\mathrm{n}=$ 27). Measurements were carried out between December 2015 and May 2016

Figure 3.9 Analytical run showing the effect of sample concentration (CRM-Ga single element standard; 1 ppb, 5, ppb, 15 ppb, 30 ppb, 60 ppb and 100 ppb) on the calculated gallium isotope ratio using the simple sample-standard bracketing technique when bracketed with SRM994 gallium isotope standard (100 ppb). Between $60 \mathrm{ppb}$ and $100 \mathrm{ppb}$ the gallium ratio value falls within $2 \mathrm{sd}$ of the average for CRM-Ga single element standards analysed in this study (average = $2.04 \%$ ).

Figure 3.10 External reproducibility of the simple sample-standard bracketing method assessed by repeated measurements of SRM994 gallium isotope standard ( $n=$ 293). Measurements were carried out between April 2015 and May 2016

Figure $3.11 \mathrm{Ln}$-Ln plots of the two zinc ratios, ${ }^{68} \mathrm{Zn} /{ }^{64} \mathrm{Zn}$ and ${ }^{68} \mathrm{Zn} /{ }^{66} \mathrm{Zn}$, that have the best linear lest squares correlations when plotted against ${ }^{71} \mathrm{Ga} /{ }^{69} \mathrm{Ga}$. These two have been used to calculate the corrected gallium isotope ratio. The linear fit indicates that the $\beta Z n / \beta G a$ is constant during an analytical session.

Figure $3.12 \mathrm{Ln}$-Ln plots of remaining zinc isotope pairs. Pairs containing ${ }^{70} \mathrm{Zn}$ and ${ }^{67} \mathrm{Zn}$ have consistently poor linear correlations to the natural logarithm of the gallium ratio. .42

Figure 3.13 External reproducibility of the zinc doped sample-standard bracketing method assessed by repeated measurements of CRM gallium single element standard ( $\mathrm{n}$ = 11) corrected using the ${ }^{68} \mathrm{Zn} /{ }^{64} \mathrm{Zn}$ isotope pair. Measurements were carried out between March and May 2016.

Figure 3.14 Analytical run showing the effect of sample concentration (CRM-Ga single element standard; 1 ppb, 5, ppb, 15 ppb, 30 ppb, 60 ppb and 100 ppb) on the calculated gallium isotope ratio using the $\mathrm{Zn}$-doped sample-standard bracketing technique when bracketed with SRM994 gallium isotope standard (100 ppb) doped with CRM-Zn Single element standard corrected using the ${ }^{68} \mathrm{Zn} /{ }^{64} \mathrm{Zn}$ isotope pair. Samples measured at $\leq 60 \mathrm{ppb}$ are very different to those measured at $100 \mathrm{ppb}$.

Figure 3.15 A: External reproducibility of the zinc doped sample-standard bracketing technique assessed by repeated measurements of SRM994 gallium isotope standard $(n=72)$ corrected by the ${ }^{68} \mathrm{Zn} /{ }^{64} \mathrm{Zn}$ isotope pair. B: Corrected by the ${ }^{68} \mathrm{Zn} /{ }^{66} \mathrm{Zn}$ isotope pair. Measurements were carried out between September 2015 and May 2016.

Figure 4.1 Comparison of $\delta^{71} \mathrm{G}$ a values analysed in this study and previously measured stony-iron meteorites. 


\section{LIST OF TABLES}

Table 1.1 Concentration of Gallium in Hydrothermal-Related Locations ................................... 2

Table 1.2 Isotope composition of gallium in iron meteorites....................................................... 3

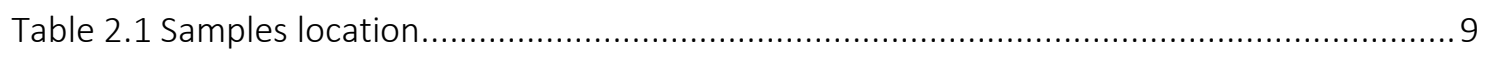

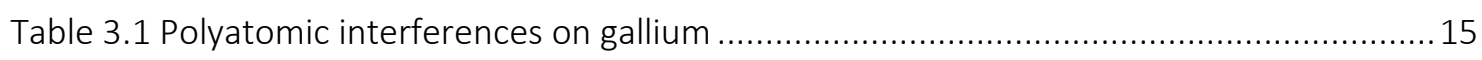

Table 3.2 Elements present in the gallium eluate for $\mathrm{HCl}+$ concentrated $\mathrm{TiCl}_{3}$ in $\mathrm{AG} 50 \mathrm{~W}-\mathrm{X} 4$.... 29

Table 3.3 Elements present in the gallium eluate for $\mathrm{HCl}+$ dilute $\mathrm{TiCl}_{3}$ using $\mathrm{AG} 50 \mathrm{~W}-\mathrm{X} 8$........... 30

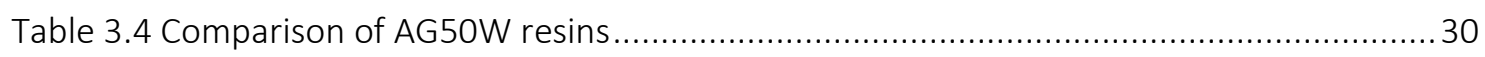

Table 3.5 Results from SRM994 gallium isotope standard tests with final column procedure ... 34

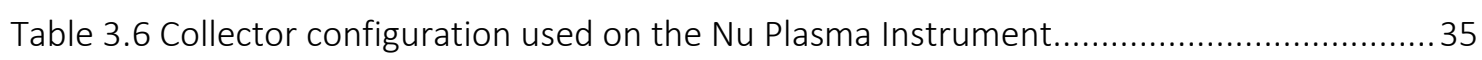

Table 3.7 Operating conditions used on the Nu Plasma Instrument......................................... 36

Table 3.8 Effect on the standard bracket corrected $\delta^{71} \mathrm{G}$ a value when the standard (run as a sample) is doped with various concentrations of elements known to cause non-

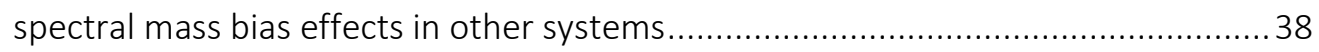

Table 3.9 Isotopic mass and abundances of gallium and zinc isotopes..................................... 41

Table 3.10 Effect on the zinc corrected $\delta^{71} \mathrm{Ga}$ value when the standard (run as a sample) is doped with various concentrations of elements known to cause non-spectral mass bias effects in other systems

Table 4.1 Trace element analysis of collected samples: First row transition metals and gallium 50

Table 4.2 Trace element analysis of collected samples: metals commonly associated with hydrothermal systems and gallium.

Table $4.3 \delta^{71} \mathrm{Ga}$ value for analysed hydrothermal samples, epithermal ore minerals and rock standards 


\section{CHAPTER 1. INTRODUCTION}

The geochemistry of gallium has been little studied and in particular, the chemical behaviour of the two stable isotopes of gallium in natural systems and under hydrothermal conditions is unknown. Gallium is a rare element in the Earth's crust, occurring mainly as a trace element in minerals (Shaw, 1957) such as the aluminium oxides and hydroxides (böhmite, gibbsite, and diaspore) which comprise "bauxite", the main source of gallium that is extracted as a by-product of aluminium production. Its average crustal abundance is $18 \mathrm{ppm}$ (John, 2001). Gallium minerals are few and rare and have been found mainly in two sulfide ore deposits (i.e. at Tsumeb, Namibia and at the Kipushi deposit, Katanga, Democratic Republic of the Congo). These rare minerals include gallite $\left(\mathrm{CuGaS}_{2}\right)$, ishiharaite $((\mathrm{Cu}, \mathrm{Ga}, \mathrm{Fe}, \mathrm{In}, \mathrm{Zn}) \mathrm{S})$ and several supergene phases such as sohngeite $\left(\mathrm{Ga}(\mathrm{OH})_{3}\right)$, tsumgallite $(\mathrm{GaO}(\mathrm{OH}))$, gallobeudantite $\left(\mathrm{PbGa}_{3}(\mathrm{AsO} \mathrm{O}\right.$ $\left.\left.{ }_{4}\right)\left(\mathrm{SO}_{4}\right)(\mathrm{OH})_{6}\right)$ and krieselite $\left((\mathrm{Al}, \mathrm{Ga})_{2}\left(\mathrm{GeO}_{4}\right)(\mathrm{OH})_{2}\right)$. Gallium also occurs in concentrations up to $2 \mathrm{wt} \%$ in the two Ge-containing sulfide minerals renierite $\left((\mathrm{Cu}, \mathrm{Zn})_{11} \mathrm{Fe}_{4}(\mathrm{Ge}, \mathrm{Ga})_{2} \mathrm{~S}_{16}\right)$ and briartite $\left(\mathrm{Cu}_{2}(\mathrm{Zn}, \mathrm{Fe})(\mathrm{Ge}, \mathrm{Ga}) \mathrm{S}_{4}\right)$, both of which occur in the hydrothermal sulfide ores at Tsumeb and Kipushi. The distribution of trace gallium in various Earth materials has been summarised by Shaw (1957), Wood and Samson (2006) and Rytuba et al. (2003).

In New Zealand, spectacular and globally unique concentrations of gallium occur in surface precipitates and well discharges in several active geothermal systems (Rotokawa, Waiotapu, and Ohaaki-Broadlands) in the Taupo Volcanic Zone of the North Island (Weissberg et al., 1979; Krupp and Seward, 1987; 1990; Crump, 1995). Gallium precipitation from the surface discharging hydrothermal fluids is currently on-going. Gallium concentrations up to $700 \mathrm{ppm}$ (Table 1.1) occur in the sulfide rich, siliceous precipitates, which also contain up to $10 \mathrm{wt} \%$ of arsenic and antimony, as well as anomalous concentrations of $\mathrm{Au}, \mathrm{Ag}$, $\mathrm{Tl}$ and $\mathrm{Hg}$ (Weissberg et al., 1979).

Of particular interest is the stable isotope chemistry of gallium in natural Earth systems, which has been hitherto, essentially unstudied. There are two stable isotopes of gallium: ${ }^{69} \mathrm{Ga}$ and ${ }^{71} \mathrm{Ga}$ and the natural abundance of these is $60.11 \%$ and $39.89 \%$ respectively (Aston, 1935; De Laeter, 1948; Machlan et al., 1986). Reported values of isotopic fractionation extend to greater than $30 \%$, a variation thought to be a result of measurement imprecision. Significant fractionation has been detected when sending a continuous electrical current through gallium metal (Neif and Roth, 1954; Goldman et al., 1956; Gramlich and Machlan, 1985; Machlan et al., 1986), as well as in ion exchange chromatographic columns (Gramlich and Machlan, 1985; Machlan and Gamlich, 1988; Dembinski et al., 2006). Inghram et al. (1948) and De Laeter (1972) measured the isotopic composition of gallium in a number of meteorites and a single terrestrial sample (i.e. 
a syenite rock standard, SY-3 of Gillieson; 1969). Both concluded that the isotopic composition of meteorites agreed (within error at that time) with the terrestrial SRM994 gallium isotope standard, the deviation from the terrestrial mean ranging significantly from $+0.6 \%$ to $-1.1 \%$ o (Table 1.2).

Table 1.1 Concentration of Gallium in Hydrothermal-Related Locations

\begin{tabular}{|c|c|c|c|c|}
\hline Location & $\begin{array}{l}\text { Number of } \\
\text { Samples }\end{array}$ & $\begin{array}{l}\text { Gallium } \\
\text { Concentrations* }\end{array}$ & Sample Types & Source \\
\hline Japan & 98 & $0.11-72 \mathrm{ppb}(2.5)$ & $\begin{array}{l}\text { Hot spring waters and } \\
\text { precipitates }\end{array}$ & $\begin{array}{l}\text { Uzumasa and Nasu } \\
(1960)\end{array}$ \\
\hline Paradise Peak, Nevada & - & 84-118 ppm & - & \multirow{2}{*}{ Rytuba et al. (2003) } \\
\hline McDermitt, Nevada & - & $2.0-93 \mathrm{ppm}$ & - & \\
\hline Champagne Pool, New Zealand & 49 & 1.1-4.9 ppb (3.3) & Hot spring waters & Ullrich (2012) \\
\hline Taupo Volcanic Zone, New Zealand & 48 & 8-144 ppm & Geothermal muds & Crump (1995) \\
\hline Rotokawa & 12 & $1-120 \mathrm{ppm}$ & $\begin{array}{l}\text { Geothermal well } \\
\text { discharge, geothermal } \\
\text { muds, geothermal } \\
\text { precipitates, hot spring } \\
\text { froth }\end{array}$ & $\begin{array}{l}\text { Krupp and Seward } \\
\text { (1987) }\end{array}$ \\
\hline Ohaaki-Broadlands, New Zealand & - & $150-700$ ppm & $\begin{array}{l}\text { Geothermal well discharge } \\
\text { and deposit inside silencer }\end{array}$ & $\begin{array}{l}\text { Weissberg et al. } \\
\text { (1979) }\end{array}$ \\
\hline
\end{tabular}

* Mean values given in parentheses

The gallium isotope system has not yet been investigated since the revolution of high precision isotopic ratio measurements by Multi-Collector Inductively-Coupled Plasma Mass Spectroscopy (MC-ICPMS). Therefore, an analytical protocol must be established. Any isotopic analysis of multi-isotope elements must satisfy a number of requirements in order for results to be both reliable and meaningful (Albarède and Beard, 2004). Most importantly, the analysis must represent the true isotopic composition of the sample. The efficiency of ion extraction from the plasma and/or transportation of the ions within the mass spectrometer can affect change in the measured isotopic ratio. This change is known as instrumental mass bias or mass fractionation. To correct the measured isotopic ratio for mass bias, an isotopic standard of the analyte can be monitored between running samples and the bias can be interpolated (i.e. "standard bracketing"). This can also be achieved by introducing an element of known isotopic composition and similar mass of the element to the samples (analyte) being analysed (i.e. "external normalisation", or "doping"). Additionally, the matrix composition of the sample analysed may influence the measured ratio of the element of interest. An evaluation of how the sample matrix may affect the isotopic ratio is required for every system, and the influences of the various elements must be evaluated. This requires the removal of the significant interfering elements in the sample matrix leaving a purified sample of the element of interest (Albarède and Beard, 2004). Ion-exchange chromatography is generally utilised to purify samples, but care must be taken to recover as close to $100 \%$ of the element of interest as possible, as column chromatography can also result in 
fractionation of isotopes (Gramlich and Machlan, 1985; Machlan and Gramlich, 1988; Albarède and Beard, 2004; Dembinski et al., 2006).

Table 1.2 Isotope composition of gallium in iron meteorites

\begin{tabular}{lll}
\hline Meteorite Sample & $\boldsymbol{\delta}^{71} \mathbf{G a}(\mathbf{\% o})$ & Source \\
\hline Canyon Diablo & -1.1 & De Laeter (1972) \\
Mt Dooling & +0.6 & Inghram et al. (1948) \\
Mt Stirling & -1.1 & De Laeter (1972) \\
Mundrabilla & -0.5 & De Laeter (1972) \\
Toluca & -0.3 & De Laeter (1972) \\
Youndegin & -0.9 & De Laeter (1972) \\
\hline * In this thesis Ga isotope variations are recorded as \\
per mille deviations from a recorded standard, see \\
Chapter 3.1 for details.
\end{tabular}

Strelow and associates made significant progress in the 1970s and 1980s on a method to extract gallium from various matrices, including from a rock standard of South African origin (Strelow, 1980a, b; Strelow and van der Walt, 1987; Strelow et al., 1974; van der Walt and Strelow, 1983). Their ion-exchange chromatography method claimed to yield $99 \%$ or greater of the gallium in their synthetic mixes. However, their aim was to quantitatively separate trace gallium concentrations from various solids and not to prepare samples for gallium isotopic analysis. Over the time of this current project, a new method, in part based on the work by Strelow and co-workers, has been developed and tested to ensure a quantitative and clean separation of gallium from the majority of elements commonly associated with hydrothermal precipitates and waters (i.e. As, $\mathrm{Sb}, \mathrm{Mo}, \mathrm{Hg}, \mathrm{W}, \mathrm{Tl}, \mathrm{Fe}$ and other transition metals). In order to interrogate the isotopic ratio, MC-ICPMS was chosen due to the precision shown in the measurement of other stable isotope systems such as $\mathrm{Fe}, \mathrm{Zn}$ and $\mathrm{Cu}$ (de Groot, 2009). There are currently no published methods for the measurement of gallium isotopes utilising the high precision of MC-ICPMS instruments, so this work is a beginning.

\subsection{Objective of investigation}

The aim of this study has been to measure the gallium isotopic composition of deep hydrothermal fluids and phase separated steam (due to boiling) as well as surface hot spring precipitates in several active geothermal systems in which gallium anomalies are well documented. It is of much interest to evaluate the possible isotopic fractionation which might occur as the bonding environment of gallium changes as it is partitions amongst high temperature liquid water (i.e. hydrothermal solution), steam and precipitating minerals as well as during deposition of siliceous and sulfide rich precipitates in surface hot springs. 
An additional, but necessary, objective of this thesis has also been to develop a method to quantitatively separate trace (ppb to ppm) amounts of gallium from a complex matrix of elements, some of which would cause mass interferences in MC-ICPMS analysis.

There are essentially no data pertaining to the isotope geochemistry of gallium in terrestrial systems (de Groot, 2009) with the exception of a single analysis of a standard rock reported more than forty years ago by De Laeter (1972). The only other published data are the early studies of the gallium isotopic composition of extra-terrestrial samples (i.e. meteorites) by Aston (1935), De Laeter (1972), Inghram et al. (1948) and Machlan et al. (1986). This study, was designed as a reconnaissance for gallium isotopes in active hydrothermal systems of New Zealand. Gallium has two isotopes, ${ }^{69} \mathrm{Ga}$ and ${ }^{71} \mathrm{Ga}$, and only one oxidation state, $\mathrm{Ga}^{3+}$, in aqueous media (Kloo et al., 2002). Thus, the fractionation of gallium isotopes should not be effected by redox changes in the environment of hydrothermal systems in the Earth's crust.

Finally we note that gallium occurs together with elevated $\mathrm{Au}, \mathrm{Ag}, \mathrm{Tl}, \mathrm{Hg}, \mathrm{As}$ and $\mathrm{Sb}$ concentrations in a number of active geothermal systems in New Zealand, which are considered to be modern analogues of epithermal ore depositing systems (Weissberg et al., 1979). Gallium is thus probably a "fellow traveller" during the formation of many epithermal gold deposits and data on its isotope chemistry could provide insight in physical and chemical processes operating in such systems in the Earth's crust. 


\section{CHAPTER 2. SAMPLES AND PREPARATION}

\subsection{Fieldwork and sampling}

Geothermal systems occur in a number of locations around New Zealand, with high temperature geothermal fields being predominantly located in the Taupo Volcanic Zone (TVZ). Moderate to low and very low temperature systems are widely dispersed across the rest of the country. The TVZ extends from White Island in the Bay of Plenty southwest to Mount Ruapehu. The geothermal fields of the TVZ are associated with young rhyolitic volcanism. Magma that has been intruded into the stretched and deformed crust of the TVZ has resulted in temperatures of $350^{\circ} \mathrm{C}$ at depths of less than $5 \mathrm{~km}$ providing a heat source from which geothermal systems have been developed and can be sustained for up to thousands of years. A total of 29 geothermal areas have been identified in the TVZ, generally about $12 \mathrm{~km}^{2}$ in surface area, based on resistivity boundaries. They display features such as hot and boiling springs and streams, geysers, silica sinter deposits, mud-pools, fumaroles, hot and steaming ground, altered ground, and hydrothermal eruption craters. The active geothermal systems present the opportunity to observe the isotope geochemistry of gallium within a geothermal system where phase change (i.e. flashing of hydrothermal fluids), or a change of ligand (i.e. precipitation from hot spring fluids) may affect the isotopic composition.

\subsubsection{Site descriptions}

Hydrothermal brine and steam samples from a number of hydrothermal wells have been collected and analysed from the Rotokawa geothermal system, as well as mud, sinter and hot spring fluid samples from the surface expressions of geothermal activity. At the Waiotapu geothermal area, a number of hot spring fluid, mud, and sinter samples were taken and analysed from Champagne Pool and the associated sinter flat, as well as several other locations around the field. Several geothermal related samples from the Ohaaki-Broadlands geothermal Field, TVZ (Figure 2.1) were also analysed; as well as a number of gallium containing mineralogical samples from the Kipushi Mine, Democratic Republic of the Congo, and Tsumeb Mine, Namibia (Figure 2.2).

\subsubsection{Rotokawa Geothermal Field}

Rotokawa is an active geothermal field located $14 \mathrm{~km}$ to the northeast of the Taupo township (Figure 2.1). There are two operational power stations utilising the energy potential of the field, Rotokawa I and Nga Awa Purua (Rotokawa II). Rotokawa I, originally commissioned in 1957, currently produces $34 \mathrm{MW}$ of power from four production wells and Nga Awa Purua, commissioned in 2008, produces $138 \mathrm{MW}$ from six production wells. There are extensive surface geothermal features, including numerous hot springs and pools, eruption craters, collapse pits, and altered and steaming ground. Lake Rotokawa fills one of the hydrothermal eruption craters, 
and large deposits of sulphur lie around and beneath it (Krupp and Seward, 1987, 1990). The lake is $1.15 \mathrm{~km}$ across and the lake sediments are comprised of diatomaceous precipitated sulfur beds.

\subsubsection{Waiotapu}

The Waiotapu geothermal field is located to the north of the Reporoa Valley, $23 \mathrm{~km}$ to the southeast of Rotorua (Figure 2.1). A variety of features, including geysers, hot pools, eruption craters, sinter deposits, hot streams, altered and steaming ground. The surface features that comprise Waiotapu make up the largest area of surface geothermal activity in New Zealand. Champagne Pool is a prominent feature within the Waiotapu geothermal area and it has a diameter of approximately $65 \mathrm{~m}$ and a depth of about $60 \mathrm{~m}$ with a discharge rate of about $10 \mathrm{~L} \mathrm{~s}^{-1}$ (Ulrich, 2012). It lies at the south of the Waiotapu geothermal field in a 900 year old hydrothermal eruption crater. Once discharged from the pool, the geothermal waters generally follow a clear path along a silica terrace (i.e. the Artists Palate and down the Primrose Terraces to Bridal Veil Falls). Below the Bridal Veil Falls, fluids from Champagne Pool mix with acid sulphate waters from the east side of the Primrose Terrace and Sulfur Mounds Valley. Most of the waters draining from Champagne Pool along the Primrose Terrace collect in a shallow channel alongside the footpath that leads to Bridal Veil Falls. As a result, discharged fluid from Champagne Pool can be sampled without significant dilution for about $300 \mathrm{~m}$ from Champagne Pool to Bridal Veil Falls.

\subsubsection{Ohaaki-Broadlands}

The Ohaaki-Broadlands geothermal field is located approximately $30 \mathrm{~km}$ northeast of Taupo (Figure 2.1). Surface geothermal activity is minor at the Ohaaki-Broadlands geothermal field. Historically there were alkaline hot springs and bathing pools at Ohaaki, these and a cave were flooded when the river level was raised to fill Lake Ohakuri for the hydro-electric power scheme in 1961. Ohaaki Ngawha is a boiling pool and the dominant surface expression of geothermal activity at Ohaaki-Broadlands, prior to geothermal power development the pool had clear turquoise-blue water and an extensive white sinter terrace. Gallium containing, antimony rich siliceous precipitates formed from the Ohaaki Pool waters and lined parts of the pool. The Ohaaki geothermal power station was commissioned in 1989 and currently comprises 65 wells (including make-up wells) to recover $65 \mathrm{MW}$ from the Ohaaki-Broadlands geothermal field.

\subsubsection{Kipushi Mine, Democratic Republic of the Congo}

The Kipushi mine was formally known as the Prince Leopold Mine in Kipushi, southwest of the capital Lubumbashi, Democratic Republic of the Congo (Figure 2.2). It is an underground Zn$\mathrm{Pb}-\mathrm{Cu}$ mine that features a suite of $\mathrm{Zn}-\mathrm{Pb}-\mathrm{Cu}-\mathrm{Fe}$ sulfides and accessory $\mathrm{Ga}, \mathrm{Ge}, \mathrm{Mo}, \mathrm{W}$ and $\mathrm{V}$ mineralisation in dolomite and schist dolomites. 


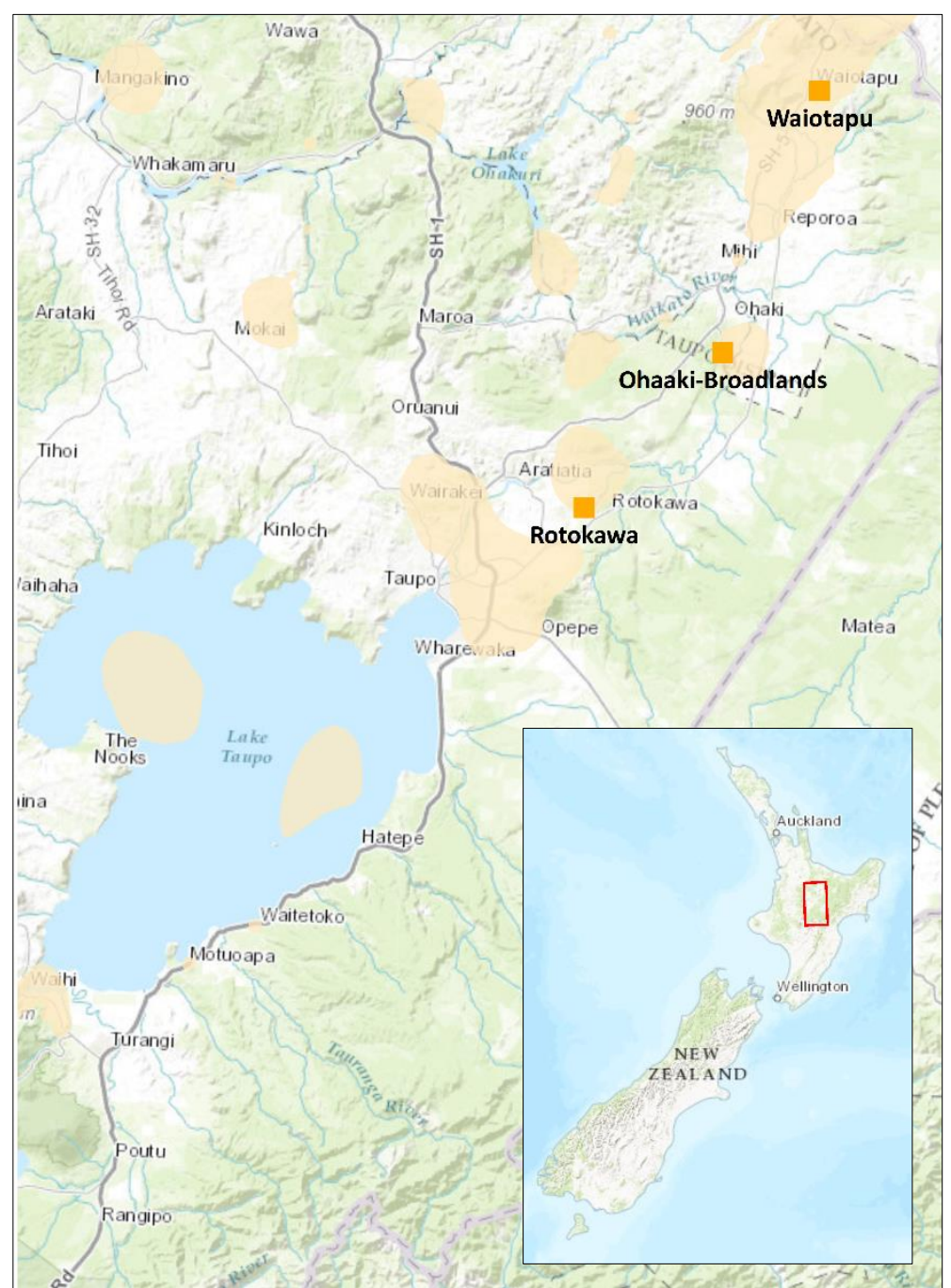

Figure 2.1 Location of geothermal fields sampled for this study. Areas in brown indicate active hydrothermal zones. The map created using ESRI ArcGIS 10.4 utilising available basemaps.

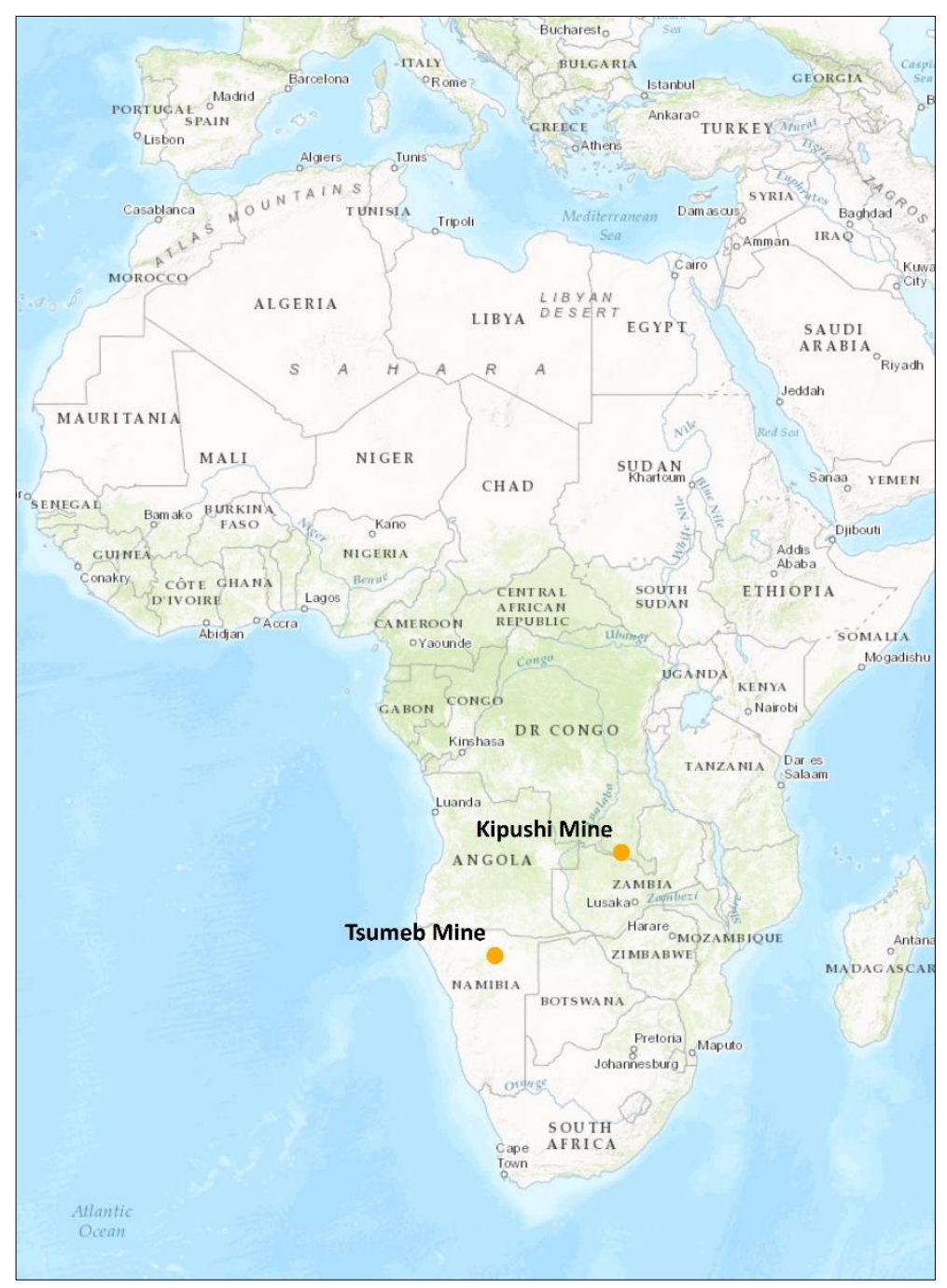

Figure 2.2 Location of Tsumeb Mine, Tsumeb, Namibia and Kipushi Mine, Kipushi, Democratic Republic of the Congo. The map created using ESRI ArcGIS 10.4 utilising available basemaps. 


\subsubsection{Tsumeb Mine, Namibia}

The Tsumeb mine in Namibia (Figure 2.2) is a Cu-Pb-Zn-Ag-Ge-Cd mine and is well known for its diverse range of rare and unusual minerals. There are 243 validated minerals identified in the Tsumeb mine, and is the type location for 56 of these. Many of the germanium minerals can only be found at the Tsumeb mine, and a number of rare gallium minerals such as gallite $\left(\mathrm{CuGaS}_{2}\right)$ and söhngeite $\left(\mathrm{Ga}(\mathrm{OH})_{3}\right)$ occur in the ore mineral assemblage.

\subsubsection{Sample collection}

At each sample site (i.e. geothermal systems) where fluids (i.e. samples from hot springs and pools) were collected, $100 \mathrm{ml}$ filtered $(0.45 \mu \mathrm{m}$ Millipore) and un-filtered water samples were collected and acidified with $5 \mathrm{ml}$ concentrated ultra-pure nitric acid (Optima, Fisher Chemical). Samples were collected with disposable Terumo $60 \mathrm{ml}$ syringes and stored in Nalgene polypropylene $100 \mathrm{ml}$ bottles, which had been previously acid washed with ultra-pure $6 \mathrm{M} \mathrm{HNO}_{3}$ (Optima, Fisher Chemical) and sample rinsed, prior to analysis. For filtered samples, the collection syringe was fitted with a Swinnex $47 \mathrm{~mm}$ filter holder containing a disposable Millipore S-Pak $0.45 \mu \mathrm{m}$ sterile filter.

At sample sites where precipitates were collected, solid samples up to $150 \mathrm{~g}$ were carefully broken from the edge of accessible active hot pools, air dried and stored in sterile zip lock bags prior to analysis. Where muddy precipitates were collected, acid washed $100 \mathrm{ml}$ Nalgene polypropelene bottles were used to scoop and store samples prior to analysis. These were air dried over 2 weeks in the clean laboratory facilities at the School of Geography, Environmental and Earth Science, Victoria University of Wellington.

At production well sites in the Rotokawa geothermal field, condensed flashed steam (gas condensate) was separated from the liquid phase (brine) using a Weber Separator (Ellis and Mahon, 1977). One litre of each phase (i.e. steam condensate and liquid phase) was collected in Nalgene polypropelene $1 \mathrm{~L}$ bottles that had been previously acid washed and the samples were acidified with $10 \mathrm{ml}$ of ultra-pure concentrated nitric acid. Table 2.1 summarises the type and location of samples analysed. 
Table 2.1 Samples location

\begin{tabular}{|c|c|c|c|c|c|}
\hline Location & SampleID & Sample Type & Description & Longitude & Latitude \\
\hline \multirow{15}{*}{$\begin{array}{l}\text { Lake Rotokawa, } \\
\text { Rotokawa, New Zealand }\end{array}$} & RKL-01 & & Grey/black boiling water pool, gas is $\mathrm{CO}_{2}$ etc. Black mud, and particulate (floc) perhaps Fe-S? & \multirow{6}{*}{176.1913} & \multirow{6}{*}{-38.6272} \\
\hline & RKL-02 & Filtered Hot Spring Water & & & \\
\hline & RKL-03 & Unfiltered Hot Spring Water & \multirow{2}{*}{ Yellow boiling pool (likely As and Sb sulfides) } & & \\
\hline & RKL-04 & Unfiltered Hot Spring Water & & & \\
\hline & RKL-05 & Hot Spring Precipitate (Mud) & Yellow pool (same as RKL-03/04), yellow-brown colour & & \\
\hline & RKL-06 & Hot Spring Precipitate (Mud) & Black/grey pool (same as RKL-01/02), Black thick "ooze-like" mud & & \\
\hline & RKL-07 & Sinter & Sulfide containing siliceous sinter from around a yellow boiling pool, pool is yellow-brown in colour & 176.1909 & -38.6270 \\
\hline & RKL-08 & Sinter & Sulfide containing siliceous sinter from around draining pool & 176.1912 & -38.6270 \\
\hline & RKL-09 & Sinter & Sulfide containing siliceous sinter from lake front & & \\
\hline & RKL-10 & Sinter & Sulfide containing siliceous sinter, lack of $\mathrm{As} / \mathrm{Sb}$ (white colour) & & \\
\hline & RKL-11 & Sinter & Algal stromatilites/silica sinter & & \\
\hline & RKL-12 & Sulfide & As-Sb sulfide taken close to where the ion flotation bubbles of metals formed on the surface of the pool & 176.1912 & -38.6273 \\
\hline & RKL-13 & Hot Spring Precipitate (Mud) & Small pool, wet mud sample & & \\
\hline & RKL-14 & Hot Spring Precipitate (Mud) & Small yellow boiling pool, sample taken yellow hard mud & & \\
\hline & RKL-14A & Sinter & $3 \mathrm{~m}$ towards lake front, another sinter sample taken & & \\
\hline \multirow{9}{*}{$\begin{array}{l}\text { Rotokawa Geothermal } \\
\text { Power Station, } \\
\text { Rotokawa, New Zealand }\end{array}$} & RK17-BR & Well discharge, liquid phase & $1 \mathrm{~L}$ of liquid phase (brine) taken from production well & \multirow{9}{*}{176.1817} & \multirow{9}{*}{-38.6496} \\
\hline & RK17-CS & Well discharge, steam phase & $1 \mathrm{~L}$ of steam condensate taken from production well & & \\
\hline & RK26-BR & Well discharge, liquid phase & $1 \mathrm{~L}$ of liquid phase (brine) taken from production well & & \\
\hline & RK26-CS & Well discharge, steam phase & $1 \mathrm{~L}$ of steam condensate taken from production well & & \\
\hline & RK27-BR & Well discharge, liquid phase & $1 \mathrm{~L}$ of liquid phase (brine) taken from production well & & \\
\hline & RK27-CS & Well discharge, steam phase & $1 \mathrm{~L}$ of steam condensate taken from production well & & \\
\hline & RK28-BR & Well discharge, liquid phase & $1 \mathrm{~L}$ of liquid phase (brine) taken from production well & & \\
\hline & RK28-CS & Well discharge, steam phase & $1 \mathrm{~L}$ of steam condensate taken from production well & & \\
\hline & RK29-BR & Well discharge, liquid phase & $1 \mathrm{~L}$ of liquid phase (brine) taken from production well & & \\
\hline
\end{tabular}




\begin{tabular}{|c|c|c|c|c|c|}
\hline Location & SampleID & Sample Type & Description & Longitude & Latitude \\
\hline & RK29-CS & Well discharge, steam phase & $1 \mathrm{~L}$ of steam condensate taken from production well & & \\
\hline & RK32-BR & Well discharge, liquid phase & $1 \mathrm{~L}$ of liquid phase (brine) taken from production well & & \\
\hline & RK22-CS & Well discharge, steam phase & $1 \mathrm{~L}$ of steam condensate taken from production well & & \\
\hline & RK33-BR & Well discharge, liquid phase & $1 \mathrm{~L}$ of liquid phase (brine) taken from production well & & \\
\hline & RK33-CS & Well discharge, steam phase & $1 \mathrm{~L}$ of steam condensate taken from production well & & \\
\hline \multirow{10}{*}{$\begin{array}{l}\text { Champagne Pool, } \\
\text { Waiotapu, New Zealand }\end{array}$} & WCP-01 & Filtered Water & & \multirow{10}{*}{176.3691} & \multirow{10}{*}{-38.3586} \\
\hline & WCP-02 & Filtered Water & & & \\
\hline & WCP-03 & Filtered Water & $60 \mathrm{ml}$ of waters from Champagne Pool water sampled $60 \mathrm{~cm}$ from the edge of the pool & & \\
\hline & WCP-04 & Unfiltered Water & & & \\
\hline & WCP-05 & Unfiltered Water & & & \\
\hline & WCP-06 & Sinter + Precipitate & Solid sample with white silica core, orange sulfide crust & & \\
\hline & WCP-07 & Filtered Water & Sinter flat sample near top of flat. Filtered from $1 \mathrm{~cm}$ deep pool. & & \\
\hline & WCP-08 & Unfiltered Water & Unfiltered sample & & \\
\hline & WCP-09 & Sinter & Solid sample from drainage channel nearest path & & \\
\hline & WCP-10 & Sinter & Solid sample 2-3 m NE of drainage channel sample & & \\
\hline \multirow{3}{*}{$\begin{array}{l}\text { Bridal Veil Falls, } \\
\text { Waiotapu, New Zealand }\end{array}$} & WCP-11 & Filtered Water & Filtered water sample from cleanest, least turbulent pool & \multirow{3}{*}{176.3695} & \multirow{3}{*}{-38.3608} \\
\hline & WCP-12 & Sinter & Solid sinter sample & & \\
\hline & WCP-13 & Sinter & Layered sinter silica/sulfur precipitate & & \\
\hline \multirow{3}{*}{$\begin{array}{l}\text { Frying Pan Flat, } \\
\text { Waiotapu, New Zealand }\end{array}$} & WCP-14 & Altered Sample & Soft, fibrous sample from altered wall rock & \multirow{3}{*}{176.3692} & \multirow{3}{*}{-38.3619} \\
\hline & WCP-15 & Filtered Water & $\begin{array}{l}\text { As-S water sample from pool ( } 30 \mathrm{~cm} \text { diameter) near the edge of sinter flat, black/grey water, yellow } \\
\text { surrounding precipitate }\end{array}$ & & \\
\hline & WCP-16 & Mud & Sample from yellow pool (0.5 - $1 \mathrm{~m}$ diameter), $2 \mathrm{~m}$ from WCP-15 & & \\
\hline \multirow{3}{*}{$\begin{array}{l}\text { Ohaaki-Broadlands } \\
\text { hydrothermal area, New } \\
\text { Zealand }\end{array}$} & BR27 & Oriface Plate & Black, metallic powder taken from the orifice plate of well BR27 & \multirow{3}{*}{176.2960} & \multirow{3}{*}{-38.5275} \\
\hline & BR27 & Filtered Water & Freeze dried sample of $1 \mathrm{~L}$ of brine solution from well BR27 & & \\
\hline & TMS-BR & Sinter + Sulfide Precipitate & Solid sample with white silica core and dark orange-red sulfide crust from Ohaaki Pool & & \\
\hline
\end{tabular}




\begin{tabular}{llll}
\hline Location & SamplelD & Sample Type & Description \\
\hline $\begin{array}{l}\text { Kipushi Mine, } \\
\text { Democratic Republic of } \\
\text { the Congo }\end{array}$ & TMS-5 & Mineral & Renierite/briartite metallic intergrowth \\
\hline & TMS-1 & Mineral & White fibrous schaurteite \\
& TMS-2 & Mineral & Tennantite/renierite. Massive metallic intergrowth, associated with the white fibrous schaurteite (TMS- \\
& TMS-3 & Mineral & Ga-beudantite/hidalgoite, hexagonal crystal intergrowth \\
Tsumeb Mine, Namibia, & TMS-4 & Mineral & Tennantite/germanite, associated with Ga-beudantite (TMS-3) \\
Africa & TMS-6 & Mineral & Renierite/germanite metallic ore \\
& TMS-7 & Mineral & Pink söhngeite \\
& TMS-8 & Mineral & Renierite/germanite/tennantite, metallic intergrowth from TMS-7 adjacent to söhngeite \\
\hline
\end{tabular}




\subsection{Sample preparation}

\subsubsection{Reagents and apparatus employed}

All hydrochloric acid based reagents were prepared from in house twice distilled (in Teflon) 10M $\mathrm{HCl}$ (concentrated $\mathrm{HCl}$ ) unless otherwise mentioned. All nitric acid based reagents were prepared from ultra-pure Fisher Chemical Optima $14 \mathrm{M} \mathrm{HNO}_{3}$ (concentrated $\mathrm{HNO}_{3}$ ). The various dilutions of these acids were made by mixing the concentrated $\mathrm{HCl}$ or $\mathrm{HNO}_{3}$ with MilliQ water (MQ, resistivity of $18.2 \mathrm{M} \Omega$ ), produced using an Elba PURELAB water purification system. The concentrated HF used is ultra-pure Fisher Chemical Optima HF.

\subsubsection{Precipitates}

Samples of both sulfur-rich and sulfur-poor silica 'sinters' were collected for analysis. Some solid samples were comprised predominantly of amorphous silica enclosing layers of brightly coloured amorphous As-Sb sulfides. Up to $100 \mathrm{mg}$ of air-dried siliceous precipitate samples, along the sulfide-rich horizons within bulk samples, were extracted from the bulk sample. The samples were weighed into a $22 \mathrm{ml}$ Savillex Teflon beaker ready for digestion.

Digestion of the samples was completed in multiple steps as follows. In order to remove any silica present, the sample was first dissolved in a solution containing $10 \mathrm{ml}$ concentrated $\mathrm{HNO}_{3}$ and between 3 and $5 \mathrm{ml}$ of concentrated $\mathrm{HF}$ and refluxed for 12 hours at $120^{\circ} \mathrm{C}$. This solution was dried at $90^{\circ} \mathrm{C}$ and digested in $5 \mathrm{ml}$ of concentrated $\mathrm{HCl}$ and then refluxed for 12 hours at $120^{\circ} \mathrm{C}$. If there was any undissolved residue, these steps were repeated. If an undissolved residue still remained, the solution was dried again at $90^{\circ} \mathrm{C}$ and brought up in $2 \mathrm{ml}$ of concentrated ultrapure $\mathrm{HCl}$ with $10-20$ drops of ultra-pure $\mathrm{HF}$ and refluxed at $120^{\circ} \mathrm{C}$ overnight. Once fully in solution, the dissolved samples were dried at $90^{\circ} \mathrm{C}$, then were brought up in $8 \mathrm{M} \mathrm{HCl}$ and ready for gallium ion-exchange column chemistry.

\subsubsection{Hot spring waters}

Sample aliquots of $90 \mathrm{ml}$ were evaporated at $70^{\circ} \mathrm{C}$ in $90 \mathrm{ml}$ Savillex Teflon beakers. Once evaporated, the samples were dissolved in $10 \mathrm{ml}$ of concentrated $\mathrm{HNO}_{3}$ and refluxed at $120^{\circ} \mathrm{C}$ for 12 hours. This was then transferred into a $22 \mathrm{ml}$ Savillex Teflon beaker and taken to dryness on a hotplate at $90^{\circ} \mathrm{C}$. To remove silica, the samples were treated with 40 drops of concentrated $\mathrm{HNO}_{3}$ and 10-15 drops concentrated $\mathrm{HF}$ before refluxing for 12 hours at $120^{\circ} \mathrm{C}$. This solution was dried at $90^{\circ} \mathrm{C}$ and brought up in $2 \mathrm{ml}$ of concentrated $\mathrm{HCl}$ and again refluxed at $120^{\circ} \mathrm{C}$ for 12 hours. This latter step was repeated twice and then the dried residue was dissolved in $8 \mathrm{M}$ $\mathrm{HCl}$. 


\subsubsection{Brine}

One litre of each of the brine samples was dried at $70^{\circ} \mathrm{C}$ in $90 \mathrm{ml}$ Savillex Teflon beakers. As the aliquots neared dryness, the beakers were topped up and the drying process continued until the full one litre of sample had been processed, which took approximately 4 weeks. Once dry, $60 \mathrm{ml}$ of $6 \mathrm{M} \mathrm{HNO}_{3}$ was added to the samples and they were refluxed at $120^{\circ} \mathrm{C}$ overnight. A translucent white insoluble precipitate was observed in all samples and is thought to be amorphous $\mathrm{SiO}_{2}$. To remove the precipitate, the brine samples were repeatedly treated with $40 \mathrm{ml}$ concentrated $\mathrm{HNO}_{3}$ and $10 \mathrm{ml}$ concentrated $\mathrm{HF}$ and refluxed at $120^{\circ} \mathrm{C}$. When there was no precipitate persisting, a $5 \mathrm{ml}$ aliquot was transferred to a $22 \mathrm{ml}$ Savillex Teflon beaker and dried at $90^{\circ} \mathrm{C}$. The sample was dissolved in $2 \mathrm{ml}$ of concentrated $\mathrm{HCl}$ and refluxed at $120^{\circ} \mathrm{C}$ for 12 hours, this step was repeated twice more before the dried sample was brought up in $8 \mathrm{M} \mathrm{HCl}$.

\subsubsection{Steam condensates}

One litre of each of the steam condensate samples were dried at $70^{\circ} \mathrm{C}$ in $90 \mathrm{ml}$ Savillex Teflon beakers over 4 weeks, topping up with fresh solution as they neared dryness, until all of brine or steam solution had been dried. Once dry, solutions were brought up in $10 \mathrm{ml}$ of concentrated $\mathrm{HNO}_{3}$ and refluxed at $120^{\circ} \mathrm{C}$ overnight to ensure complete dissolution and then transferred to smaller $22 \mathrm{ml}$ Savillex Teflon beakers. To remove any silica, the dried steam condensate samples were treated with 40 drops of concentrated $\mathrm{HNO}_{3}$ and 10-15 drops concentrated $\mathrm{HF}$ and refluxed for 12 hours at $120^{\circ} \mathrm{C}$. This solution was dried at $90^{\circ} \mathrm{C}$ and brought up in $2 \mathrm{ml}$ of concentrated $\mathrm{HCl}$ and refluxed at $120^{\circ} \mathrm{C}$ for 12 hours, this step was repeated twice and the final residuate then dissolved in $8 \mathrm{M} \mathrm{HCl}$.

\subsubsection{Mineral samples}

Each of the mineral samples from Tsumeb and Kipushi were weighed into a $7 \mathrm{ml}$ Savillex Teflon beaker. These samples were treated with $0.5 \mathrm{ml}$ of concentrated $\mathrm{HNO}_{3}$ and 10 drops of $\mathrm{HF}$ then refluxed at $120^{\circ} \mathrm{C}$ for 24 hours, or until fully dissolved. Once the minerals were fully dissolved, the solutions were dried at $90^{\circ} \mathrm{C}$ and treated as described previously.

\subsubsection{Trace element analysis}

Trace elements were analysed using a Thermo Scientific Element 2 ICPMS. Low resolution was used to measure $\mathrm{Ag}, \mathrm{Au}, \mathrm{Bi}, \mathrm{Cd}, \mathrm{Hg}$, Ir, Mo, Os, Pd, Pt, Re, Ph, Ru, Sb, Sn, Tl and W, due to the range and complexity of interferences, medium resolution $(R=4,000)$ was used to accurately measure Al, Co, Cr, Fe, Ga, Mg, Mn, Ni, Sc, Ti, V and Zn, and high resolution ( $\mathrm{R}=10,000)$ for As and Ge. All elements analyses were obtained within a single analysis of sample without changing the instrument operating conditions (except to select resolution mode). An aliquot of each sample was taken to dryness at $90^{\circ} \mathrm{C}$ and dissolved in $100 \mu \mathrm{l}$ of concentrated $\mathrm{HNO}_{3}$. This 
solution was refluxed for 4 hours before being dried again at $90^{\circ} \mathrm{C}$. This procedure was repeated twice before finally bringing the samples up in $1 \% \mathrm{HNO}_{3}$ and analysing the solution for trace elements on the Element 2 ICPMS. As the Element 2 has a high instrumental precision, a large dilution factor can be used for those samples as required. For precipitates and rock standards, a dilution factor of approximately 1,000 was used. For geothermal well brine solutions, a dilution factor of 50 was employed, and for geothermal well steam condensates and hot water spring samples, a dilution factor of 10 was used. An external calibration using an aqueous synthetic standard solution was used to quantify the concentration of trace elements in the sample. Precision for all elements was between $2 \%$ and $15 \%$ RSD. 


\section{CHAPTER 3. METHOD DEVELOPMENT}

In order to determine the gallium isotope composition of Earth materials such as geothermal brines and steam condensates as well as mineral phases (both silicate and sulfide), the gallium must be separated and concentrated prior to multi-collector inductively coupled plasma mass spectrometry (MC-ICPMS) analysis. The final gallium containing solution to be analysed should be as free of major matrix elements as possible, and free from those elements that may interfere with the gallium signal during the mass spectrometric analysis. The latter is important given the formation of numerous possible polyatomic species that may interfere with the measurement of gallium isotopes as shown in Table 3.1. The various metals that contribute to the various ionic species (Table 3.1) should be removed from the final solution so as to prevent the formation of the potentially mass-interfering ionic species in the plasma. There are a number of ways to separate gallium from various matrices. This chapter describes the development of the analytical protocol used for MC-ICPMS analysis of gallium isotopes.

Table 3.1 Polyatomic interferences on gallium

\begin{tabular}{|c|c|c|}
\hline Isotope & Abundance & Interference \\
\hline${ }^{69} \mathrm{Ga}$ & $60.16 \%$ & $\begin{array}{l}{ }^{35} \mathrm{Cl}^{16} \mathrm{O}^{18} \mathrm{O}^{+},{ }^{35} \mathrm{Cl}^{17} \mathrm{O}_{2}^{+},{ }^{37} \mathrm{Cl}^{16} \mathrm{O}_{2}^{+},{ }^{36} \mathrm{Ar}^{33} \mathrm{~S}^{+},{ }^{33} \mathrm{~S}^{18} \mathrm{O}_{2}^{+},{ }^{34} \mathrm{~S}^{17} \mathrm{O}^{18} \mathrm{O}^{+},{ }^{36} \mathrm{~S}^{16} \mathrm{O}^{17} \mathrm{O}^{+},{ }^{33} \mathrm{~S}^{36} \mathrm{~S}^{+}, 137 \mathrm{Ba}^{++}, \\
{ }^{53} \mathrm{Cr}^{16} \mathrm{O}^{+},{ }^{54} \mathrm{Fe}^{16} \mathrm{O}^{+},{ }^{31} \mathrm{P}^{38} \mathrm{Ar}^{+},{ }^{29} \mathrm{Si}^{40} \mathrm{Ar}^{+},{ }^{33} \mathrm{~S}^{36} \mathrm{Ar}^{+},{ }^{22} \mathrm{Cr}^{17} \mathrm{O}^{+},{ }^{51} \mathrm{~V}^{18} \mathrm{O}^{+},{ }^{138} \mathrm{Ba}^{++},{ }^{138} \mathrm{La}^{++},{ }^{138} \mathrm{Ce}^{++},{ }^{139} \mathrm{La}^{++}\end{array}$ \\
\hline${ }^{71} \mathrm{Ga}$ & $39.84 Z \%$ & $\begin{array}{l}{ }^{35} \mathrm{Cl}^{18} \mathrm{O}_{2}^{+},{ }^{37} \mathrm{Cl}^{16} \mathrm{O}^{18} \mathrm{O}^{+},{ }^{37} \mathrm{Cl}^{17} \mathrm{O}_{2}+,{ }^{36} \mathrm{Ar}^{35} \mathrm{Cl}^{+},{ }^{36} \mathrm{~S}^{17} \mathrm{O}^{18} \mathrm{O}^{+},{ }^{38} \mathrm{Ar}^{33} \mathrm{~S}^{+},{ }^{141} \mathrm{Pr}^{++},{ }^{55} \mathrm{Mn}^{16} \mathrm{O}^{+},{ }^{54} \mathrm{Fe}^{17} \mathrm{O}^{+}, \\
{ }^{31} \mathrm{P}^{40} \mathrm{Ar}^{+},{ }^{53} \mathrm{Cr}^{18} \mathrm{O}^{142} \mathrm{Nd}^{++},{ }^{142} \mathrm{Ce}^{++},{ }^{40} \mathrm{Ar}^{15} \mathrm{~N}^{16} \mathrm{O}^{+},{ }^{40} \mathrm{Ar}^{14} \mathrm{~N}^{17} \mathrm{O}^{+},{ }^{143} \mathrm{Nd}^{++}\end{array}$ \\
\hline
\end{tabular}

Tan and Horlick, 1986; May and Wiedmeyer, 1998; Pesch, 2001

\subsection{Analytical considerations}

The Nu Plasma MC-ICPMS instrument at Victoria University of Wellington has been chosen to measure gallium isotopes. MC-ICPMS has become a more common choice for the measurement of non-traditional stable isotopes due to the high ionization efficiency of the Ar plasma and rapid sample through-put. Another benefit of MC-ICPMS is the smooth variability of instrumental mass bias during the course of an analytical session. Corrections for the variability (i.e. drift) in the machine during an analytical session can be made using techniques such as the simple samplestandardbracketing method. Sample introduction, the efficiency of ion extraction from the plasma and/or transportation of the ions within the mass spectrometer can also change the measured isotopic ratio. This change is known as instrumental mass bias or mass fractionation. Additionally, corrections for mass bias can be evaluated by comparison to an isotopic standard or by doping the sample with an element of similar mass (Albarède and Beard, 2004).

Variations in stable isotope ratios are ordinarily on the order of a few parts per thousand, and generally decrease as temperature increases or the mass difference between isotopes decreases. Therefore, isotopic variations are usually measured relative to a standard reference value. 
VSMOW (Vienna Standard Mean Ocean Water) is used for oxygen isotope ratios, and PDB (Pee Dee Belemnite) is used for carbon isotope ratios. Isotope ratios are usually reported in the $\delta$-notation (i.e. parts per thousand; per mille, \%o) which incorporates a standard value. With this notation, the gallium isotope ratio can be measured relative to the SRM994 Gallium Isotope Standard and can be calculated as:

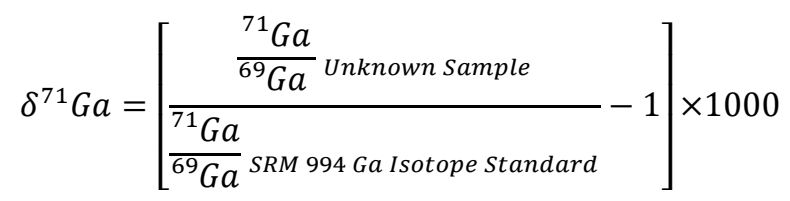

\subsubsection{Interferences derived from the Sample Matrix}

The matrix composition of the sample to be analysed may influence the measured ratio of the element of interest. There are two types of matrix effects that can influence the isotopic measurement:

- Spectral (isobaric) effects; elements and molecules in the matrix whose mass overlaps the isotope mass of interest, such as ${ }^{54} \mathrm{Fe}^{17} \mathrm{O}^{+}$at ${ }^{71} \mathrm{Ga}^{+},{ }^{53} \mathrm{Cr}^{18} \mathrm{O}^{+}$at ${ }^{71} \mathrm{Ga}^{+},{ }^{51} \mathrm{~V}^{18} \mathrm{O}^{+}$at ${ }^{69} \mathrm{Ga}^{+}$,

- Non-spectral (space-charge) effects; changes in the sensitivity of an analyte due to the presence of another element.

An evaluation of how the sample matrix may affect the isotopic ratio is required for every system and the influences must be evaluated for their significance. The aim is to obtain a final sample solution containing all the gallium in the sample that is as free from major and trace matrix elements, particularly those elements in the solution to be analysed that may form interferences and effect the gallium sensitivity. This generally results in the removal of these elements from the final solution to be analysed so as to prevent the formation of the interfering species in the plasma, leaving a purified sample of the element of interest plus any elements that have no significant effect on the isotope systems being analysed.

\subsubsection{Chemical separation of gallium}

In order to determine the isotopic fractionation of gallium in hydrothermal systems using MC-ICPMS, interferences must be eliminated from the sample that is to be analysed. It is therefore imperative that a method of separation to purify gallium from the sample matrix be developed. It is usual to employ ion-exchange chromatography to chemically purify samples. However, if yields of the target element are not quantitative during purification, then a massdependent fractionation can be introduced to the sample (Albarède and Beard, 2004).

For the isolation of gallium from complex matrices, such as geological materials, ion exchange chromatography has been commonly employed (Korkisch, 1988). Anion exchange separations 
are generally used in the determination of gallium in rocks, sediments, meteorites, biological tissue, aluminium, alloys, and other complex materials. Anion exchange in hydrochloric acid (HCl) media, using strongly basic resins, or acetone-mineral acid media with a cation exchange resin, allows for a selective separation of gallium from almost all elements. Cation exchange resins are commonly employed in the determination of gallium in industrial products, and the isolation of gallium from synthetic mixtures with numerous other elements. Less common methods include the use of chelating resins and liquid-liquid exchange. Solvent extraction is another method used to separate gallium from solution but has not been considered a suitable method of separation for this study.

\subsubsection{Anion Exchange Resins}

$\mathrm{Ga}$ (III) shows very strong adsorption onto basic resins in 3 to $12 \mathrm{M} \mathrm{HCl}$, with the species retained on the quaternary ammonium type resins being $\mathrm{GaCl}_{4}^{-}$. This anionic chloro-complex is the predominant species in 6 to $12 \mathrm{M} \mathrm{HCl}$. However, at $\mathrm{HCl}$ concentrations lower than $3 \mathrm{M}, \mathrm{Ga}^{3+}$ is the dominant species in solution, $\mathrm{GaCl}^{2+}$ and $\mathrm{GaCl}_{2}^{+}$are weak complexes (Kraus et al., 1954). The high adsorption of gallium in systems using various concentrations between 4 and $12 \mathrm{M} \mathrm{HCl}$ has been utilised in many separations from those elements that do not form anionic complexes that can be adsorbed under these conditions. These elements include alkali metals, alkaline earth elements, rare earths, $\mathrm{Al}, \mathrm{Ni}$, Th, $\mathrm{Fe}(\mathrm{II})$ and other elements. However, $\mathrm{Ga}$ (III) is not separated from $\mathrm{Fe}(\mathrm{III}), \mathrm{UO}_{2}$ (II), $\mathrm{Pu}(\mathrm{IV}), \mathrm{Cu}(\mathrm{II}), \mathrm{Bi}, \mathrm{Sn}, \mathrm{Zn}, \mathrm{Cd}, \mathrm{Hg}$, In, and Tl(III) (Korkisch, 1988). To prevent the adsorption of some of these metals (e.g. $\mathrm{Fe}(\mathrm{III}), \mathrm{Pu}(\mathrm{IV}), \mathrm{Cu}(\mathrm{II})$, and $\mathrm{Sb}(\mathrm{IV})$ ) it has been suggested that the sample be dissolved in an atmosphere of nitrogen (de Laeter, 1972), or that the sample be reduced prior to the passage of eluent through the column (Zweidinger et al., 1973; Stulzaft et al., 1980). Reductants include Ag (Zweidinger et al., 1973), $\mathrm{TiCl}_{3}$ (Stulzaft et al., 1967; Korkisch et al., 1979), ascorbic acid (Miner and de Grazio, 1965, Korkisch and Hazan, 1965), and hydroxylamine hydrochloride (Nadezhina, 1970).

Gallium is also retained on anionic columns in phosphoric acid and thiocyanate media as the likely complexes $\mathrm{Ga}\left(\mathrm{PO}_{4}\right)_{2}^{3-}$ and $\mathrm{Ga}(\mathrm{SCN})_{4}^{-}$respectfully (Korkisch, 1988). Co-adsorbed with gallium in thiocyanate media are $\mathrm{Fe}(\mathrm{II}), \mathrm{Co}, \mathrm{UO}_{2}(\mathrm{II}), \mathrm{Mo}, \mathrm{Zn}, \mathrm{Cd}$ and several other elements. In phosphoric acid media, indium is co-adsorbed. Gallium is less strongly adsorbed in $\mathrm{HF}$ and $\mathrm{HBr}$ media than in $\mathrm{HCl}$, and the adsorption in $\mathrm{HI}$ acid solutions is negligible. However, the nonabsorption of gallium can be employed to separate gallium from indium, which is strongly adsorbed at $\mathrm{pH}=1$ in iodide solutions. No adsorption of gallium on anionic resins is observed in sulphuric, nitric and perchloric acid media. Therefore, the possibility arises to separate gallium from $\mathrm{U}$, Th, Mo, Zr, Hf, and Fe(III) in concentrated nitric acid media, and from Th, $\mathrm{Np}$ (IV), $\mathrm{Pu}(\mathrm{IV})$, and $\mathrm{Bi}(\mathrm{III})$ in dilute sulphuric acid media (Korkisch, 1988). The elution of gallium can 
be achieved using water (Denisova and Tsvetkova, 1961). However, it is more common to use a dilute solution of $\mathrm{HCl}$ (Korkisch and Hazan, 1964; Miner and de Grazio, 1965; de Laeter, 1972; Strelow and Victor, 1972; Zweidinger et al., 1973; Stulzaft et al., 1980), in which the distribution coefficient of gallium is very low and therefore gallium is not retained on the anionic resin.

\subsubsection{Cation Exchange Resins}

High and low concentrations of gallium are strongly retained on sulfonic acid type resins in both $\mathrm{HCl}$ and $\mathrm{HBr}$ solutions (Korkisch, 1988). When absorbing gallium from dilute solutions of $\mathrm{HCl}$, $\mathrm{HBr}$ or $\mathrm{HNO}_{3}$ a number of other elements are co-adsorbed. This includes alkali metals, alkaline earth elements, rare earth elements and those metals that do not form stable anionic complexes in $\mathrm{HCl}, \mathrm{HBr}$, and $\mathrm{HNO}_{3}$. However, gallium separates well from common anions such as phosphate, sulphate, nitrate, chloride and fluoride (Korkisch, 1988). In the presence of dilute HF, elements that readily from anionic fluoride complexes (i.e. Ti, Ze, Hf, $\mathrm{Fe}(\mathrm{III}), \mathrm{Al}, \mathrm{W}$ and $\mathrm{Mo}$ ) are not adsorbed with Ga. Elements that are coadsorbed with the gallium include alkali metals, Zn, $\mathrm{Cu}, \mathrm{Mn}, \mathrm{Ni}$ and rare earth elements (Korkisch, 1988).

Selective separations of gallium from other metals can be achieved using acetone-mineral acid media. The use of $0.5 \mathrm{M} \mathrm{HBr}$ in $80 \%$ acetone results in a separation factor of $\sim 8$ for the separation of gallium from $\mathrm{Fe}(\mathrm{III})$ and $\mathrm{Cu}(\mathrm{II})$. Similarly, a high selectivity of separation of gallium from many elements (not including $\mathrm{Fe}(\mathrm{III})$ ) can be achieved using $8 \mathrm{M} \mathrm{HCl}$. However, separation from $\mathrm{Fe}(\mathrm{III})$ can be achieved by reducing the sample prior to passing through the column similar to several anion exchange methods. Titanium trichloride and sodium iodide have been used as reductants to reduce Fe(III) to Fe(II) (Neirinckx and van der Merwe, 1971; van der Walt and Strelow, 1983; Korkisch et al., 1988).

Gallium can be eluted using various concentrations of $\mathrm{HCl}$ acid media (de Laeter, 1972; Korkisch et al., 1979; Strelow, 1980a; Strelow, 1980b; van der Walt and Strelow, 1983). Alternatively, $2 \mathrm{M} \mathrm{NaCl}$ and $1 \mathrm{M} \mathrm{HF}$ can be used for the quantitative elution of gallium (Korkisch, 1988). Solutions of complexing agents will elute gallium as an anionic complex, which include oxalic acid, tartrate, sulfosalicylate, EDTA (ethylenediaminetetraacetic) acid. $4 \mathrm{M} \mathrm{KSCN}$ in $0.1 \mathrm{M} \mathrm{HCl}$ will also elute gallium as an anionic complex (Korkisch, 1988). Ammonia based eluents will elute gallium as an anionic-hydroxide complex (i.e. $\mathrm{Ga}(\mathrm{OH})_{4}^{-}$), where the elements that form cationic amine complexes, i.e. $\mathrm{Cu}, \mathrm{Ni}, \mathrm{Co}$ and $\mathrm{Zn}$, will be retained by the cation exchange resin (Korkish, 1988).

\subsubsection{Mass Fractionation Corrections}

Machine fractionation effects, also referred to as mass bias, are isotopic fractionation effects produced by processes that occur within the mass spectrometer. The most common source of 
mass bias occurs during plasma ionisation of the sample; other sources include, but are not limited to, ion extraction and ion transmission in the mass spectrometer. These effects can produce a measurable change from the true isotopic composition of a sample and must be monitored and corrected. The Nu Plasma MC-ICPMS employed at Victoria University of Wellington produces a considerable machine fractionation of gallium isotopes (approximately $2 \% / \mathrm{amu}$ ), whereby the heavier isotope is preferentially extracted/transmitted in the ion beam. The consistency of the fractionation varies day to day, but is generally consistent during an analytical run.

The mass fractionation of the Nu Plasma can be described in terms of the $\beta$-factor, which can be calculated as follows (Albarède and Beard, 2004):

$$
\beta=\frac{\ln \left(\frac{{ }^{71} G a /{ }^{69} G a_{\text {true }}}{{ }^{71} G a /{ }^{69} G a_{\text {measured }}}\right)}{\ln \left(\frac{\text { MasS }{ }^{71} G a}{M a S S{ }^{69} G a}\right)}
$$

The average fractionation coefficient $(\beta)$ for SRM994 gallium isotope standard on the Nu Plasma is $-1.85(\mathrm{n}=297)$. The machine fractionation factor, $f f$, is applied to the measured ratio of the element of interest to correct it and can be calculated as based on the exponential law:

$$
\left({ }^{71} \mathrm{Ga} /{ }^{69} \mathrm{Ga}\right)_{\text {corrected }}=\left({ }^{71} \mathrm{Ga} /{ }^{69} \mathrm{Ga}\right)_{\text {measured }} \times f f
$$

where:

$$
f f=\left(\frac{\operatorname{Mass}_{i}}{\operatorname{Mass}_{\mathrm{k}}}\right)^{\beta}
$$

The average machine fractionation factor for gallium isotopes measured on the Nu Plasma is 0.9483 using the exponential law. However, this value cannot be used for individual analytical sessions as the machine drift needs a slightly different correction to be applied for each measurement. Machine mass fractionation of gallium isotopes can be corrected for by either of two methods:

- The sample-standard bracketing method, which corrects machine fractionation by normalising the sample with a value determined from bracketing the sample with an analysis of a standard of known isotopic composition;

- the external normalisation method, also known as external element doping, which requires doping the samples with a different element of known isotopic composition from which a fractionation factor is determined and applied to the isotopes of interest. Many 
investigators have proven that analytical precision can be improved by the analysis of standards between the unknown samples during the course of an analytical run, i.e. the combination of sample-standard bracketing with external element doping (Maréchal et al., 1999; Rouxel et al., 2004; Graham et al., 2004; Ehrlich et al., 2004).

The double (or triple) spike technique is another method by which to correct for mass bias, however cannot be used in the case of gallium isotopes (as there are only two stable isotopes) and therefore it will not be discussed further.

\subsubsection{Simple Sample-Standard Bracketing Correction}

This method consists of running standards alternately with unknown samples, and using these to determine the correction for machine fractionation and machine drift at the same time (Figure 3.1). The true ${ }^{71} \mathrm{Ga} /{ }^{69} \mathrm{Ga}$ can be determined as follows:

$$
\mathrm{R}_{\mathrm{A}}=\mathrm{R}_{\mathrm{Std}} \times \frac{\mathrm{r}_{\mathrm{A}}}{\sqrt{\left(\mathrm{r}_{\mathrm{Std} 1} \times \mathrm{r}_{\mathrm{Std} 2}\right)}}
$$

where:

$$
\begin{aligned}
R_{A} & =\frac{{ }^{1} e}{{ }^{2} e} ; \text { the true value of the sample } \\
r_{A} & =\frac{{ }^{1} e}{{ }^{2} e} ; \text { the measured value of the sample } \\
R_{S t d} & =\frac{{ }^{x} e}{{ }^{y} e} ; \text { the true ratio of the standard } \\
r_{S t d x} & =\frac{{ }^{x} e}{{ }^{\mathrm{y}} e} ; \text { the measured value of the standard }
\end{aligned}
$$

Assuming that drift between standard measurements can be approximated by the exponential law, an interpolation is made to determine the ratio of the standard at the time the unknown sample is analysed (i.e. the ratio of the interpolated standard $=\sqrt{ }\left(\mathrm{r}_{\mathrm{Std} 1} \times \mathrm{r}_{\mathrm{Std} 2}\right)$; Albarède and Beard, 2004).

For this method to be considered reliable, the mass fractionation response must be the same for the bracketing standard and the unknown sample being analysed. Albarède et al. (2004) suggests the concentration and matrix of the solutions should be the same or very similar in order for the sample-standard bracketing correction to be considered applicable. 


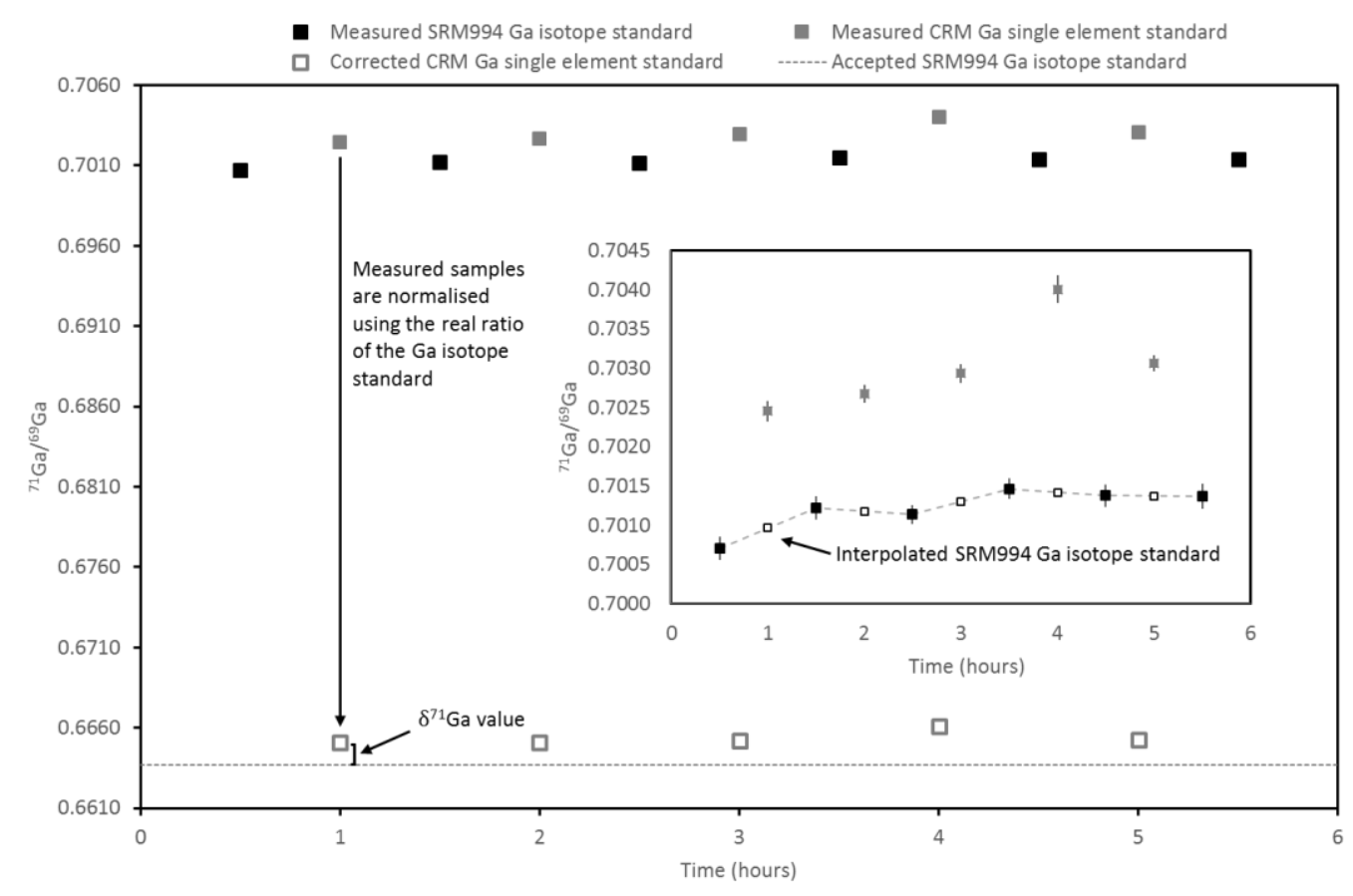

Figure 3.1 Graphical representation of the simple sample-standard bracketing correction. This method corrects for drift and machine fractionation at the same time. The insert shows the drift between standards over the course of the analysis, can be approximated by the exponential law between standards.

\subsubsection{Element Doping Correction}

This method involves doping the samples with a known isotope system that has a similar mass and mass distribution to the system being investigated. For gallium isotopes zinc can be used as a doping element. The isotopes of zinc are sufficiently similar in mass to gallium as so that they should fractionate similarly during analysis. Generally, mass bias laws are applied in a form whereby a fractionation factor, $f$, is calculated and then applied to all other ratios measured during a single run. A precise MC-ICPMS dataset can be produced using the following correction for an isotope pair of element, $e$, by calculating $\beta$ (Equation 3.2) empirically from standards of known concentration (Equation 3.5).

This method relies on the similar fractionation of isotopes between each element pair. If they are sufficiently different to prevent the direct application of the zinc isotope fractionation factor and hence, to correct the gallium measurement, the ratio of the fractionation coefficients $(\beta)$ of the gallium and zinc isotopes can be plotted to determine a correction factor. This factor, based on the zinc isotopes, can be used to account for the difference in machine fractionation between gallium and zinc. White et al. (2000) present the mathematical basis for this correction. The ratio of $\beta^{\mathrm{Zn}} / \beta^{\mathrm{Ga}}$ must remain constant during an analytical run in order to successfully apply the correction. Plotting the natural logarithm of each to the zinc isotope pairs verses the measured gallium isotope pair allows the graphical interpretation of the constancy of $\beta^{\mathrm{Zn}} / \beta^{\mathrm{Ga}}$. If, when fitted with a linear lest squares fit, the data lie on a straight line, the requirement that $\beta^{\mathrm{Zn}} / \beta^{\mathrm{Ga}}$ is 
constant is satisfied. The $\beta^{\mathrm{Ga}}$ can then be corrected relative to the deviation of the line from the theoretical behaviour, i.e. no machine fractionation for any isotopes (Albarède and Beard, 2004). The correction is calculated using the slope of the natural logarithm of the target isotopic ratio versus the correcting isotopic ratio, i.e. $\beta^{G a}=s\left(\ln r_{G a} / \ln r_{Z n}\right) \times \beta^{Z n}$. When combining the sample-standard bracketing technique in conjunction with this method, the correction to $\beta^{\mathrm{Ga}}$ is not required.

$$
\mathrm{R}_{\mathrm{A}}=\mathrm{r}_{\mathrm{A}} \times\left[\frac{m_{1}}{m_{2}}\right]^{f}
$$

where:

$$
\begin{aligned}
R_{A} & =\frac{{ }^{1} e}{{ }^{2} e} ; \text { the true value of the ratio } \\
r_{A} & =\frac{{ }^{1} e}{{ }^{2} e} ; \text { the measured value of the ratio } \\
f & =\ln \left[\frac{R_{B}}{r_{B}}\right] / \ln \left[\frac{m_{x}}{m_{y}}\right] \\
R_{B} & =\text { the true value of the ratio } \frac{{ }^{x} e}{y_{e}} \\
r_{B} & =\text { the measured value of the ratio } \frac{{ }^{x} e}{y_{e}}
\end{aligned}
$$

\section{2 lon-exchange separation development}

This section describes the progression of the column chromatographic separations used to develop a method to quantitatively separate gallium from a suite of metals commonly associated with hydrothermal samples (i.e. aqueous solutions/fluid and mineral precipitates) for isotopic analysis. The initial methods were simple and utilised short columns to reduce the chance of fractionation of gallium isotopes during column separation. As the development process progressed, it became evident that a longer column was required to effectively separate gallium from elements such as Fe and $\mathrm{Zn}$ while a shorter column was sufficient to separate gallium from most other elements. A number of polystyrene sulphonated resins with various cross-linkages and dry mesh sizes were tested to determine which provided the "cleanest" and most quantitative separation of Ga. A summary of the gallium eluant of columns tested can be found in the Appendix.

\subsubsection{Reagents and apparatus employed}

The $\mathrm{HCl}$ reagent was prepared by double distillation in Teflon (in house) of $10 \mathrm{M} \mathrm{HCl}$ (i.e. concentrated $\mathrm{HCl}$ ) unless otherwise mentioned. All nitric acid based reagents were prepared from 
ultra-pure Optima $14 \mathrm{M} \mathrm{HNO}_{3}$ (i.e. concentrated $\mathrm{HNO}_{3}$ ). The various dilutions of these acids were made by mixing the concentrated ultra-pure $\mathrm{HCl}$ or $\mathrm{HNO}_{3}$ with MilliQ water (MQ, resistivity of $18.2 \mathrm{M} \Omega$ ), produced using an Elba PURELAB water purification system.

Two types of ion exchange column were used: (1) a Savillex Teflon $30 \mathrm{ml}$ Microcolumn with a $6.4 \mathrm{~mm}$ internal diameter and $25 \mathrm{~cm}$ capillary fitted with a $2.5 \mathrm{~mm}$ PTFE frit (Savillex columns); and (2) an Eichrom polypropylene $2 \mathrm{ml}$ column with a $0.8 \mathrm{~cm}$ internal diameter and $7 \mathrm{~cm}$ capillary fitted with an $8 \mathrm{~mm}$ PTFE frit (Eichrom columns). Both these types of columns were mounted using custom-made Perspex column stands. Columns were cleaned using MQ and 2.5 M HCl before the resins were settled.

Various sizes of Savillex screw top beakers were used (i.e. $2 \mathrm{ml}, 7 \mathrm{ml}, 22 \mathrm{ml}, 60 \mathrm{ml}$ and $90 \mathrm{ml}$ ) and all were cleaned using the type of acid the beaker would be holding. The beakers were rinsed three times with MQ water before batch refluxing in a 1:1 mixture of concentrated AR grade $\mathrm{HCl}$ and MQ water at $60^{\circ} \mathrm{C}$ for 12 hours. These were then rinsed again three times with MQ water before batch refluxing in a 1:1 mixture of concentrated $\mathrm{AR}$ grade $\mathrm{HNO}_{3}$ and MQ water at $60^{\circ} \mathrm{C}$ for another 12 hours. These beakers were again rinsed three times in MQ water before being individually refluxed in either 6-7 $\mathrm{M} \mathrm{HNO}_{3}$ or $\mathrm{HCl}$ depending on the type of reagent the beaker would be holding. The beakers were rinsed a final three times in MQ water before use.

A multi-element standard stock solution of $100 \mathrm{ppb}$ was prepared using ARISTAR ICP single element and multi-element standards and the SRM 944 gallium isotope standard. The multielement selection included $\mathrm{Cu}, \mathrm{Zn}, \mathrm{Fe}$, Ga, etc. These were weighed into a clean $7 \mathrm{ml}$ Savillex beaker before being dried at $80^{\circ} \mathrm{C}$ then dissolved in concentrated $\mathrm{HNO}_{3}$, this procedure was repeated once more before finally being dried at $80^{\circ} \mathrm{C}$ and dissolved in $5 \% \mathrm{HNO}_{3}$.

A SRM994 gallium isotope stock solution of 600 ppm was prepared by dissolving the SRM994 gallium isotope standard metal in concentrated ultra-pure $\mathrm{HNO}_{3}$ and then diluting to $600 \mathrm{ppm}$ gallium solution in $10 \% \mathrm{HNO}_{3}$ using MQ water.

\subsection{2 $\mathrm{HCl}$ separation using AG50W-X4}

A simple approach using $\mathrm{HCl}$ media with BioRad AG50W-X4 resin in hydrogen form at 100200 dry mesh size was first trialled to determine the ability of the resin to separate gallium from various metals. A list of reagents and apparatus, and the procedure are as follows:

Reagents and Apparatus

BioRad AG50W-X4, 100-200 mesh

Eichrom columns

$\mathrm{HCl}$

$\mathrm{HNO}_{3}$ 
$22 \mathrm{ml}$ Savillex beakers

Procedure

The resin was settled in a slurry with MQ to $2.5 \mathrm{~cm}, 3.5 \mathrm{~cm}$ and $5.5 \mathrm{~cm}$ in length, with volumes of about $1.5 \mathrm{ml}, 2.1 \mathrm{ml}$ and $3.3 \mathrm{ml}$ respectively, in Eichrom columns. The resin was equilibrated by elution of $30 \mathrm{ml}$ of MQ water followed by $10 \mathrm{ml}$ of $2.5 \mathrm{M} \mathrm{HCl}$ and $10 \mathrm{ml}$ of $8 \mathrm{M} \mathrm{HCl}$. One millilitre of the multi-element standard was taken to dryness at $90^{\circ} \mathrm{C}$ and dissolved in $200 \mu \mathrm{l}$ of $8 \mathrm{M} \mathrm{HCl}$. This was passed though the column. $20 \mathrm{ml}$ of $8 \mathrm{M} \mathrm{HCl}$ was then passed through the column to elute the majority of metals. Following this, gallium was collected using $10 \mathrm{ml}$ of 2.5 $\mathrm{M} \mathrm{HCl}$ in a $22 \mathrm{ml}$ beaker. The gallium eluate was taken to dryness at $90^{\circ} \mathrm{C}$ then brought up in $500 \mu \mathrm{l}$ of concentrated $\mathrm{HNO}_{3}$ that was capped and refluxed for 2 hours at $120^{\circ} \mathrm{C}$ and then dried at $90^{\circ} \mathrm{C}$. This procedure was repeated twice and the residue finally brought up in $1 \% \mathrm{HNO}_{3}$ and refluxed overnight ready for analysis on the Thermo-Fisher Element 2 ICPMS.

Results

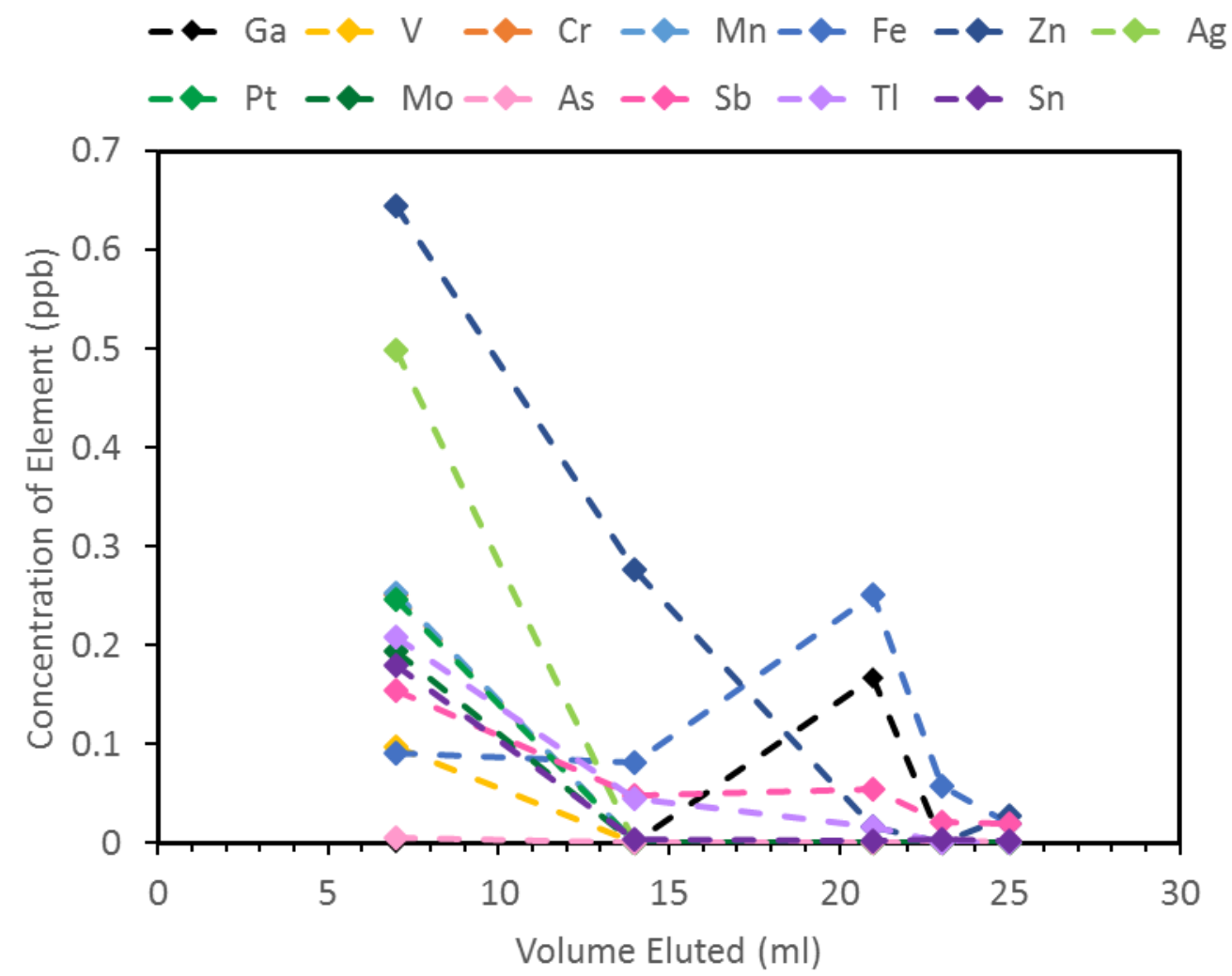

Figure 3.2 Elution curve for $\mathrm{HCl}$ separation using $5.5 \mathrm{~cm}$ AG50W-X4, 100-200 mesh. gallium is separated from Ag, $\mathrm{Cr}, \mathrm{Mn}, \mathrm{Mo}, \mathrm{Pt}, \mathrm{Sn}$, and $\mathrm{V}$. Fe, Sb and Tl display a second peak in $2.5 \mathrm{M} \mathrm{HCl}$. Zn, and As persist in the Gallium eluate.

Analysis of the gallium eluate in $\mathrm{HCl}$ media indicated that gallium was separated from most elements (Figure 3.2). However, the separation from $\mathrm{Fe}, \mathrm{Zn}$ and $\mathrm{Sb}$ was poor. This is likely due to the higher distribution coefficients of $\mathrm{Fe}^{3+}, \mathrm{Tl}^{3+}$ and $\mathrm{Sb}^{3+}$ in AG50W type acids in $8 \mathrm{M} \mathrm{HCl}$ 
(Saito, 1984). The following two methods describe attempts to reduce and separate these species using $\mathrm{HBr}$-acetone mixture, and iodide as reducing agents.

\subsection{3 $\mathrm{HBr}+$ Acetone separation using AG50W-X4}

The first attempt to reduce and separate $\mathrm{Fe}$ and zinc from gallium was tried according to a similar procedure in Strelow (1980b). The reagents and apparatus used and the procedure followed were as outlined below:

Reagents and Apparatus

AG 50W-X4, 200-400 mesh

Eichrom columns

Ultra-pure Seastar $\mathrm{HBr}$

AR grade Acetone

$\mathrm{HCl}$

$\mathrm{HNO}_{3}$

$22 \mathrm{ml}$ Savillex beakers

Procedure

The resin was settled in a slurry with MQ to $5.5 \mathrm{~cm}$ in length with a volume of about $3.3 \mathrm{ml}$, in Eichrom columns. This was equilibrated by passing $10 \mathrm{ml}$ of $0.2 \mathrm{M}$ hydrobromic acid in $80 \%$ acetone. One millilitre of the multi-element standard was taken to dryness at $90^{\circ} \mathrm{C}$ and dissolved in $10 \mathrm{ml}$ of $0.2 \mathrm{M} \mathrm{HBr}$ in $80 \%$ acetone and passed through the column, this was followed by an additional $12 \mathrm{ml}$ of the same reagent. $12 \mathrm{ml}$ of a solution containing $0.5 \mathrm{M} \mathrm{HBr}$ in $80 \%$ acetone were then passed through the column before eluting the gallium using $4 \mathrm{ml}$ of $2.5 \mathrm{M}$ hydrochloric acid. Eluates collected were taken to dryness at $80^{\circ} \mathrm{C}$ then brought up in $500 \mu \mathrm{l}$ of concentrated $\mathrm{HNO}_{3}$ which was then capped and refluxed for 2 hours at $120^{\circ} \mathrm{C}$ before being dried at $90^{\circ} \mathrm{C}$. This procedure was repeated twice. The dried residue was then brought up in $1 \% \mathrm{HNO}_{3}$ and refluxed overnight prior to analysis on the Thermo-Fisher Element 2 ICPMS.

Results

A large amount of iron in the gallium eluant, as well as insufficient separation for other transition metals (Figure 3.3) indicates this is not a suitable method for the quantitative and "clean" separation of $\mathrm{Ga}$. 


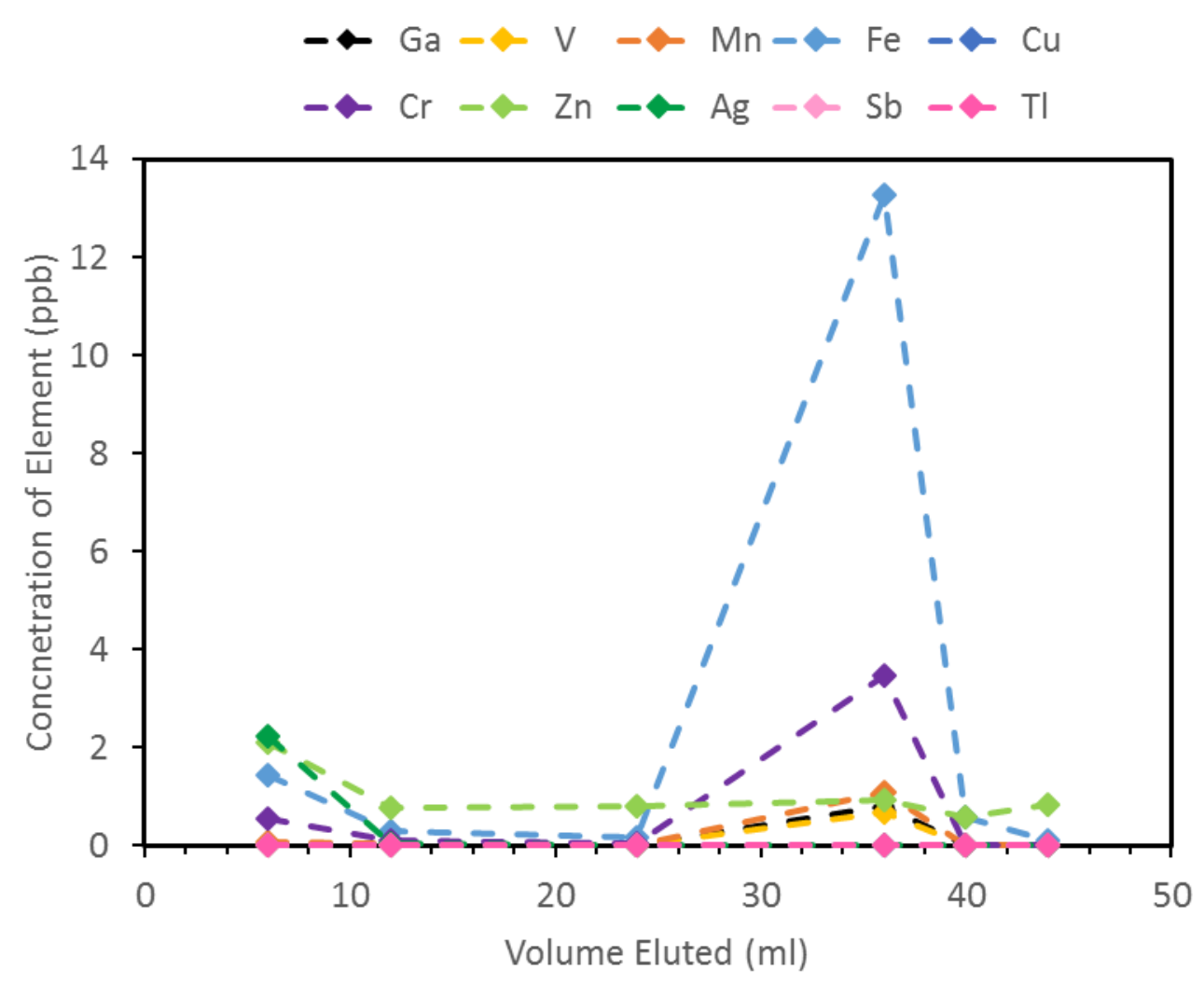

Figure 3.3 Elution curve for $\mathrm{HBr}+$ Acetone using $5.5 \mathrm{~cm}$ AG50W-X4, 100-200 mesh. gallium is separated from Ag, $\mathrm{Cu}, \mathrm{Sb}$ and $\mathrm{Tl}$. $\mathrm{Cr}, \mathrm{Fe}, \mathrm{Mn}$ and $\mathrm{V}$ display a second peak in $2.5 \mathrm{M} \mathrm{HCl}$. Zinc persists in the Gallium eluate.

\subsection{4 $\mathrm{Nal}+\mathrm{HCl}$ separation using AG50W-X4}

The iodide ion was also used in an attempt to reduce and separate $\mathrm{Fe}$ (as well as $\mathrm{Zn}$ ) from gallium in $\mathrm{HCl}$ solutions. The reagents and apparatus used and the procedure followed are outlined below:

Reagents and Apparatus

AG 50W-X4, 100-200 mesh

Eichrom columns

AR grade $\mathrm{NaI}$

$\mathrm{HCl}$

$22 \mathrm{ml}$ Savillex beakers

\section{Procedure}

The resin was settled in a slurry with MQ water to $2.5 \mathrm{~cm}$ in length in an Eichrom column, a volume of about $1.5 \mathrm{ml}$. This was equilibrated by eluting $30 \mathrm{ml}$ of $0.001 \% \mathrm{NaI}$ in $8 \mathrm{M}$ hydrochloric acid. One millilitre of the multi-element standard was taken to dryness at $90^{\circ} \mathrm{C}$ and dissolved in $500 \mu \mathrm{l}$ of the NaI solution. This was passed through the column followed by $6 \mathrm{ml}$ of the same reagent. Following this, $8 \mathrm{ml}$ of $8 \mathrm{M} \mathrm{HCl}$ was passed through the column to remove iodide. Gallium was then eluted from the column with $7 \mathrm{ml}$ of $2.5 \mathrm{M} \mathrm{HCl}$. As previously, eluates 
collected were taken to dryness at $80^{\circ} \mathrm{C}$ and then brought up in $500 \mu \mathrm{l}$ concentrated $\mathrm{HNO}_{3}$, capped an refluxed for 2 hours at $120^{\circ} \mathrm{C}$ and then dried at $90^{\circ} \mathrm{C}$ with this procedure twice repeated. The resulting dried residue was then brought up in $1 \% \mathrm{HNO}_{3}$ and refluxed overnight prior to analysis on the Thermo-Fisher Element 2 ICPMS.

\section{Results}

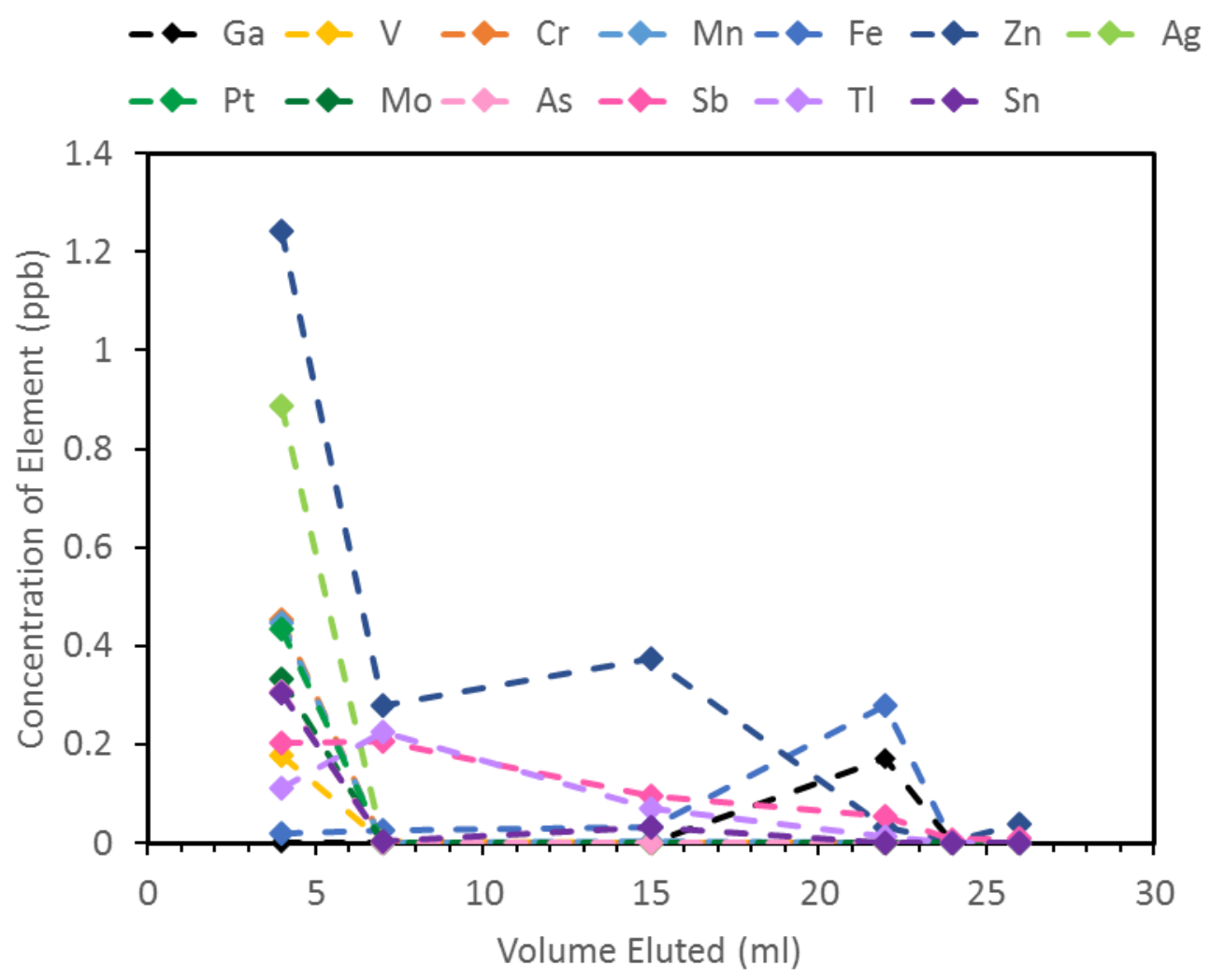

Figure 3.4 Elution curve for $\mathrm{Nal}$ in $\mathrm{HCl}$ using $3.5 \mathrm{~cm}$ AG50W-X4, 100-200 mesh. gallium is separated from $\mathrm{Ag}, \mathrm{Cr}$, $\mathrm{Mn}, \mathrm{Mo}, \mathrm{Pt}, \mathrm{As}$, and V. Fe displays a second peak in $2.5 \mathrm{M} \mathrm{HCl}$. Sb, Sn, and zinc persist in the Gallium eluate.

Fe was not sufficiently separated from gallium using this method (Figure 3.4) and so a stronger reductant is required.

\subsection{5 $\mathrm{HCl}+$ concentrated $\mathrm{TiCl}_{3}$ using $\mathrm{AG1}$-X8}

Titanium trichloride has been proven to be a successful reductant in the separation of gallium from Fe(III) in aqueous media (Korkisch et al., 1979; van der Walt and Strelow, 1983). A procedure modified from Korkisch et al. (1979) was trialled to determine if it could sufficiently separate small amounts of $\mathrm{Fe}$ and zinc from $\mathrm{Ga}$.

Reagents and Apparatus

AG1-X8, 100-200 mesh

Savillex columns

Crystalline titanium, $\geq 99.99 \%$ trace element basis, Sigma Aldrich 
$\mathrm{HCl}$

$\mathrm{HNO}_{3}$

$22 \mathrm{ml}$ Savillex beakers

\subsection{6 $\mathrm{HCl}+$ concentrated $\mathrm{TiCl}_{3}$ using $\mathrm{AG} 1-\mathrm{X} 8$}

Titanium trichloride was proven to be a successful reductant in the separation of gallium from $\mathrm{Fe}(\mathrm{III})$ in aqueous media (Korkisch, 1979; van der Walt and Strelow, 1983). A procedure modified from Korkisch et al. (1979) was trialled to determine if it could sufficiently separate small amounts of $\mathrm{Fe}$ and zinc from $\mathrm{Ga}$.

Reagents and Apparatus

AG1-X8, 100-200 mesh

Savillex columns

Crystalline titanium, $\geq 99.99 \%$ trace element basis, Sigma Aldrich

$\mathrm{HCl}$

$\mathrm{HNO}_{3}$

$22 \mathrm{ml}$ Savillex beakers

Procedure

A concentrated $\mathrm{TiCl}_{3}$ solution in $8 \mathrm{M} \mathrm{HCl}$ was synthesised using crystalline, elemental $\mathrm{Ti}$ and concentrated $\mathrm{HCl} .5 \mathrm{~g}$ of Ti were weighed into a $500 \mathrm{ml}$ Teflon bottle and $100 \mathrm{ml}$ of concentrated $\mathrm{HCl}$ was added. The solution was refluxed at $65^{\circ} \mathrm{C}$ for $72 \mathrm{hrs}$, and resulted in a solution containing $\sim 15 \% \mathrm{TiCl}_{3}$ and $\sim 25 \mathrm{wt} \% \mathrm{HCl}(\sim 8 \mathrm{M})$. Resin was settled in a slurry with MQ water to $11 \mathrm{~cm}$ in length and a volume of $4.5 \mathrm{ml}$. This was equilibrated by eluting $50 \mathrm{ml}$ of $6 \mathrm{M} \mathrm{HCl}$, followed by $10 \mathrm{ml}$ of $4 \mathrm{M} \mathrm{HCl}$ and finally $10 \mathrm{ml}$ of the $\mathrm{TiCl}_{3}$ solution $\left(7.5 \%\right.$ solution of $\mathrm{TiCl}_{3}$ in $\left.3 \mathrm{M} \mathrm{HCl}\right)$. One millilitre of the multi-element standard was taken to dryness at $90^{\circ} \mathrm{C}$ and dissolved $6 \mathrm{M} \mathrm{HCl}$ (10 $\mathrm{ml}$ per $0.1 \mathrm{~g}$ of sample) then treated with $5 \mathrm{ml}$ of the $\mathrm{TiCl}_{3}$ solution before being introduced to the column. $25 \mathrm{ml}$ of the $\mathrm{TiCl}_{3}$ solution was added to the column to elute residual $\mathrm{Fe}$ and other elements such as $\mathrm{Mn}, \mathrm{Al}$, alkaline earths, alkalis, etc. $20 \mathrm{ml}$ of $6 \mathrm{M} \mathrm{HCl}$ was then passed through the column to remove Ti followed by $40 \mathrm{ml} 2 \mathrm{M} \mathrm{HNO}_{3}$ to elute Ga. All eluates were taken to dryness at $90^{\circ} \mathrm{C}$ and treated as described previously for analysis on the Thermo-Fisher Element 2 ICPMS.

Results

Ti was concentrated in all eluates collected such that in $\mathrm{HNO}_{3}$, it precipitated and so an elution curve was not measured for this column. The table below (Table 3.2) gives the elements present in the gallium eluate. It should be noted that $\mathrm{Ti}$ is still very concentrated where gallium is eluted as noted by the opaque white colour of the gallium solution before diluting for analysis. A secondary column, or a method with a lower concentration of $\mathrm{TiCl}_{3}$ was therefore required to 
decrease the Ti content so that gallium isotopes could be analysed by MC-ICPMS without concern for non-spectral interferences in the plasma.

Table 3.2 Elements present in the gallium eluate for $\mathrm{HCl}+$ concentrated $\mathrm{TiCl}_{3}$ in $\mathrm{AG}^{-} \mathrm{WW}-\mathrm{X} 4$

\begin{tabular}{ll}
\hline Eluate & Elements present (ppb) \\
\hline First $20 \mathrm{ml}$ of $2 \mathrm{M} \mathrm{HNO}_{3}$ & $21 \mathrm{ppb} \mathrm{Ga}, 21 \mathrm{ppb} \mathrm{Fe}, 0.7 \mathrm{ppb} \mathrm{Ag}$ \\
Second $20 \mathrm{ml}$ of $2 \mathrm{M} \mathrm{HNO}_{3}$ & $0.1 \mathrm{ppb} \mathrm{Ga}, 13.2 \mathrm{ppb} \mathrm{Fe}, 0.7 \mathrm{ppb} \mathrm{Ag}$ \\
\hline
\end{tabular}

\subsection{7 $\mathrm{HCl}+$ dilute $\mathrm{TiCl}_{3}$ method using AG50W-X4}

As the concentration of Ti eluted with gallium using the Korkisch method was too large, a secondary method utilising a more dilute solution of $\mathrm{TiCl}_{3}$ was investigated following aspects of van der Walt and Strelow (1983).

Reagents and Apparatus

AG50W-X4, 200-400 mesh

Savillex columns

Crystalline titanium, $\geq 99.99 \%$ trace element basis

$\mathrm{HCl}$

$\mathrm{HNO}_{3}$

$22 \mathrm{ml}$ Savillex beakers

Procedure

A concentrated $\mathrm{TiCl}_{3}$ solution in $8 \mathrm{M} \mathrm{HCl}$ was synthesised as described above then diluted to $0.3 \% \mathrm{TiCl}_{3}$ in $8 \mathrm{M} \mathrm{HCl}$. The resin slurry was settled into an $11 \mathrm{~cm}$ column, i.e. a volume of 4.5 $\mathrm{ml}$. This was equilibrated by eluting $50 \mathrm{ml}$ of $2.5 \mathrm{M} \mathrm{HCl}$, followed by $50 \mathrm{ml}$ of $8 \mathrm{M} \mathrm{HCl}$ and finally $20 \mathrm{ml}$ of the $0.3 \% \mathrm{TiCl}_{3}$ solution. One millilitre of the multi-element standard was taken to dryness at $90^{\circ} \mathrm{C}$ and dissolved in $4 \mathrm{ml}$ of the $0.3 \% \mathrm{TiCl}_{3}$ solution then treated with $50 \mu \mathrm{l}$ of the concentrated $\mathrm{TiCl}_{3}$ solution. The sample was introduced to the column by washing onto the resin with small amounts of the $\mathrm{TiCl}_{3}$ solution, followed by $80 \mathrm{ml}$ of the $\mathrm{TiCl}_{3}$ solution was added to the column to elute residual Fe and other elements such as Mn, Al, alkaline earths, alkalis, etc. $90 \mathrm{ml}$ of $8 \mathrm{M} \mathrm{HCl}$ was passed through the column to remove the majority of Ti followed by 20 $\mathrm{ml}$ of $2.5 \mathrm{M} \mathrm{HCl}$ to elute $\mathrm{Ga}$. All eluates were taken to dryness at $90^{\circ} \mathrm{C}$ following the previously described procedure prior for analysis on the Thermo-Fisher Element 2 ICPMS.

Results

Ti was still concentrated in all eluates collected such that in $\mathrm{HNO}_{3}$ it precipitated and formed an opaque white dispersion, and therefore an elution curve was not measured for this column. Table 3.3 gives the elements present in the gallium eluate. It was noted that Ti was still concentrated when gallium was eluted as noted by the translucent white colour of the gallium solution before 
diluting for analysis. A secondary column was required to remove the remaining gallium from solution.

Table 3.3 Elements present in the gallium eluate for $\mathrm{HCl}+$ dilute $\mathrm{TiCl}_{3}$ using AG50W-X8

\begin{tabular}{ll}
\hline Eluate & Elements present (ppb) \\
\hline Final $20 \mathrm{ml}$ of $8 \mathrm{M} \mathrm{HCl}$ & $0.1 \mathrm{ppb} \mathrm{Ga}, 0.5 \mathrm{ppb} \mathrm{Cr}, 16.3 \mathrm{ppb} \mathrm{Mn}, 5.2 \mathrm{ppb}$ Fe, $0.8 \mathrm{ppb} \mathrm{Ag}$ \\
First $20 \mathrm{ml}$ of $2.5 \mathrm{M} \mathrm{HCl}$ & $0.4 \mathrm{ppb} \mathrm{Ga}, 0.2 \mathrm{ppb} \mathrm{Cr}, 8.5 \mathrm{ppb} \mathrm{Ga}, 0.7 \mathrm{ppb} \mathrm{Ag}$ \\
Second $20 \mathrm{ml}$ of $2.5 \mathrm{M} \mathrm{HCl}$ & $25.2 \mathrm{ppb} \mathrm{Ga}, 0.5 \mathrm{ppb} \mathrm{Cr}, 2.4 \mathrm{ppb} \mathrm{Fe}, 0.2 \mathrm{ppb} \mathrm{Ag}$ \\
\hline
\end{tabular}

\subsubsection{Comparison of $A G 50 W$ resins}

As the van der Walt and Strelow (1984) method has proven the most successful at separating gallium from the majority of other elements, a number of different resins were trialled to determine which resin obtains the best separation of gallium from $\mathrm{Al}, \mathrm{Fe}$ and $\mathrm{Zn}$. The method outlined in Section 3.2.7 was followed for each of the different resins. Table 3.4 shows that the separation of gallium was best-achieved using AG50W-X8 100-200 mesh.

Table 3.4 Comparison of AG50W resins

\begin{tabular}{|c|c|c|c|c|c|}
\hline Resin & Length & Eluents & Volume & $\begin{array}{l}\text { Elements present } \\
\text { in gallium eluate }\end{array}$ & Ga recovered (\%) \\
\hline AG50W-X12, 100-200 & $15 \mathrm{~cm}$ & $\begin{array}{l}8 \mathrm{M} \mathrm{HCl}+0.3 \% \mathrm{TiCl} 3 \\
8 \mathrm{M} \mathrm{HCl}^{2.5 \mathrm{M} \mathrm{HCl}^{*}}\end{array}$ & $\begin{array}{r}90 \mathrm{ml} \\
100 \mathrm{ml} \\
40 \mathrm{ml}\end{array}$ & $\begin{array}{l}\mathrm{Ag}, \mathrm{Sn}, \mathrm{Hg}, \mathrm{Tl}, \mathrm{Mg}, \\
\mathrm{Al}, \mathrm{Sc}, \mathrm{Ti}, \mathrm{Cr}, \mathrm{Fe}, \mathrm{Ni}, \\
\mathrm{Cu}, \mathrm{Zn}\end{array}$ & $54.16 \%$ \\
\hline AG50W-X4, 200-400 & $15 \mathrm{~cm}$ & $\begin{array}{l}8 \mathrm{M} \mathrm{HCl}+0.3 \% \mathrm{TiCl}^{3} \\
8 \mathrm{M} \mathrm{HCl} \\
2.5 \mathrm{M} \mathrm{HCl}^{*}\end{array}$ & $\begin{array}{r}90 \mathrm{ml} \\
100 \mathrm{ml} \\
40 \mathrm{ml}\end{array}$ & $\begin{array}{l}\mathrm{Tl}, \mathrm{Ag}, \mathrm{V}, \mathrm{Cr}, \mathrm{Mn}, \\
\mathrm{Fe}\end{array}$ & $93.23 \%$ \\
\hline AG50W-X4, 50-100 & $15 \mathrm{~cm}$ & $\begin{array}{l}8 \mathrm{M} \mathrm{HCl}+0.3 \% \mathrm{TiCl} 3 \\
8 \mathrm{M} \mathrm{HCl} \\
2.5 \mathrm{M} \mathrm{HCl}^{*}\end{array}$ & $\begin{array}{r}90 \mathrm{ml} \\
100 \mathrm{ml} \\
40 \mathrm{ml}\end{array}$ & $\begin{array}{l}\mathrm{Ag}, \mathrm{Sn}, \mathrm{Hg}, \mathrm{Tl}, \mathrm{Al}, \\
\mathrm{Sc}, \mathrm{Ti}, \mathrm{V}, \mathrm{Cr}, \mathrm{Mn} \text {, } \\
\mathrm{Fe}, \mathrm{Co}, \mathrm{Ni}, \mathrm{Cu}, \mathrm{Zn} \text {, } \\
\text { As }\end{array}$ & $65.96 \%$ \\
\hline AG50W-X8, 100-200 & $15 \mathrm{~cm}$ & $\begin{array}{l}8 \mathrm{M} \mathrm{HCl}+0.3 \% \mathrm{TiCl} 3 \\
8 \mathrm{M} \mathrm{HCl} \\
2.5 \mathrm{M} \mathrm{HCl}^{*}\end{array}$ & $\begin{array}{r}90 \mathrm{ml} \\
100 \mathrm{ml} \\
40 \mathrm{ml}\end{array}$ & $\mathrm{V}, \mathrm{Cr}, \mathrm{Mn}, \mathrm{Fe}$ & $99.47 \%$ \\
\hline AG50W-X8, 200-400 & $15 \mathrm{~cm}$ & $\begin{array}{l}8 \mathrm{M} \mathrm{HCl}+0.3 \% \mathrm{TiCl} \\
8 \mathrm{M} \mathrm{HCl} \\
2.5 \mathrm{M} \mathrm{HCl}^{*}\end{array}$ & $\begin{array}{r}90 \mathrm{ml} \\
100 \mathrm{ml} \\
40 \mathrm{ml}\end{array}$ & $\begin{array}{l}\mathrm{Bi}, \mathrm{Mg}, \mathrm{Al}, \mathrm{Sc}, \mathrm{Ti} \\
\mathrm{Cr}, \mathrm{Fe}, \mathrm{Ni}, \mathrm{As}, \mathrm{Zn}\end{array}$ & $95.70 \%$ \\
\hline
\end{tabular}

* indicates eluant collected for Ga

\subsection{Final ion exchange column procedure}

The final ion exchange procedure to separate gallium from a sample matrix is presented below.

\subsection{1 $\mathrm{HCl}+$ dilute $\mathrm{TiCl}_{3}$ using a second pass through AG50W-X8}

AG50W-X8 100-200 mesh has proven the most successful method for the separation of gallium from other elements. However, Ti was still present in the gallium eluate after the first elution 
through the column. A second pass through a shorter column of AG50W-X8 100-200 mesh resin was employed to remove the remaining adsorbed $\mathrm{Ti}$ because the initial concentration of $\mathrm{TiCl}_{3}$ introduced to the column had resulted in the saturation of the resin with Ti.

Reagents and Apparatus

AG50W-X8, 100-200 mesh

Savillex columns

Eichrom columns

Crystalline titanium, $\geq 99.99 \%$ trace element basis

$\mathrm{HCl}$

$\mathrm{HNO}_{3}$

$22 \mathrm{ml}$ Savillex beakers

Procedure

The method outlined in Section 3.2.7 was followed using AG50W-X4, 100-200 mesh size, until the gallium eluate was taken to dryness. The dried gallium eluate was brought up in $5 \mathrm{ml}$ of $8 \mathrm{M}$ $\mathrm{HCl}$ and refluxed at $120^{\circ} \mathrm{C}$ for 4 hours. A second smaller column containing $2 \mathrm{ml}$ of resin was settled in an Eichrom column and equilibrated with $20 \mathrm{ml} 2.5 \mathrm{M} \mathrm{HCl}$ followed by $20 \mathrm{ml}$ of $8 \mathrm{M}$ $\mathrm{HCl}$. The sample was introduced to the column and washed onto the resin with a small amount ( $2 \mathrm{ml}$ ) of $8 \mathrm{M} \mathrm{HCl} .40 \mathrm{ml}$ of $8 \mathrm{M} \mathrm{HCl}$ was then added to elute residual Ti, followed by $20 \mathrm{ml}$ of $2.5 \mathrm{M} \mathrm{HCl}$ to elute $\mathrm{Ga}$. All eluates were taken to dryness at $90^{\circ} \mathrm{C}$ as previously described (above) before analysis using the Thermo-Fisher Element 2 ICPMS.

Results

The elution curve (Figure 3.5 and Figure 3.6) shows that the Ti concentration was less than $1 \mathrm{ppb}$ in the gallium eluate. Also, $\mathrm{Mg}, \mathrm{Fe}, \mathrm{Zn}$ and other metals that are known to cause non-spectral mass bias when analysing for gallium isotopes were less than $5 \mathrm{ppb}$ in the final gallium eluate. Other elements that are commonly concentrated in geothermal samples were also been removed using this procedure. This method was used henceforth to separate gallium from the sample matrix in all samples that were collected and analysed for gallium isotopes in this study. 

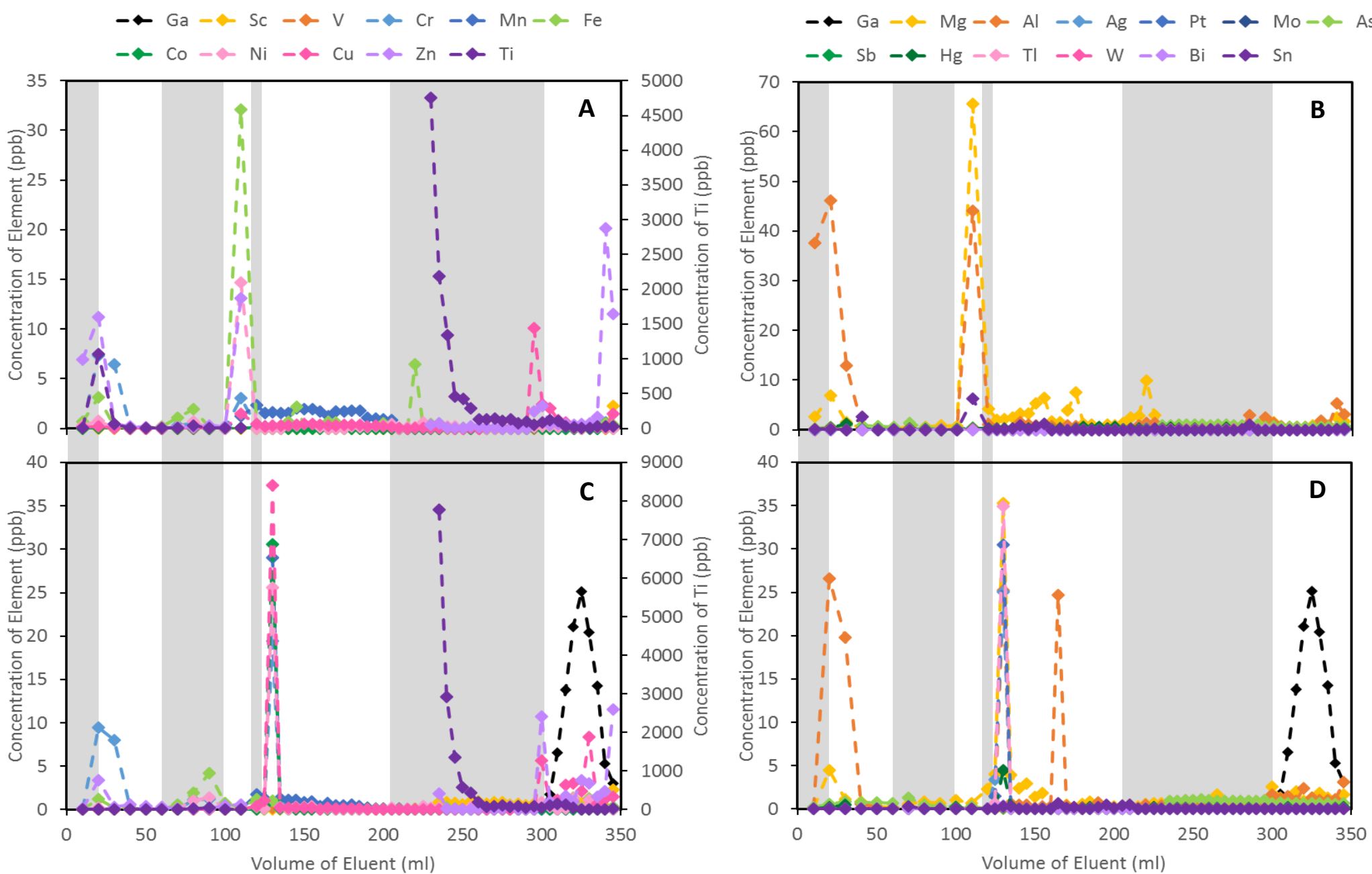

Figure 3.5 First pass through $11 \mathrm{~cm}$ AG50W-X8, 100-200 mesh. A and B are elements eluted in a blank column, i.e. no sample was loaded, $C$ and $D$ are elements eluted when the synthetic standard is loaded. In the order of alternating grey and white boxes: 0-10 ml. MQ water, 10-50 ml 2.5 M HCl, 50-100 ml, $8 \mathrm{M} \mathrm{HCl}, 100-110 \mathrm{ml} \mathrm{HCl}+0.3 \% \mathrm{TiCl}, 110-115 \mathrm{ml}$ sample is loaded in $\mathrm{HCl}+0.3 \% \mathrm{TiCl}_{3}, \mathbf{1 1 5 - 2 0 5} \mathrm{ml} \mathrm{HCl}+\mathbf{0 . 3} \% \mathrm{TiCl}_{3}, 205-305 \mathrm{ml} 8 \mathrm{M} \mathrm{HCl}, 305-350 \mathrm{ml} 2.5 \mathrm{M} \mathrm{HCl}$ (Ga eluent). Gallium has been satisfactorily separated from Sc, $\mathrm{V}, \mathrm{Cr}, \mathrm{Mn}, \mathrm{Co}, \mathrm{Ni}, \mathrm{Ag}, \mathrm{Pt}, \mathrm{Mo}, \mathrm{Sb}$, $\mathrm{TI}, \mathrm{Bi}$ and $\mathrm{Sn}$. Small amounts of $\mathrm{Fe}, \mathrm{Zn}, \mathrm{W}, \mathrm{As}, \mathrm{Au}, \mathrm{Mg}$, Al, and $\mathrm{Hg}$ remain. Errors are below $5 \%$ for all elements except Au, Mo and $\mathrm{W}$ which are below $35 \%$. 

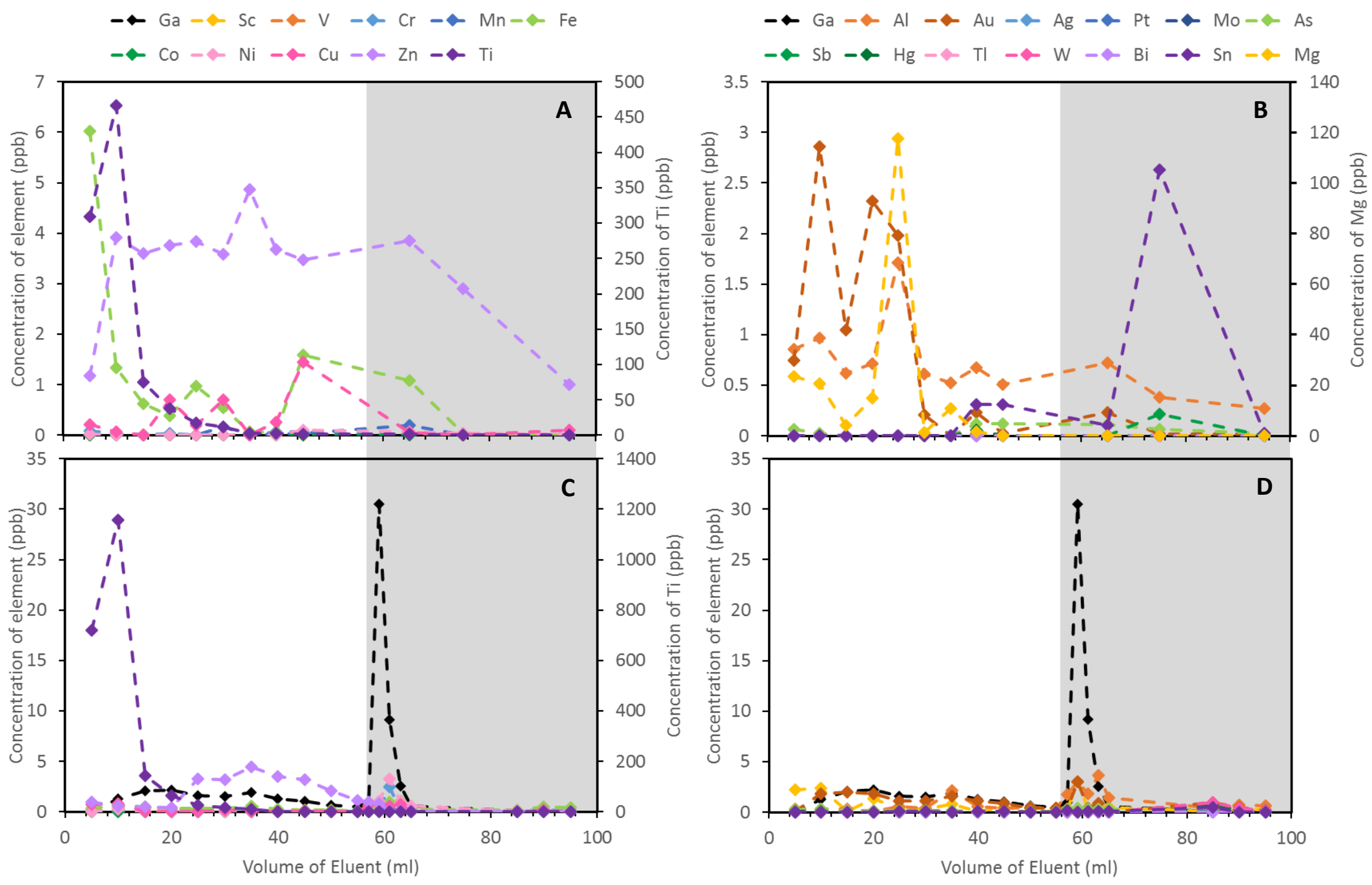

Figure 3.6 Second pass through $11 \mathrm{~cm}$ AG50W-X8, 100-200 mesh. A and B are elements eluted in a blank column, C and D are elements eluted when the synthetic standard is loaded. In the order of alternating grey and white boxes: $0-5 \mathrm{ml}$ sample is loaded, $5-55 \mathrm{ml} 8 \mathrm{M} \mathrm{HCl}, 55-100 \mathrm{ml} 2.5 \mathrm{M} \mathrm{HCl}$ (Ga eluent). Gallium has been satisfactorily separated from the remaining elements. Less than 5 ppb persists of $\mathrm{Al}, \mathrm{Cu}, \mathrm{Mn}$, and Fe. Errors are below $3 \%$ for all measureable elements except $\mathrm{Au}, \mathrm{Mo}$ and $\mathrm{W}$ which are below $40 \%$. 


\subsubsection{Quantitative extraction of gallium}

To ensure that the columns quantitatively separated gallium at various concentrations, three different concentrations of the SRM994 gallium isotope standard were passed through the ion exchange column using the method discussed above in Section 3.4. If the value of the isotopic ratio of gallium after processing through the ion exchange columns and analysing using the simple sample-standard bracketing technique is the same as the SRM994 gallium isotope standard (i.e. $\delta^{71} \mathrm{Ga}=-0.003 \%$ o $\pm 0.07 \%$; Figure 3.10 ), the column can be considered to be successful at quantitatively separating gallium from the sample matrix. Table 3.5 shows that samples with $100 \mathrm{ppb}$ gallium and above can be processed using this column procedure and successfully analysed for gallium isotopes. Blank columns analysed (i.e. samples processed without a standard or sample) show no trace of gallium in the final eluate and therefore a blank correction is not required when analysing gallium isotopes by MC-ICPMS.

Table 3.5 Results from SRM994 gallium isotope standard tests with final column procedure

\begin{tabular}{lcc}
\hline Sample Type & $\delta^{71} \mathrm{Ga}$ & 2 se \\
\hline $\begin{array}{l}\text { 1,000 ng SRM994 gallium isotope } \\
\text { standard }\end{array}$ & $-0.09 \%$ & $\pm 0.03 \%$ \\
$100 \mathrm{ng}$ SRM994 gallium isotope & $-0.02 \%$ & $\pm 0.02 \%$ \\
standard & & \\
$10 \mathrm{ng}$ SRM994 gallium isotope standard & $-728 \%$ & $\pm 14 \% \mathrm{o}$ \\
0 ng SRM994 gallium isotope standard & B.D. & B.D. \\
\hline B.D. is below detection & &
\end{tabular}

\subsubsection{Reproducibility of $\delta^{71} \mathrm{Ga}$ in natural samples}

The ability of the final column procedure to reproducibly separate gallium from a natural sample matrix was trialled using rock standards JR-2 (rhyolite powder; Geological Survey of Japan) and BHVO-2 (basalt powder; United States Geological Survey). If the results are reproducible with different batches of digestions and different aliquots from the same digestion, the ion-exchange column procedure can be considered robust and reproducible with regard to analysing gallium isotopes using the simple sample-standard analysis with MC-ICPMS as discussed in Section 3.4.

One digested sample of BHVO-2 was split into three different parts and each was analysed using the finalised method for the ion-exchange column separation and three different samples of JR2 were digested and processed through the final ion-exchange column separation. Figure 3.7 shows that the column separation is reproducible. The $\delta^{71}$ Ga value for JR-2 is $-0.92 \% 0 \pm 0.12 \%$ o ( 2 se) based on three analyses of different samples and for BHVO-2 the $\delta^{71}$ Ga value is $-1.91 \%$ o $\pm 0.23 \%$ (2se) base on three analyses of the same digested sample. 


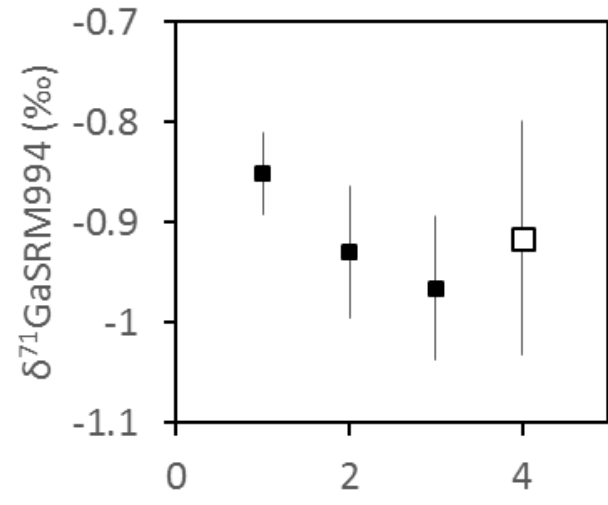

JR-2 Rhyolite Powder

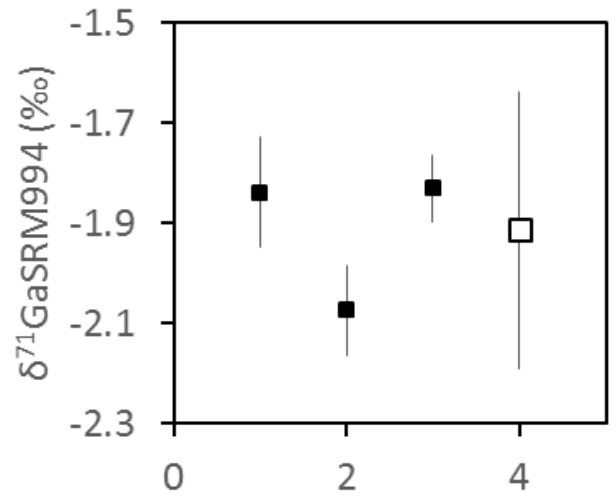

BHVO-2 Basalt Powder

Figure 3.7 Repeat analyses on two rock standards: JR-2, rhyolite powder, Geological Survey of Japan; BHVO-2, basalt powder, United States Geological Survey. Three different portions of JR-2 powder were digested and processed separately for gallium isotope analysis and three aliquots of the same portion of digested BHVO-2 powder were taken and processed individually for gallium isotope analysis. Filled squares indicate individual analyses; open squares indicate the mean of the individual analyses (i.e. black squares) and the associated error bars reporting two times the standard deviation.

\subsection{MC-ICPMS}

A new protocol for the measurement of gallium isotopes was established on the $\mathrm{Nu}$ Plasma multiple collector inductively-coupled plasma mass spectrometer. Tests comprising simple sample-standard bracketing and Zn-doped sample-standard bracketing were carried out to determine the method that best ensured that the gallium isotope measurements are both accurate and reproducible.

\subsubsection{Operation Conditions}

The MC-ICPMS was operated under normal conditions (Table 3.7). However, the mass resolution was increased from $0.333 \mathrm{amu}$ to $0.5 \mathrm{amu}$ to allow the full suite of zinc isotopes to be measured in conjunction with the gallium isotopes (Table 3.6). The quad settings were adjusted so as to align the flat tops of each of the peaks to be investigated before any analysis or testing began and these were checked periodically to ensure peak tops remained horizontal and aligned.

Table 3.6 Collector configuration used on the Nu Plasma Instrument

\begin{tabular}{ccccccc}
\hline \multicolumn{2}{l}{ Collector Configuration: } & & & & \\
\hline $\mathrm{H} 6$ & $\mathrm{H} 5$ & $\mathrm{H} 4$ & $\mathrm{H} 2$ & $\mathrm{Ax}$ & $\mathrm{L} 2$ & $\mathrm{~L} 4$ \\
$71 \mathrm{Ga}$ & $70 \mathrm{Zn}$ & $69 \mathrm{Ga}$ & $68 \mathrm{Zn}$ & $67 \mathrm{Zn}$ & $66 \mathrm{Zn}$ & $64 \mathrm{Zn}$ \\
\hline
\end{tabular}


Table 3.7 Operating conditions used on the Nu Plasma Instrument

\begin{tabular}{ll}
\hline Setting & \\
\hline Coolant Ar flow & $13.0 \mathrm{I} \mathrm{\textrm {min } ^ { - 1 }}$ \\
Auxiliary Ar flow & $0.79 \mathrm{I} \mathrm{\textrm {min } ^ { - 1 }}$ \\
Nebuliser Ar flow & $36.5 \mathrm{psi}$ \\
RF Coil Power & $1,300 \mathrm{~W}$ \\
Reflected Power & $0 \mathrm{~W}$ \\
Cones & $6 \mathrm{kV}$ \\
Uptake & $120 \mu \mathrm{l} \mathrm{min}{ }^{-1}$ \\
Mass Resolution & $0.5 \mathrm{amu}$ \\
\hline Dry Plasma & $\mathrm{DSN}-100$ \\
\hline Spray Chamber Temperature & $111^{\circ} \mathrm{C}$ \\
Desolvator Temperature & $113^{\circ} \mathrm{C}$ \\
Hot Gas Flow & $32 \mathrm{psi}$ \\
Membrane Gas Flow & $3.65-4.10 \mathrm{psi}$ \\
\hline
\end{tabular}

\subsubsection{Mass fractionation correction}

Simple sample-standard bracketing and external element doping were tested in order to determine the most robust method with which to measure gallium isotopes. Both methods were rigorously tested using different concentrations of gallium between standards and samples to ensure that any differences in concentration did not affect the outcome of the gallium isotope ratio. Various amounts of the elements that may persist in low concentrations (after the ion-exchange column) were added to the samples in each of the methods to determine if these elements also would affect the outcome analysis of the gallium isotope ratio. The external reproducibility was also assessed to determine the most consistent method over time. Upon consideration of the outcomes of these tests, the simple sample-standard bracketing technique was chosen to measure the gallium isotope ratio of the various unknown samples collected.

\subsubsection{Simple sample-standard bracketing}

Two gallium standards were measured against each other using the simple sample-standard bracketing method (i.e. SRM994 gallium isotope standard was used as the bracketing standard and the CRM-Ga single element standard was considered the unknown analyte; Figure 3.8). It was found that samples between $60 \mathrm{ppb}$ and $120 \mathrm{ppb}$ give analytically identical results (Figure $3.9)$ as the sample run at the same concentration to the bracketing standards (100 ppb). It appears that the standard-standard drift is constant and generally uniform during the course of an analytical session (e.g. Figure 3.1). Where a large drift between standards was identified, repeat analyses of the unknown sample were made until the bracketing standards stabilised and separated by less drift. 


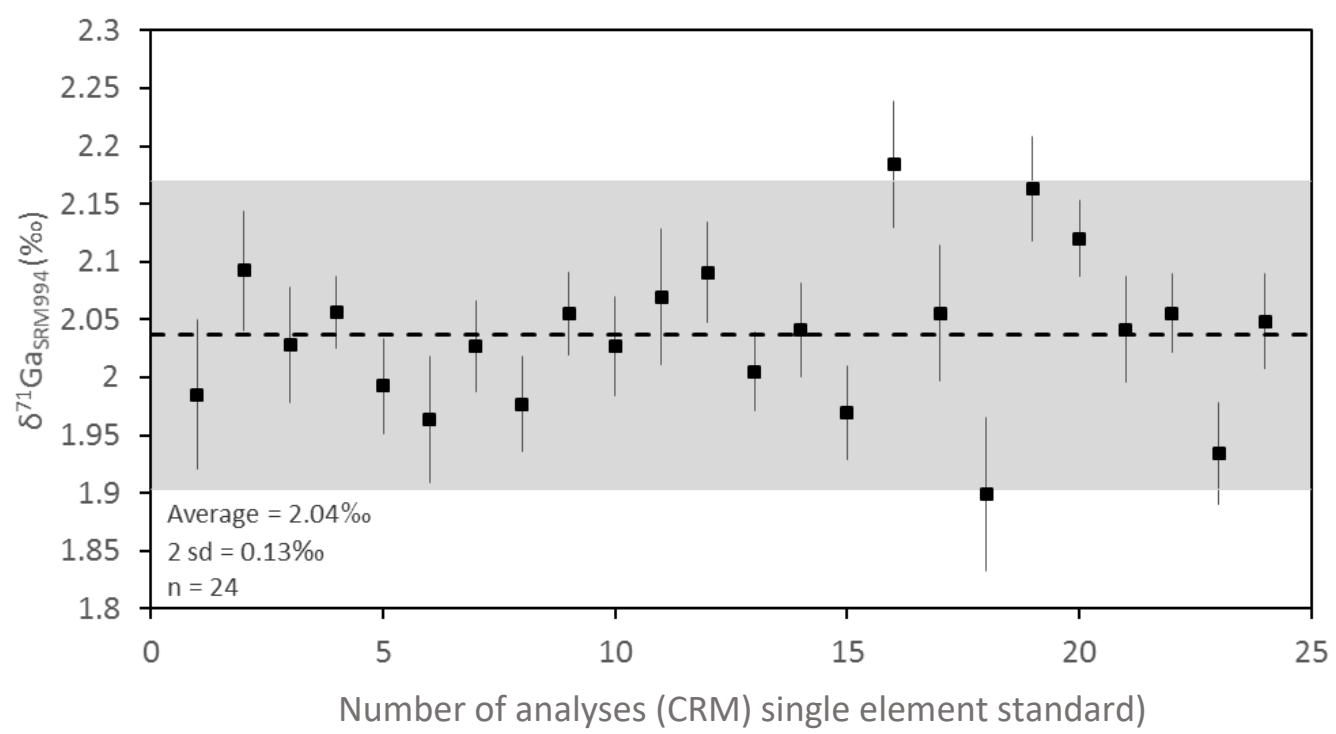

Figure 3.8 External reproducibility of the simple sample-standard bracketing method assessed by repeated measurements of $\mathrm{CM}$ gallium single element standard $(n=27)$. Measurements were carried out between December 2015 and May 2016.

To determine the acceptable threshold at which other elements can be present in the final gallium solution to be analysed, the SRM994 gallium isotope standard was doped with $2 \mathrm{ppb}, 5 \mathrm{ppb}$ and $10 \mathrm{ppb}$ of a number of elements that are commonly known to cause non-spectral mass bias in the plasma (i.e. $\mathrm{Na}, \mathrm{Mg}, \mathrm{Mn}, \mathrm{Fe}, \mathrm{Ti}, \mathrm{Ca}$, and $\mathrm{Al}$ ). Each of these doped standards was run as the analyte using the simple sample-standard bracketing technique. It was found that the gallium isotope ratio is perturbed by the presence of as little as $2 \%$ of the listed element. In some cases, the presence of $5 \%-10 \%$ of $\mathrm{Mn}$ and $\mathrm{Fe}$, and $10 \%$ of $\mathrm{Al}, \mathrm{Ca}, \mathrm{Mg}$ or $\mathrm{Ti}$ as a percent of the total gallium concentration of the sample appear to have no effect on the $\delta^{71} \mathrm{Ga}$ value. Table 3.8 below shows the effect the various elements at different concentrations have on the gallium isotope ratio. This emphasises the importance of removing (by column extraction) these trace elements for the reliable determination of the true Ga isotope ratio.

For this method of correction to be reliable, the mass fractionation response must be the same for the standard and the unknown sample. The results from doping and concentration experiments show that this is a robust method to measure unknown samples between $60 \mathrm{ppb}$ and $120 \mathrm{ppb}$ of gallium in solution that contain less than $2 \%$ (of the total gallium concentration) of other elements. The long term reproducibility of the simple sample-standard bracketing technique was $\pm 0.07 \%$, as determined from repeat analyses of the SRM994 gallium isotope standard (Figure 3.10). 
Table 3.8 Effect on the standard bracket corrected $\delta^{71} \mathrm{Ga}$ value when the standard (run as a sample) is doped with various concentrations of elements known to cause non-spectral mass bias effects in other systems

\begin{tabular}{|c|c|c|c|c|}
\hline Element & $\begin{array}{l}\text { Concentration as a } \\
\text { percentage of SRM994 } \\
\text { gallium isotope standard }\end{array}$ & $\delta^{71} \mathrm{Ga}$ & $2 \mathrm{se}$ & $\begin{array}{l}\text { Within error of the mean, } \\
\text { SRM994 gallium isotope } \\
\text { standard?* }\end{array}$ \\
\hline \multirow[t]{2}{*}{$\begin{array}{c}\text { Pure Ga } \\
\text { standard } \\
\text { (undoped) }\end{array}$} & $100 \%$ (100 ppb) & $-0.003 \%$ & $\pm 0.07 \%$ & - \\
\hline & $2 \%$ & $-0.39 \%$ & $\pm 0.02 \%$ & No \\
\hline \multirow[t]{3}{*}{$\mathrm{Al}$} & $5 \%$ & $-0.19 \%$ & $\pm 0.02 \%$ & No \\
\hline & $10 \%$ & $+0.14 \%$ & $\pm 0.03 \%$ 。 & Yes \\
\hline & $2 \%$ & $-2.89 \%$ & $\pm 0.03 \%$ & No \\
\hline \multirow[t]{3}{*}{$\mathrm{Ca}$} & $5 \%$ & $-0.21 \%$ o & $\pm 0.02 \%$ & No \\
\hline & $10 \%$ & $+0.11 \%$ & $\pm 0.02 \%$ & Yes \\
\hline & $2 \%$ & $-0.23 \%$ & $\pm 0.03 \%$ & No \\
\hline \multirow[t]{3}{*}{$\mathrm{Fe}$} & $5 \%$ & $-0.16 \%$ & $\pm 0.02 \%$ & Yes \\
\hline & $10 \%$ & $+0.12 \%$ & $\pm 0.02 \%$ & Yes \\
\hline & $2 \%$ & $-0.51 \%$ o & $\pm 0.02 \%$ & No \\
\hline \multirow[t]{3}{*}{$\mathrm{Mg}$} & $5 \%$ & $-0.34 \%$ & $\pm 0.02 \%$ & No \\
\hline & $10 \%$ & $-0.04 \%$ o & $\pm 0.03 \%$ 。 & Yes \\
\hline & $2 \%$ & $-0.29 \%$ & $\pm 0.02 \%$ & No \\
\hline \multirow[t]{3}{*}{$\mathrm{Mn}$} & $5 \%$ & $-0.09 \%$ & $\pm 0.02 \%$ & Yes \\
\hline & $10 \%$ & $-0.11 \%$ & $\pm 0.03 \%$ & Yes \\
\hline & $2 \%$ & $-1.70 \%$ & $\pm 0.03 \%$ & No \\
\hline \multirow[t]{3}{*}{$\mathrm{Na}$} & $5 \%$ & $+0.18 \%$ o & $\pm 0.02 \%$ & No \\
\hline & $10 \%$ & $-0.19 \%$ & $\pm 0.02 \%$ & No \\
\hline & $2 \%$ & $-0.84 \%$ & $\pm 0.03 \%$ & No \\
\hline \multirow[t]{2}{*}{$\mathrm{Ti}$} & $5 \%$ & $-0.27 \%$ & $\pm 0.02 \%$ & No \\
\hline & $10 \%$ & $-0.04 \%$ & $\pm 0.02 \%$ & Yes \\
\hline
\end{tabular}

$*-0.073 \%<<<<+0.067 \%$ is considered acceptable, i.e. 2 sd of the SRM994 gallium isotope standard mean. 


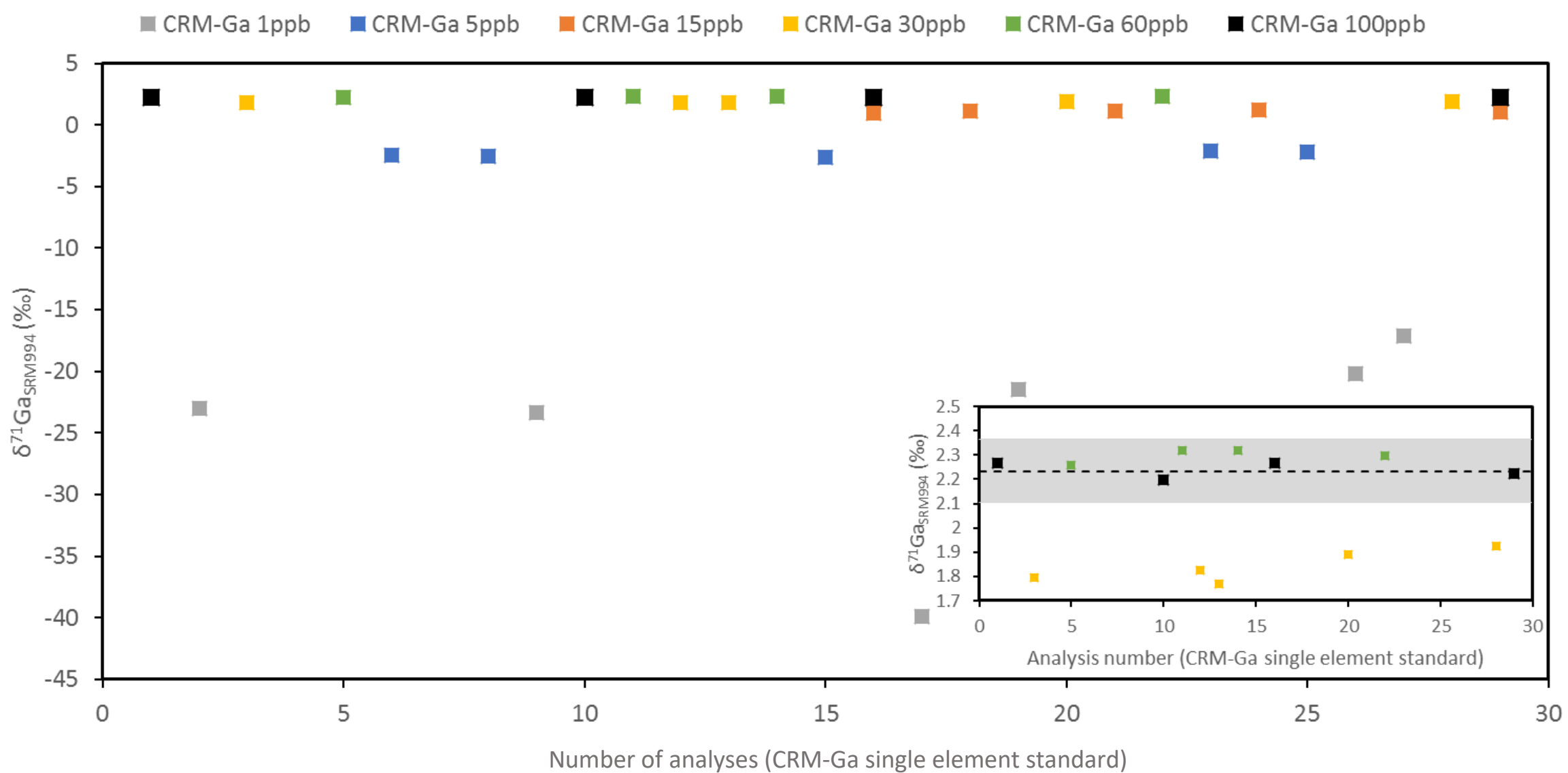

Figure 3.9 Analytical run showing the effect of sample concentration (CRM-Ga single element standard; 1 ppb, 5, ppb, 15 ppb, 30 ppb, 60 ppb and 100 ppb) on the calculated gallium isotope ratio using the simple sample-standard bracketing technique when bracketed with SRM994 gallium isotope standard (100 ppb). Between $60 \mathrm{ppb}$ and $100 \mathrm{ppb}$ the gallium ratio value falls within 2 sd of the average for CRM-Ga single element standards analysed in this study (average $=2.04 \%$ ). 


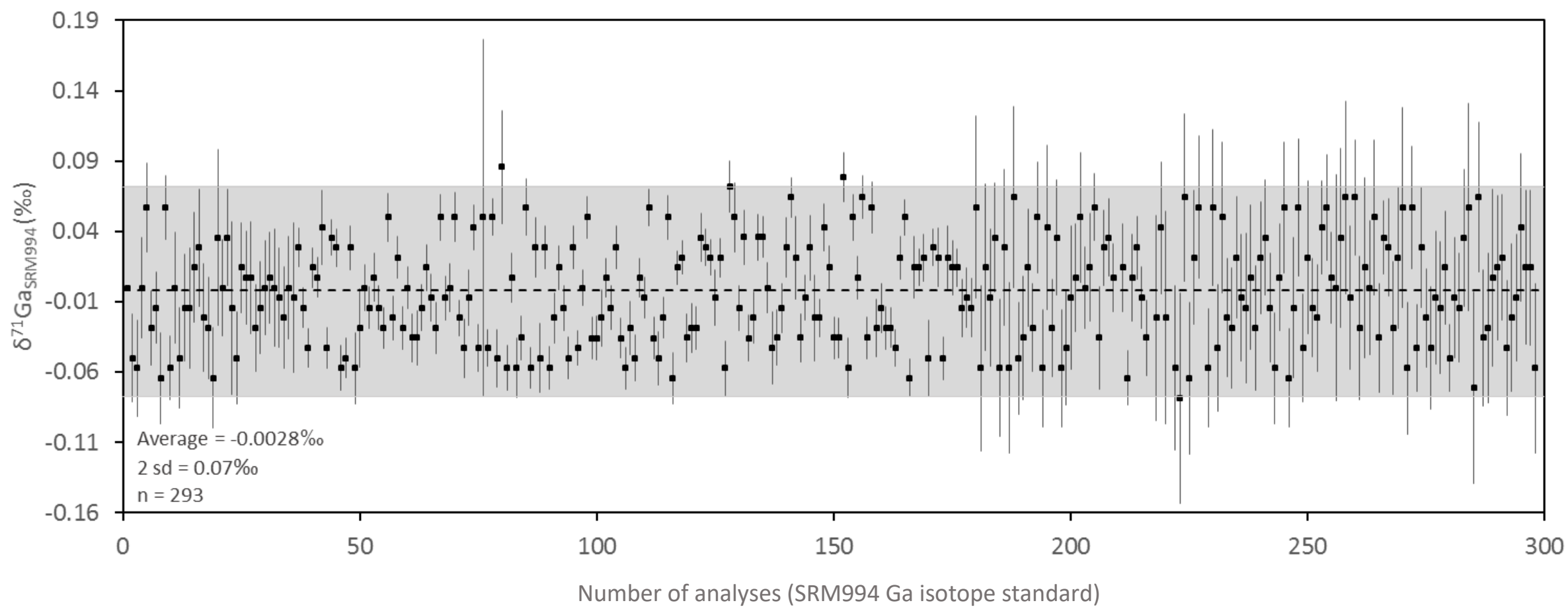

Figure 3.10 External reproducibility of the simple sample-standard bracketing method assessed by repeated measurements of SRM994 gallium isotope standard ( $\mathrm{n}=293$ ). Measurements were carried out between April 2015 and May 2016. 


\subsubsection{Zinc doping}

Zinc isotopes were also used for the external correction of the gallium isotope measurements.

The Aristar Zn ICPMS standard was used and assumed to have the natural abundance of zinc isotopes (Table 3.9). Enough of the zinc standard was added to the samples so that the intensity of ${ }^{66} \mathrm{Zn}$ roughly matched ${ }^{69} \mathrm{Ga}$. Zinc isotopes were found to be fractionated similarly to gallium isotopes on the $\mathrm{Nu}$ Plasma MC-ICPMS. A number of zinc isotope pairs were tested to determine the best correcting isotope pairs (Figure 3.11), these were ${ }^{68} \mathrm{Zn} /{ }^{64} \mathrm{Zn}$ and ${ }^{68} \mathrm{Zn} /{ }^{66} \mathrm{Zn}$.

Table 3.9 Isotopic mass and abundances of gallium and zinc isotopes

\begin{tabular}{ccc}
\hline Nuclei & Isotopic Mass (u) & Isotopic Abundance (\%) \\
\hline $69 \mathrm{Ga}$ & $68.9255736(13)$ & $60.108(9)$ \\
$71 \mathrm{Ga}$ & $70.9247013(11)$ & $39.892(9)$ \\
$64 \mathrm{Zn}$ & $63.9291422(7)$ & $49.17(75)$ \\
$66 \mathrm{Zn}$ & $65.9260334(10)$ & $27.73(98)$ \\
$67 \mathrm{Zn}$ & $66.9271273(10)$ & $4.04(16)$ \\
$68 \mathrm{Zn}$ & $67.9248442(10)$ & $18.45(63)$ \\
$70 \mathrm{Zn}$ & $69.9253193(21)$ & $0.61(10)$ \\
\hline
\end{tabular}

In order for this method to be successful, the fractionation coefficient, $\beta$, of the zinc isotopes and gallium isotopes in the doped sample change linearly with respect to each other. From this, a correction factor can be determined and applied to the measured gallium isotope ratios to account for the different mass bias in the machine between zinc and gallium. The natural logs of each gallium and zinc isotope pairs are plotted against each other to determine if the $\beta^{\mathrm{Zn}} / \beta^{\mathrm{Ga}}$ are constant, i.e. there is a linear relationship between the natural logarithm of each zinc isotope ratio pair vs the natural logarithm of the gallium isotope ratio (Figure 3.11, Figure 3.12).
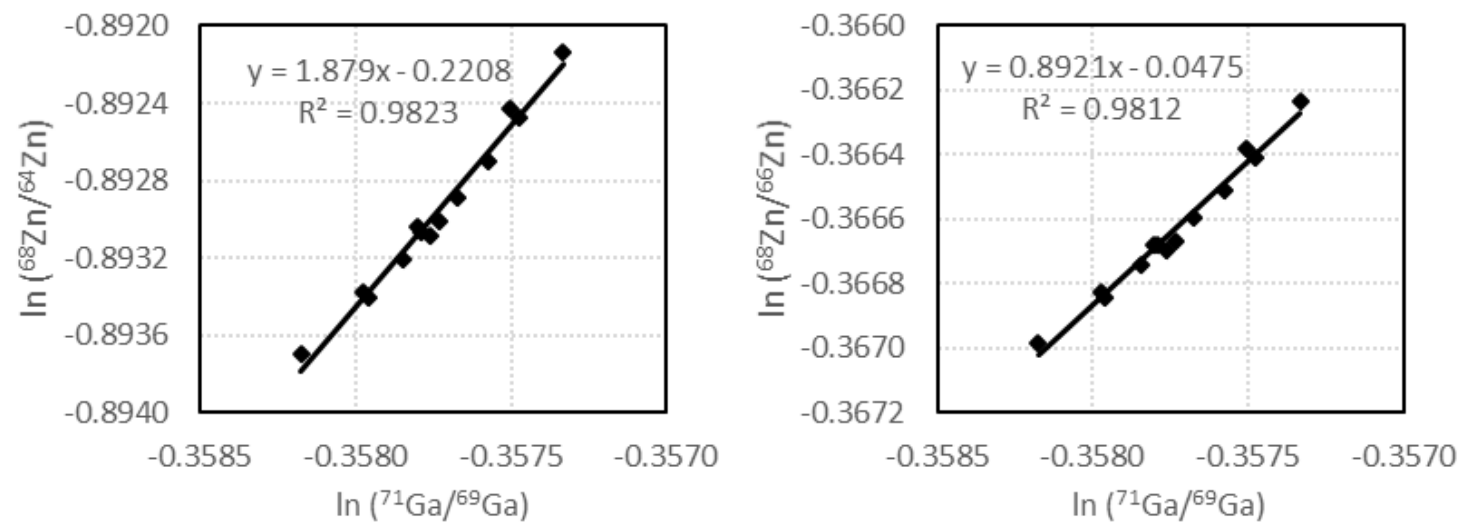

Figure $3.11 \mathrm{Ln}$-Ln plots of the two zinc ratios, ${ }^{68} \mathrm{Zn} /{ }^{64} \mathrm{Zn}$ and ${ }^{68} \mathrm{Zn} /{ }^{66} \mathrm{Zn}$, that have the best linear lest squares correlations when plotted against ${ }^{71} \mathrm{Ga} /{ }^{69} \mathrm{Ga}$. These two have been used to calculate the corrected gallium isotope ratio. The linear fit indicates that the $\beta \mathrm{Zn} / \beta \mathrm{Ga}$ is constant during an analytical session. 

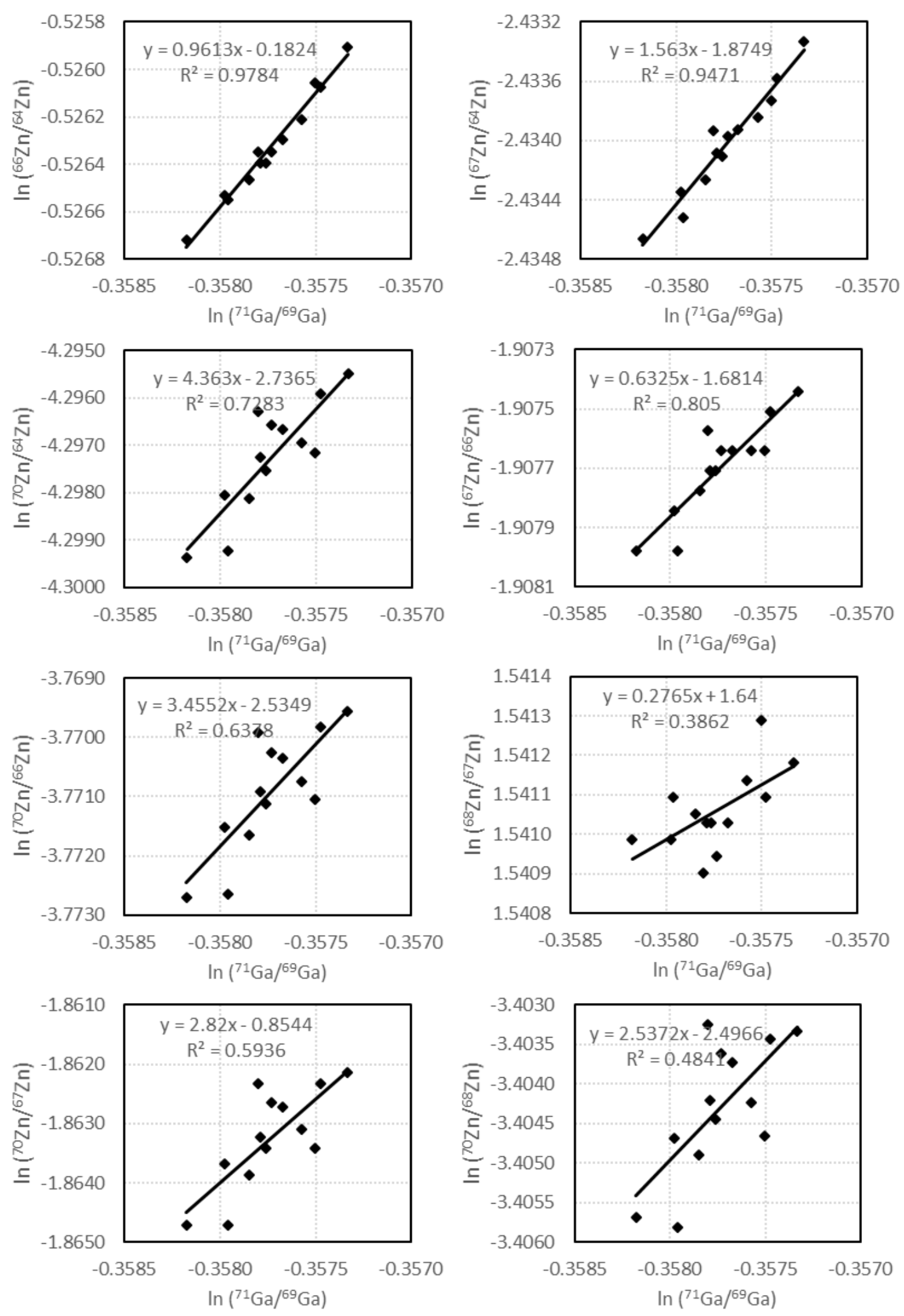

Figure 3.12 Ln-Ln plots of remaining zinc isotope pairs. Pairs containing ${ }^{70} \mathrm{Zn}$ and ${ }^{67} \mathrm{Zn}$ have consistently poor linear correlations to the natural logarithm of the gallium ratio. 
Two gallium standards were doped with zinc and then measured against each other as for the simple sample-standard bracketing method (Figure 3.13). compared to the sample run at the same concentration to the bracketing standards (i.e. $100 \mathrm{ppb}$ ). The results of this (Figure 3.14) indicated that the $\mathrm{Zn}$-doping technique was not suitable to measure samples at a concentration appreciably different from the bracketing gallium standard. As for the simple sample-standard bracketing technique, where a large drift between standards was identified, repeat analysis of the unknown sample was made until the bracketing standards stabilised and were separated by less drift.

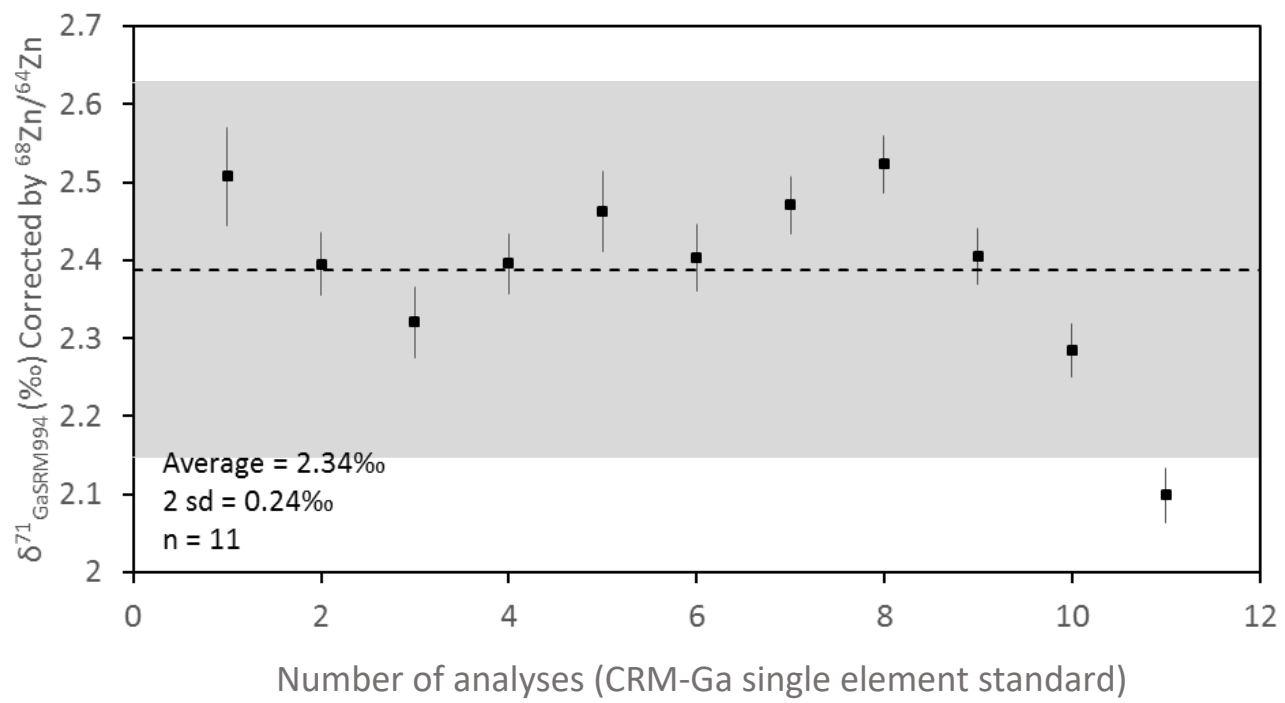

Figure 3.13 External reproducibility of the zinc doped sample-standard bracketing method assessed by repeated measurements of CRM gallium single element standard $(n=11)$ corrected using the ${ }^{68} \mathrm{Zn} /{ }^{64} \mathrm{Zn}$ isotope pair. Measurements were carried out between March and May 2016.

The long-term reproducibility of the zinc doped sample-standard bracketing technique was $\pm 0.11 \%$ o (two standard deviations) for the ${ }^{68} \mathrm{Zn} /{ }^{64} \mathrm{Zn}$ corrected dataset and $\pm 0.07 \%$ or the ${ }^{68} \mathrm{Zn} /{ }^{66} \mathrm{Zn}$ corrected dataset, as determined from repeat analyses of the SRM994 gallium isotope standard (Figure 3.15). The ${ }^{68} \mathrm{Zn} /{ }^{64} \mathrm{Zn}$ corrected dataset has significantly less scatter between individual analyses in comparison to the ${ }^{68} \mathrm{Zn} /{ }^{66} \mathrm{Zn}$ corrected dataset (i.e. the difference between the maximum and minimum $\delta^{71} \mathrm{Ga}$ values is $0.36 \%$ and $0.691 \%$ respectively). Based on these results in combination with the better correlation of the measured ratios in logarithmic space, the isotope pair of choice to correct the gallium ratio would be ${ }^{68} \mathrm{Zn} /{ }^{64} \mathrm{Zn}$. 




Figure 3.14 Analytical run showing the effect of sample concentration (CRM-Ga single element standard; 1 ppb, 5, ppb, 15 ppb, 30 ppb, 60 ppb and 100 ppb) on the calculated gallium isotope ratio using the $\mathrm{Zn}$-doped sample-standard bracketing technique when bracketed with SRM994 gallium isotope standard (100 ppb) doped with CRM-Zn Single element standard corrected using the ${ }^{68} \mathrm{Zn} /{ }^{64} \mathrm{Zn}$ isotope pair. Samples measured at $\leq 60 \mathrm{ppb}$ are very different to those measured at $100 \mathrm{ppb}$. 

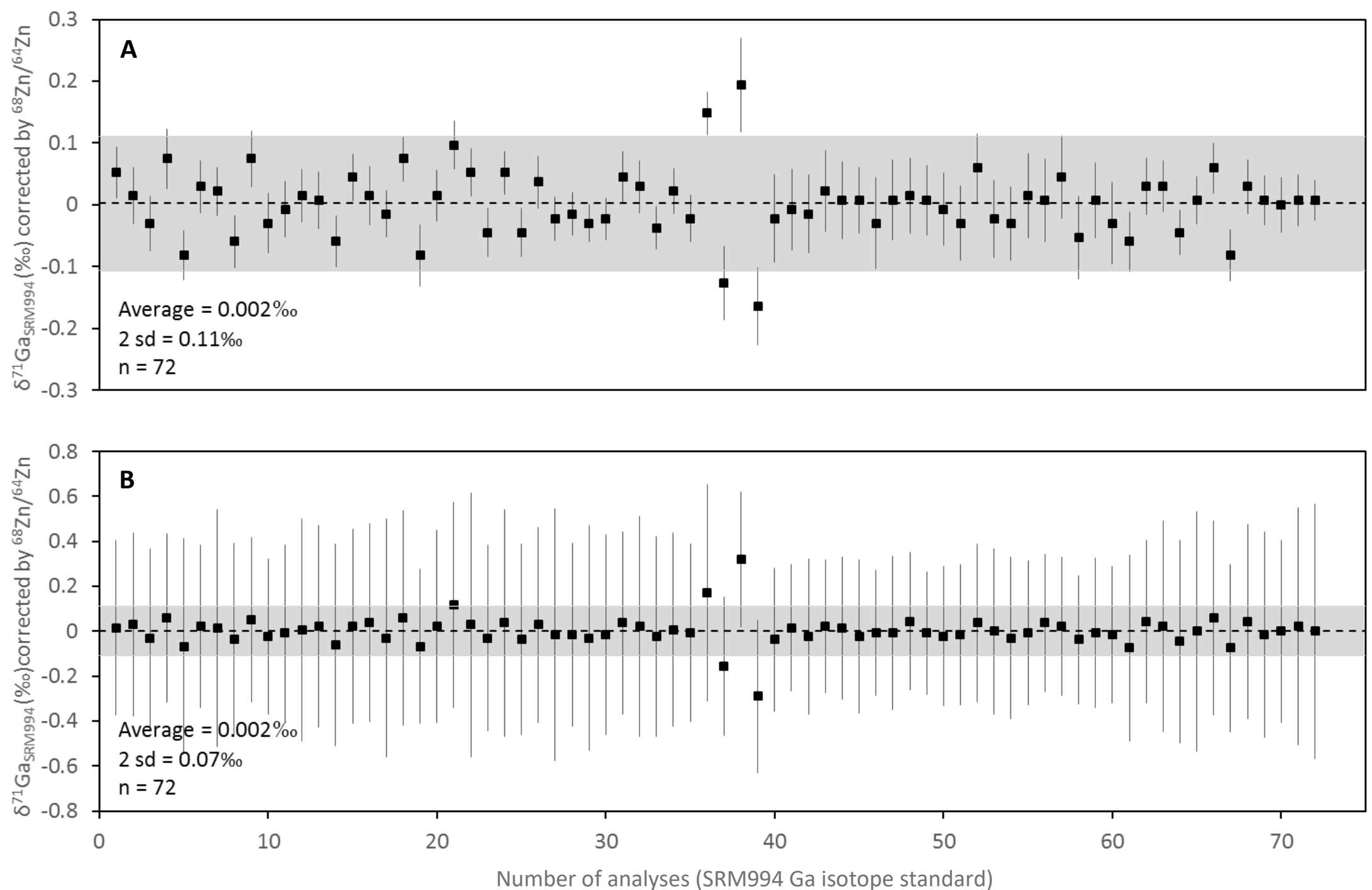

Figure 3.15 A: External reproducibility of the zinc doped sample-standard bracketing technique assessed by repeated measurements of SRM994 gallium isotope standard ( $\mathrm{n}=$ 72) corrected by the ${ }^{68} \mathrm{Zn} /{ }^{64} \mathrm{Zn}$ isotope pair. B: Corrected by the ${ }^{68} \mathrm{Zn} /{ }^{66} \mathrm{Zn}$ isotope pair. Measurements were carried out between September 2015 and May 2016. 
As for the simple sample-standard bracketing technique, the threshold for which other elements can be present in a sample to be analysed by the zinc doping technique was tested using the same suite of elements. It was found that the zinc doping method is even more sensitive than the simple sample-standard bracketing method to the presence of elements in the matrix solution of the gallium sample to be analysed. All elements, except $2 \% \mathrm{Mg}$, perturbed the measured gallium isotope ratio with as little as $2 \mathrm{ppb}$ presence of each element in solution (Table 3.10).

Table 3.10 Effect on the zinc corrected $\delta^{71} \mathrm{Ga}$ value when the standard (run as a sample) is doped with various concentrations of elements known to cause non-spectral mass bias effects in other systems

\begin{tabular}{|c|c|c|c|c|}
\hline Element & $\begin{array}{l}\text { Concentration as a } \\
\text { percentage of SRM994 } \\
\text { gallium isotope standard }\end{array}$ & $\delta^{71} \mathrm{Ga}$ & $2 \mathrm{se}$ & $\begin{array}{l}\text { Within error of the mean, } \\
\text { SRM994 gallium isotope } \\
\text { standard?* }\end{array}$ \\
\hline \multirow[t]{2}{*}{$\begin{array}{c}\text { Pure Ga } \\
\text { standard } \\
\text { (undoped) }\end{array}$} & $100 \%$ (100 ppb) & $+0.002 \%$ & $\pm 0.11 \%$ & - \\
\hline & $2 \%$ & $+0.23 \%$ & $\pm 0.03 \%$ & No \\
\hline \multirow[t]{3}{*}{$\mathrm{Al}$} & $5 \%$ & $+0.58 \%$ & $\pm 0.04 \%$ o & No \\
\hline & $10 \%$ & $+1.50 \%$ & $\pm 0.05 \%$ & No \\
\hline & $2 \%$ & $-2.50 \%$ & $\pm 0.04 \%$ & No \\
\hline \multirow[t]{3}{*}{$\mathrm{Ca}$} & $5 \%$ & $+0.55 \%$ & $\pm 0.04 \%$ & No \\
\hline & $10 \%$ & $+1.50 \%$ o & $\pm 0.04 \%$ 。 & No \\
\hline & $2 \%$ & $+0.37 \%$ & $\pm 0.05 \%$ & No \\
\hline \multirow[t]{3}{*}{$\mathrm{Fe}$} & $5 \%$ & $+0.49 \%$ & $\pm 0.04 \%$ & No \\
\hline & $10 \%$ & $1.26 \%$ & $\pm 0.03 \%$ & No \\
\hline & $2 \%$ & $-0.04 \%$ & $\pm 0.03 \%$ & Yes \\
\hline \multirow[t]{3}{*}{$\mathrm{Mg}$} & $5 \%$ & $+0.43 \%$ & $\pm 0.05 \%$ & No \\
\hline & $10 \%$ & $+1.43 \%$ o & $\pm 0.03 \%$ & No \\
\hline & $2 \%$ & $+0.29 \%$ & $\pm 0.03 \%$ & No \\
\hline \multirow[t]{3}{*}{$\mathrm{Mn}$} & $5 \%$ & $+0.98 \%$ & $\pm 0.04 \%$ & No \\
\hline & $10 \%$ & $+1.33 \%$ & $\pm 0.03 \%$ 。 & No \\
\hline & $2 \%$ & $-1.61 \%$ & $\pm 0.06 \%$ & No \\
\hline \multirow[t]{3}{*}{$\mathrm{Na}$} & $5 \%$ & $+0.42 \%$ & $\pm 0.04 \%$ & No \\
\hline & $10 \%$ & $+1.35 \%$ & $\pm 0.03 \%$ & No \\
\hline & $2 \%$ & $-0.17 \%$ & $\pm 0.03 \%$ & No \\
\hline \multirow[t]{2}{*}{$\mathrm{Ti}$} & $5 \%$ & $+1.30 \%$ & $\pm 0.03 \%$ & No \\
\hline & $10 \%$ & $+1.34 \%$ o & $\pm 0.05 \%$ & No \\
\hline
\end{tabular}

* Within error of the range $-0.108 \%<x<0.112 \%$ is considered acceptable, i.e. 2 sd of the ${ }^{68} \mathrm{Zn} /{ }^{64} \mathrm{Zn}$ corrected SRM994 gallium isotope standard mean.

\subsection{Conclusions}

The column procedure for processing natural samples containing $100 \mathrm{ppb}$ or greater of gallium utilises AG50W-X8, 100-200 dry mesh size resin. A first pass using $8 \mathrm{M} \mathrm{HCl}$ with $0.3 \% \mathrm{TiCl}_{3}$ on a column of $18 \mathrm{~cm}$ in length is used to remove $\mathrm{Fe}, \mathrm{Zn}$, and the majority of other elements present in the sample. Due to the concentration of titanium in the gallium eluate a second pass 
using the same resin on a shorter column of $5 \mathrm{~cm}$ is required. The titanium and any remaining elements are removed to less than $5 \%$ of the total gallium concentration ready to be analysed by gallium isotopes. Further efforts should be spent removing what persists in the final gallium eluate in order to gain the most accurate gallium isotope results. It is recommended that the second column be trialled using ultra-pure $\mathrm{HCl}$, or a third column be introduced that uses ultrapure $\mathrm{HCl}$.

It was found that the simple sample-standard bracketing technique is the better method for measuring gallium isotopes on the $\mathrm{Nu}$ Plasma MC-ICPMS. The simple sample-standard bracketing method is more flexible with regards to concentration of samples, allowing measurements to be performed between 60 and $100 \mathrm{ppb}$, this is important for analysing samples with low concentrations of gallium such as hydrothermal brines, hot spring waters and gas condensates. The simple sample-standard bracketing has been selected as the chosen method that gives improved reproducibility (i.e. $\pm 0.07 \%$ vs $\pm 0.11 \%$ ), as well as the better precision in individual analyses and the greater flexibility concerning sample concentration. 


\section{CHAPTER 4. RESULTS AND DISCUSSION}

\subsection{Ion exchange column separation}

As shown in Section 3.3, a successful ion exchange method to quantitatively separate gallium from a natural sample matrix was developed (Table 3.5). Three analyses each of JR-2 (rhyolite powder, Geological Survey of Japan) and BHVO-2 (basalt powder, United States Geological Survey) have shown that samples processed using this procedure gave reproducible results (Figure 3.7). Further work should be carried out to completely remove any non-spectral interfering elements, as Table 3.8 shows that these may in some cases have a significant effect on the gallium isotope analysis.

\subsection{Trace element analysis}

Table 4.1 and Table 4.2 outline the trace element concentrations for gas condensate samples from the geothermal wells and precipitate samples from both Rotokawa and Waoitapu. These data were collected using an Element 2 sector field ICPMS instrument. Of particular interest is the detection of gallium in the gas condensate samples from Rotokawa geothermal field, which indicates a partitioning of gallium into the steam phase during flashing of a geothermal fluid. Such a processes may potentially induce a fractionation in isotopes with the steam likely to be depleted in the heavy isotope. Many other elements are also partitioned into the steam phase, including iron with concentrations up to $17 \mathrm{ppb}$ (RK32-CS), and mercury with concentrations up to $280 \mathrm{ppb}$ (RK32-CS). One litre of several steam condensates from different wells were dried and gallium was detectable (Table 4.1). However, these results show that there is not enough gallium to analyse these samples for their gallium isotopic composition.

There is also an appreciable enrichment of gallium in the precipitates of Waiotapu of up to 290 ppm in the antimony-arsenic sulfide precipitates of Champagne Pool and up to $97 \mathrm{ppm}$ in sulfide lenses at Lake Rotokawa. There is also a significant concentration in filtered hot spring water samples of both Waiotapu and Rotokawa of up to $0.14 \mathrm{ppb}$ of gallium. Unfortunately, not enough sample was collected ( $60 \mathrm{ml}$ were collected) to concentrate the gallium and analyse these samples for gallium isotopes. A potential fractionation may be observed between water and precipitate based on exchange of ligands, from hydroxide to sulfide, sulfate or silicate, during the precipitation process.

A number of gallium containing mineral samples were also analysed from the hydrothermal ore deposits at Tsumeb Mine (Namibia) and Kipushi Mine (Democratic Republic of the Congo). Up to $260 \mathrm{ppm}$ (Table 4.1) gallium was detected in the sulfide samples (i.e. renierite) from Tsumeb Mine. Several of the samples contain gallium as a major component (i.e. TMS-3, gallobeudantite; 
TMS-7, söhngeite). Sulfide mineral samples from the Tsumeb mine contain a significantly more gallium than the sulfide sample from Kipushi Mine. Between associated mineral samples, such as the TMS-1 sulfate and TMS-2 sulfide, we might expect to see an isotope fractionation based on the preferential partitioning of one isotope to either the sulfate or sulfide mineral during the mineralisation process during the supergene oxidation of the sulfide mineral phase. In the sulfate mineral (schaurteite) the gallium is presumably bound to a sulfate oxygen electron donor, whereas gallium in the sulfide mineral (renierite) will be bound to a sulfide ligand 
Table 4.1 Trace element analysis of collected samples: First row transition metals and gallium

\begin{tabular}{lcccccccccccc}
\hline \multicolumn{10}{c}{ Gas Condensates ( $\mu \mathrm{g} / \mathrm{kg}$ of fluid) } \\
\hline & Ga & Sc & Ti & V & Cr & Mn & Fe & Co & Ni & Cu & Zn \\
\hline RK32 CS & 0.008 & 0.005 & 1.09 & 0.02 & 0.49 & 0.32 & 16.7 & 0.009 & 0.507 & 0.023 & 1.77 \\
RK29 CS & 0.002 & 0.001 & 1.16 & 0.01 & 0.72 & 0.22 & 5.99 & 0.005 & 4.815 & 0.052 & 8.51 \\
RK26 CS & 0.002 & B.D. & 0.09 & 0.005 & 0.11 & 0.02 & 4.78 & 0.003 & 0.284 & 0.022 & 0.55 \\
RK33 CS & 0.003 & 0.001 & 0.39 & 0.012 & 0.82 & 0.11 & 6.41 & 0.014 & 1.356 & 0.007 & 1.44 \\
\hline
\end{tabular}

Liquid Phase Brines and Hot Springs ( $\mu \mathrm{g} / \mathrm{kg}$ of fluid)

\begin{tabular}{|c|c|c|c|c|c|c|c|c|c|c|c|}
\hline & Ga & Sc & $\mathrm{Ti}$ & v & $\mathrm{Cr}$ & $\mathrm{Mn}$ & $\mathrm{Fe}$ & Co & $\mathrm{Ni}$ & $\mathrm{Cu}$ & $\mathrm{Zn}$ \\
\hline RK29 BR & 0.03 & 0.00 & 0.00 & 0.01 & 0.02 & 0.14 & 16.0 & 0.11 & 0.00 & 2.25 & 0.26 \\
\hline RK33 BR & 0.02 & 0.01 & 0.00 & 0.27 & 0.05 & 6.75 & 79.6 & 0.56 & 0.03 & 9.42 & 1.41 \\
\hline RKL04 H.S. & 0.138 & 0.407 & 2.833 & 0.540 & 0.256 & 80.5 & 322 & 0.006 & B.D. & 0.074 & 6.51 \\
\hline BR27 S.R. & 12 & 0.033 & 158 & 2.17 & B.D. & 42.5 & 45.9 & 0.066 & B.D. & B.D. & B.D. \\
\hline WCP01 H.S. & 0.145 & 0.003 & 0.271 & 0.014 & 0.014 & 3.71 & 3.220 & 0.002 & 0.163 & 0.075 & 0.22 \\
\hline \multicolumn{12}{|c|}{ Mineral Samples (mg/kg) } \\
\hline & Ga & Sc & $\mathrm{Ti}$ & $\mathbf{v}$ & $\mathrm{Cr}$ & $\mathrm{Mn}$ & $\mathrm{Fe}$ & Co & $\mathbf{N i}$ & $\mathrm{Cu}$ & $\mathrm{Zn}$ \\
\hline TMS-1 & 78.5 & 17.8 & 0.2 & 59.1 & 1.8 & B.D. & B.D. & 214.4 & B.D. & B.D. & 2818 \\
\hline TMS-2 & 369.6 & 3.2 & 0.2 & 27.3 & B.D. & B.D. & B.D. & 95.2 & B.D. & 25311 & 2017 \\
\hline TMS-3 & 52738 & B.D. & 7.2 & 1764.0 & B.D. & B.D. & B.D. & B.D. & 16.2 & B.D. & 7735 \\
\hline TMS-4 & 267.5 & 5.5 & 0.2 & 119.6 & 11.8 & B.D. & B.D. & 6.8 & 0.4 & 48837 & 973.6 \\
\hline TMS-5 & 41.2 & 3.5 & 0.0 & B.D. & B.D. & B.D. & 76664 & B.D. & B.D. & 445814 & B.D. \\
\hline TMS-6 & 3061 & 4.4 & 0.1 & 37.0 & 2.0 & B.D. & 10718 & 163.5 & 9.4 & 76419 & 35850 \\
\hline TMS-7 & 258820 & 27.7 & 0.0 & 63.0 & B.D. & B.D. & 100376 & 1417.7 & 1.3 & B.D. & 2834 \\
\hline TMS-8 & 259 & $2.1 \times 10^{-4}$ & 0.036 & $8.4 \times 10^{-4}$ & B.D. & B.D. & 134 & 0.026 & 0.004 & 1420 & 518 \\
\hline
\end{tabular}




\begin{tabular}{|c|c|c|c|c|c|c|c|c|c|c|c|}
\hline \multicolumn{12}{|c|}{ Precipitates and Rock Standards (mg/kg) } \\
\hline & Ga & Sc & $\mathrm{Ti}$ & $\mathbf{v}$ & $\mathrm{Cr}$ & $\mathrm{Mn}$ & $\mathrm{Fe}$ & Co & $\mathrm{Ni}$ & $\mathrm{Cu}$ & $\mathrm{Zn}$ \\
\hline WCP06-S & 290 & 1.1 & 204 & 7.2 & 9.6 & 115 & 296 & 0.7 & 12.3 & 441 & 111 \\
\hline WCP09-S & 81.8 & 1.6 & 795 & 3.7 & 3.2 & 46.3 & 1055 & 0.3 & 7.4 & 74.9 & 146 \\
\hline WCP09-Si & 95.8 & 1.3 & 329 & 2.8 & 43.7 & 33.6 & 2260 & B.D. & 3.2 & 151 & 115 \\
\hline WCP10 & 16.9 & 1.1 & 149 & 1.3 & 9.6 & 87.8 & 1726 & 0.2 & 38.6 & 36.2 & 12.5 \\
\hline WCP12-Si & 15.1 & 0.2 & 403 & 3.0 & 2.8 & 148 & 3151 & B.D. & 19.4 & 11.7 & 14.9 \\
\hline WCP13-Si & 20.6 & 1.5 & 91.1 & 1.8 & 4.3 & 12.0 & 2331 & B.D. & 10.2 & 1.5 & 26.5 \\
\hline WCP14 & 14.0 & 8.1 & 22.5 & 6.5 & 5.0 & 458 & 39500 & 0.2 & B.D. & 9.9 & 43.8 \\
\hline WCP16 & 7.10 & 3.0 & 1353 & 6.9 & 3.0 & 56.0 & 5646 & 1.8 & 6.3 & 21.1 & 43.5 \\
\hline RKL07 & 39.0 & 12.8 & 471 & 4.5 & 0.6 & 14.7 & 2308 & B.D. & 59.5 & 3.2 & 51.8 \\
\hline RKL09 & 20.7 & 3.6 & 1278 & 8.5 & 6.1 & 142 & 8110 & 1.2 & 40.1 & 400 & 1440 \\
\hline RKL10 & 3.30 & 0.2 & 67.5 & 0.4 & 0.2 & 0.8 & 20.5 & B.D. & 0.4 & 0.1 & 1.0 \\
\hline RKL12-SO & 49.2 & 4.2 & 946 & 4.2 & B.D. & 28.3 & 360 & B.D. & 8.4 & B.D. & 290 \\
\hline RKL13 & 65.0 & 5.7 & 1837 & 15.5 & 1.8 & 98.1 & 5500 & 0.4 & 24.8 & 31.8 & 120 \\
\hline RKL13-S & 97.4 & 8.3 & 2322 & 18.1 & 32.5 & 49.1 & 3170 & 0.8 & 68.7 & 79.3 & 353 \\
\hline RKL13-mS & 61.4 & 11.5 & 3299 & 24.9 & 7.1 & 51.3 & 9443 & 1.1 & 27.9 & 11.9 & 31.6 \\
\hline RKL14 & 58.1 & 5.5 & 1188 & 10.0 & 2.6 & 84.8 & 9314 & 1.0 & 15.7 & 131 & 47.1 \\
\hline BR27 \#6 O.P. & 5.73 & 2.23 & 0.006 & 3.98 & 0.36 & 0.58 & 38032 & 124 & 1.65 & 30197 & 4702 \\
\hline BHVO-2 & 18.1 & 29.0 & 17090 & 298.3 & 270.4 & 1162 & 69718 & 37.1 & 168 & 91.8 & 68.5 \\
\hline$J R-2$ & 14.7 & 4.8 & 350.9 & 0.7 & 1.2 & 896 & 4258 & 0.9 & 10.4 & 2.3 & 22.0 \\
\hline
\end{tabular}

B.D. Below Detection; N.M. Not Measured; WCP Waiotapu Sample; RKL or RK Rotokawa Sample; BR Broadlands Sample; TMS Mineral Sample; S Sulfide; Si Silica Sinter; SO; Orange Sulfide; mS Muddy Sulfide; O.P. Oriface Plate residue; S.R. Salt Residue from Freeze-dried Brine; H.S. Hot Spring 
Table 4.2 Trace element analysis of collected samples: metals commonly associated with hydrothermal systems and gallium

\begin{tabular}{|c|c|c|c|c|c|c|c|c|c|c|c|}
\hline \multicolumn{12}{|c|}{ Gas Condensates ( $\mu \mathrm{g} / \mathrm{kg}$ of fluid) } \\
\hline & Ga & As & Sb & $\mathrm{Tl}$ & w & Sn & Mo & $\mathrm{Ag}$ & $\mathrm{Hg}$ & Mg & Al \\
\hline RK32 CS & 0.008 & 0.587 & 0.031 & 0.003 & 0.052 & 0.047 & 0.041 & 0.003 & 277 & 4.45 & 36.9 \\
\hline RK29 CS & 0.002 & 0.879 & 0.006 & 0.004 & 0.032 & 0.009 & 0.009 & 0.003 & 50.0 & 3.41 & 6.55 \\
\hline RK26 CS & 0.002 & 2.75 & 0.015 & 0.005 & 0.016 & 0.003 & 0.049 & 0.001 & 13.7 & 2.56 & 2.77 \\
\hline RK33 CS & 0.003 & 1.084 & 0.002 & 0.002 & 0.056 & 0.005 & 0.017 & B.D. & 36.4 & 1.06 & 4.11 \\
\hline \multicolumn{12}{|c|}{ Liquid Phase Brines and Hot Springs ( $\mu \mathrm{g} / \mathrm{kg}$ of fluid) } \\
\hline & Ga & As & Sb & TI & w & Sn & Mo & $\mathrm{Ag}$ & $\mathrm{Hg}$ & Mg & Al \\
\hline RK29 BR & 0.03 & 30.1 & 3.07 & 0.01 & 1.02 & 0.00 & 0.34 & 0.10 & 0.58 & 0.07 & 16.0 \\
\hline RK33 BR & 0.02 & 29.01 & 1.70 & 0.02 & 2.29 & 0.01 & 0.43 & 0.14 & 1.14 & 1.14 & 20.5 \\
\hline RKL04 H.S. & 0.138 & 25.3 & 1.22 & 0.287 & 1.351 & 0.024 & 0.031 & 0.005 & 0.473 & 601 & 1752 \\
\hline BR27 S.R. & 12 & B.D. & 3775 & 115 & 13249 & 3133 & 44.5 & B.D. & 5198 & 48.8 & 5915 \\
\hline WCP01 H.S. & 0.145 & 4.73 & 1.001 & 0.014 & 9.242 & 0.006 & 0.074 & 0.001 & 4.902 & 6.054 & 18.5 \\
\hline \multicolumn{12}{|c|}{ Mineral Samples (mg/kg) } \\
\hline & Ga & As & Sb & $\mathrm{Tl}$ & w & Sn & Mo & $\mathrm{Ag}$ & $\mathrm{Hg}$ & Mg & Al \\
\hline TMS-1 & 78.5 & B.D. & B.D. & B.D. & B.D. & 17.8 & B.D. & B.D. & B.D. & 156 & 823.8 \\
\hline TMS-2 & 370 & B.D. & B.D. & B.D. & B.D. & 3.2 & B.D. & B.D. & B.D. & B.D. & B.D. \\
\hline TMS-3 & 52738 & B.D. & B.D. & B.D. & B.D. & B.D. & B.D. & B.D. & B.D. & B.D. & 49616 \\
\hline TMS-4 & 268 & B.D. & B.D. & B.D. & B.D. & 5.5 & 197.7 & 64.0 & B.D. & 277 & 2916 \\
\hline TMS-5 & 41.2 & B.D. & B.D. & B.D. & B.D. & 3.5 & B.D. & 740.4 & B.D. & B.D. & B.D. \\
\hline TMS-6 & 3061 & B.D. & B.D. & 0.2 & 592.8 & 4.4 & B.D. & 196.6 & 498 & 290.5 & 633.3 \\
\hline TMS-7 & 258820 & B.D. & 11.0 & B.D. & 23408 & 27.7 & B.D. & B.D. & 18404 & 1709 & 573.3 \\
\hline TMS-8 & 259 & 4.27 & 0.015 & 0.006 & 64.2 & 0.031 & B.D. & 0.80 & 51.7 & 0.93 & 0.29 \\
\hline
\end{tabular}




\begin{tabular}{|c|c|c|c|c|c|c|c|c|c|c|c|}
\hline \multicolumn{12}{|c|}{ Precipitates and Rock Standards (mg/kg) } \\
\hline & Ga & As & Sb & $\mathrm{TI}$ & w & Sn & Mo & Ag & $\mathrm{Hg}$ & Mg & Al \\
\hline WCP06-S & 290 & 1226 & 25000 & 810 & 11.0 & 1.6 & 6.0 & 45.5 & 51.0 & 291 & 59770 \\
\hline WCP09-S & 81.8 & 199 & 4380 & 113 & 422 & 1.1 & 8.7 & 23.8 & 61.9 & 227 & 8255 \\
\hline WCP09-Si & 95.8 & 135 & 611 & B.D. & 176 & B.D. & B.D. & 23.5 & B.D. & 211 & 6321 \\
\hline WCP10 & 16.9 & 49.4 & 584 & 2.0 & 25.3 & 0.3 & 2.2 & 6.6 & 1.4 & 222 & 7100 \\
\hline WCP12-Si & 15.1 & 191 & 479 & 10.4 & 46.3 & 6.5 & 6.7 & 19.0 & B.D. & 425 & 8240 \\
\hline WCP13-Si & 20.6 & 147 & 949 & 4.9 & 371 & 0.3 & 1.8 & 4.9 & 3.7 & 380 & 6560 \\
\hline WCP14 & 14.0 & 58.7 & 6.00 & 0.2 & 42.0 & 0.3 & 15.0 & 0.1 & 6.1 & 1880 & 44300 \\
\hline WCP16 & 7.10 & 3679 & 462 & 13.4 & 48.3 & 0.3 & 11.3 & 1.8 & B.D. & 444 & 15674 \\
\hline RKL07 & 39.0 & 23270 & 681 & 43.5 & 223 & 5.1 & 30.1 & 0.6 & B.D. & 456 & 13660 \\
\hline RKL09 & 20.7 & 6876 & 2668 & 121.5 & 238 & 4.9 & 23.1 & 2.4 & B.D. & 1080 & 19040 \\
\hline RKL10 & 3.30 & 4.70 & 54.9 & 0.03 & 7.0 & 0.1 & 0.1 & 0.2 & B.D. & 16.9 & 1115 \\
\hline RKL12-SO & 49.2 & 6757 & 8440 & 550 & 111 & 4.2 & 14.7 & 2.1 & 39.8 & 396 & 3763 \\
\hline RKL13 & 65.0 & 3155 & 1656 & 116.3 & 230 & 4.9 & 14.6 & 2.2 & 30.9 & 326 & 21945 \\
\hline RKL13-S & 97.4 & 1690 & 4120 & 41.5 & 233 & 7.6 & 5.3 & 5.3 & 57.4 & 442 & 39230 \\
\hline RKL13-mS & 61.4 & 4542 & 6673 & 75.5 & 587 & 6.3 & 11.9 & 5.6 & 19.7 & 557 & 58610 \\
\hline RKL14 & 58.1 & 2067 & 994 & 47.9 & 191 & 1.4 & 6.9 & 1.9 & 6.7 & 354 & 26200 \\
\hline BR27 \#6 O.P. & 5.73 & B.D. & 2.05 & 0.53 & 52.6 & 2.23 & B.D. & 628 & 43 & 50 & 174 \\
\hline BHVO-2 & 18.1 & 17.7 & B.D. & B.D. & 4.8 & 1.8 & 3.9 & 1.0 & 2.3 & 36737 & 63844 \\
\hline$J R-2$ & 14.7 & 15.3 & 1.2 & 1.3 & 4.8 & 3.2 & 2.8 & 0.5 & 2.7 & 192 & 58023 \\
\hline
\end{tabular}

Error is $<10 \%$ RSD for all elements, $<5 \%$ for $G a$

B.D. Below Detection; N.M. Not Measured; WCP Waiotapu Sample; RKL or RK Rotokawa Sample; BR Broadlands Sample; TMS Mineral Sample; S

Sulfide; Si Silica Sinter; SO; Orange Sulfide; mS Muddy Sulfide; O.P. Oriface Plate residue; S.R. Salt Residue from Freeze-dried Brine; H.S. Hot Spring 


\subsection{Gallium isotopic analysis}

The gallium isotope analysis for 8 samples from Waiotapu, Rotokawa and Ohaaki-Broadlands geothermal fields, 5 mineral samples from Kipushi and Tsumeb mines, and two rock standards are presented in Table 4.3 and Figure 4.1 with reference to the type of sample analysed (i.e. sulfide, silicate, hydroxide, hydrothermal liquid phase and minerals). Due to the limited amount of sample and time constraints, each has been analysed once, many with only enough solution to make one measurement. The data from the New Zealand geothermal systems indicate a range in values from $-5.49 \%$ to $+2.65 \% 0 \delta^{71} \mathrm{Ga}$ in silica sinter, sulfide and brine samples. Mineral samples from Tsumeb and Kipushi range from $-11.92 \%$ to $+2.58 \%{ }^{71} \mathrm{Ga}$. To ensure these results are robust, each sample should ideally be analysed multiple times. It should also be noted that some of these fractionations could be exaggerated by potential presence of trace elements that were not completely removed by the column chemistry (i.e. usually on the order of a few ppb; Figure 3.6). Whilst the fractionations measured are generally several times greater than the effect of most of these elements, the presence of $\mathrm{Ca}$ or $\mathrm{Na}$ has a greater effect (up to $-2.89 \%$; Table 3.8), i.e. positive values may actually be more positive, and negative values may be exaggerated.

Table $4.3{ }^{71} \mathrm{Ga}$ value for analysed hydrothermal samples, epithermal ore minerals and rock standards

\begin{tabular}{|c|c|c|c|c|}
\hline Location & Sample ID & Sample Type & $\delta^{71} \mathrm{Ga}$ & 2 se \\
\hline \multirow{2}{*}{ Ohaaki-Broadlands geothermal field } & BR27 Salt Residue & Freeze-dried liquid phase well discharge & $-3.30 \%$ & $\pm 0.08 \%$ \\
\hline & BRL Silicate & Silica sinter & $+2.27 \%$ & $\pm 0.04 \%$ \\
\hline \multirow{4}{*}{ Rotokawa geothermal field } & RKL29-BR & Well discharge, liquid phase & $+0.11 \%$ 。 & $\pm 0.03 \%$ 。 \\
\hline & RKL33-BR & Well discharge, liquid phase & $+2.26 \%$ & $\pm 0.03 \%$ \\
\hline & RKL05 & Hot spring precipitate (mud) & $+2.65 \%$ & $\pm 0.02 \%$ \\
\hline & RKL07 & Sulfide rich siliceous sinter & $+2.40 \%$ o & $\pm 0.02 \%$ 。 \\
\hline \multirow{2}{*}{ Waiotapu geothermal park } & WCP06 Silicate & Siliceous sinter & $-5.49 \%$ & $\pm 0.12 \%$ \\
\hline & WCP06 Sulfide & Sulfide flocculent precipitate & $+1.23 \%$ & $\pm 0.03 \%$ \\
\hline \multirow{4}{*}{ Tsumeb Mine } & TMS-1 & Schaurteite; sulfate & $-11.92 \%$ & $\pm 0.10 \%$ 。 \\
\hline & TMS-2 & Tennantite/renierite; sulfide & $+1.32 \%$ & $\pm 0.04 \%$ \\
\hline & TMS-6 & Renierite/germanite; sulfide & $+2.31 \%$ & $\pm 0.04 \%$ \\
\hline & TMS-8 & Renierite/germanite/tennantite; sulfide & $+2.58 \%$ o & $\pm 0.03 \%$ 。 \\
\hline Kipushi Mine & TMS-5 & Renierite/briartite; sulfide & $-3.44 \%$ & $\pm 0.08 \%$ 。 \\
\hline Rhyolite & $\mathrm{JR}-2$ & Rhyolite powder (GSJ) & $-0.92 \%$ & $\pm 0.12 \%$ \\
\hline Basalt & BHVO-2 & Basalt Powder (USGS) & $-1.91 \%$ o & $\pm 0.23 \%$ \\
\hline
\end{tabular}

Samples measured with concentrations of gallium between $60 \mathrm{ppb}$ and $100 \mathrm{ppb}$, results are from a single analysis.

A fractionation is observed between sulfate and sulfide samples at Tsumeb Mine. TMS-1 is a sample of the mineral schaurteite, $\mathrm{Ca}_{3} \mathrm{Ge}\left(\mathrm{SO}_{4}\right)_{2}(\mathrm{OH})_{6} \cdot 4 \mathrm{H}_{2} \mathrm{O}$. It is a hydroxylated sulfate mineral and the $\delta^{71} \mathrm{Ga}$ value, $-11.92 \% 0 \pm 0.10 \%$, indicates that is depleted in ${ }^{71} \mathrm{Ga}$ in comparison to its related sulfide mineral sample TMS-2, $1.32 \%$ $\pm 0.04 \%$ (i.e. a sample of renierite, $\left.\left(\mathrm{Cu}^{1+}, \mathrm{Zn}\right)_{4} \mathrm{Fe}_{4}\left(\mathrm{Ge}^{4+}, \mathrm{As}^{5+}\right)_{2} \mathrm{~S}_{16}\right)$, which contains gallium as a common trace component. As mentioned in Wood and Samson (2006), sulfates may be an important factor in the mass transfer 


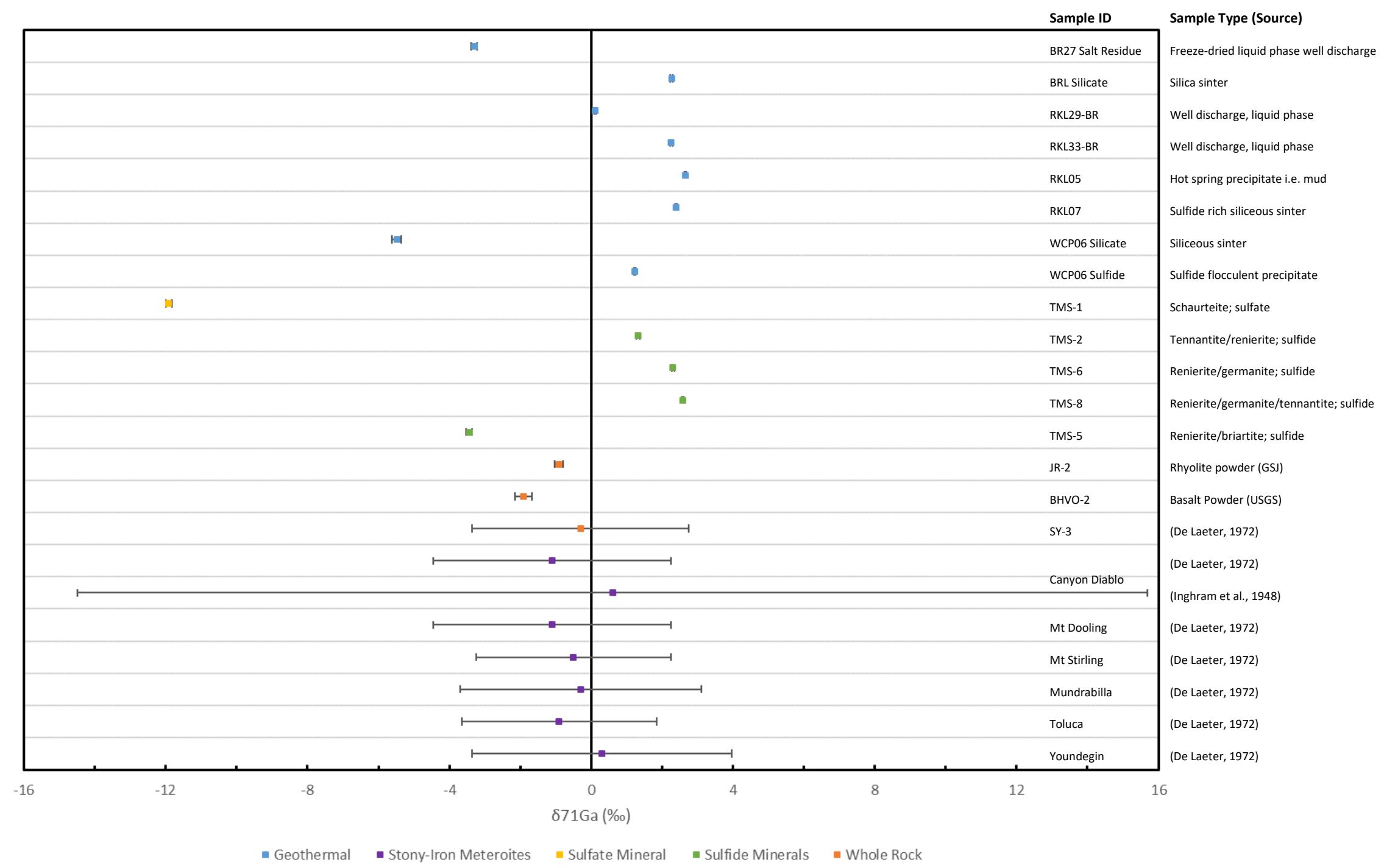

Figure 4.1 Comparison of $\delta^{71} \mathrm{Ga}$ values analysed in this study and previously measured stony-iron meteorites. 
of gallium in hydrothermal systems. A fractionation of the lighter gallium isotope into the weaker bonding environment could then be expected if the sulfate-gallium bond is in fact the weaker bond. It is interesting to note that the sulfide sample at Kipushi Mine (TMS-5; renierite/briartite) is depleted in ${ }^{71} \mathrm{Ga}\left(\delta^{71} \mathrm{Ga}:-3.44 \%\right.$ o $\pm 0.08 \%$ ) in comparison with similar sulfide minerals at Tsumeb Mine (TMS-2, 6 and 8 all-containing reinerite). Analysis from further gallium containing minerals and rocks from the Kipushi Mine would provide insight into the possible role of temperature, pressure and solution composition on the fractionation process. This indicates that the gallium isotopes undergo fractionation during precipitation of different gallium-containing sulfide minerals from hydrothermal solutions.

The samples taken at Ohaaki-Broadlands, collected in the early stages of the geothermal power extraction, where an enrichment in the light isotope is observed in the freeze-dried salt residue from a sample of geothermal brine $\left(\delta^{71} \mathrm{Ga}:-3.30 \% \pm \pm 0.08 \%\right.$ o $)$ in comparison to the silica sinter associated with the surface expression of the hydrothermal system. In comparison to the very different $\delta^{71} \mathrm{Ga}$ values of the Ohaaki-Broadlands system, the $\delta^{71} \mathrm{Ga}$ value of samples at the Rotokawa geothermal field are very similar for three of the samples, RKL33-BR, RKL05 and RKL07 (between $2.26 \%$ $\pm 0.03 \%$ and $2.65 \%$ o $\pm 0.02 \%$ ). Perhaps the re-injection process over the last 50 years, whereby geothermal fluid extracted from the reservoir for energy is recycled and re-injected into the systems so as to keep the system operational as a geothermal energy source, is affecting the isotopic composition of the system. The steam phase of the geothermal fluid may be preferentially extracting ${ }^{69} \mathrm{Ga}$ permanently from the system, leaving a reinjection fluid relatively enriched in ${ }^{71} \mathrm{Ga}$. When this ${ }^{71} \mathrm{Ga}$ enriched fluid recirculates and reaches the surface expression at Lake Rotokawa, the precipitation of more ${ }^{71} \mathrm{Ga}$ enriched silicates may occur. An isotopic analysis of the other phases in these systems (i.e. steam, sulfide, altered wall rock minerals etc.) will be useful in determining the reason for the similarity in the samples of the Rotokawa system across the different phases measured, as opposed large range observed between the brine and silicate samples of Ohaaki-Broadlands.

A fractionation of gallium isotopes is observed between sulfide and silicate samples at Waiotapu where the sulfide precipitate is relatively enriched in ${ }^{71} \mathrm{Ga}$. As the fractionation is unlikely to be redox mediated, the observed fractionation it more likely to be equilibrium, or mass-dependent induced. For lighter elements, it is known that the heavier isotope is enriched in the compound with the stronger bond (Albarède, 2003; White, 2013) during ligand exchange in precipitation processes. The fractionation is presumably the result of a stronger Ga-S compared to the Ga-O bonds. 


\section{CHAPTER 5. CONCLUSIONS}

The aim of this reconnaissance study was to determine if measurable gallium isotopic fractionations occur in natural samples from several active geothermal systems as well as in hydrothermal ore deposits. Appreciable gallium isotope fractionations have been demonstrated. These data should be a catalyst for more extensive and detailed investigations of the hitherto unstudied fractionation of gallium isotopes in natural Earth systems over wide ranges of temperature from ambient to hydrothermal environments as well as magmatic systems.

A successful method for the quantitative separation of gallium in order to analyse hydrothermalrelated samples for gallium isotopes was developed and reconnaissance measurements of samples from three geothermal fields of New Zealand as well as gallium containing minerals from Tsumeb Mine, in Namibia and Kipushi Mine in the Democratic Republic of the Congo were made. Thirty-six samples were analysed for trace elements and 15 for gallium isotopes including two rock standards. Gallium concentrations of up to $290 \mathrm{ppm}$ were found in hydrothermal sulfide precipitate samples of the Taupo Volcanic Zone. It was found that sulfide samples of New Zealand geothermal samples are enriched in ${ }^{71} \mathrm{Ga}$ with $\delta^{71} \mathrm{Ga}$ values ranging from $+2.40 \%$ to $+1.23 \%$. Sulfide minerals from Tsumeb Mine are also enriched in ${ }^{71} \mathrm{Ga}$ with $\delta^{71} \mathrm{Ga}$ values up to $2.58 \%$. However, the sulfide mineral analysed from Kipushi mine is relatively depleted in ${ }^{71} \mathrm{Ga}$ compared to its Tsumeb counterparts with a $\delta^{71} \mathrm{Ga}$ value of $-3.30 \%$. The supergene sulfate $\mathrm{m}$ mineral schaurteite contained $78 \mathrm{ppm}$ of gallium that was highly depleted in ${ }^{71} \mathrm{Ga}$ in comparison to the sulfide minerals from which the gallium was derived.

The observed fractionations do not occur because of changes in the gallium oxidation state. The fractionation of gallium in different sample types may then be attributed to mass dependent processes such as changes in ligand, with fractionation occurring due to relative bond strength of the ligands involved, or mass dependent processes related to phase separation during physical processes such as the flashing (boiling) of deep geothermal fluid to steam and liquid brine phase.

Further work needs to be undertaken to ensure the ion-exchange method can completely separate gallium from all trace metals that may impose space-charge effects in the plasma, and the "cleaner" method should be applied to reanalyse the samples presented in this thesis. Further research should be undertaken to better understand the processes that may affect the outcome of the gallium isotope ratio in hydrothermal systems and should include the following:

- Collection of more gas condensate samples. A larger sample is required to concentrate gallium to a level where isotope measurements can be made. At least $100 \mathrm{~L}$ from each well needs to be collected, pre-concentrated and analysed, in order to measure the gallium isotope composition of steam in equilibrium with the residual liquid phase. 
- Collection and analysis of more hot spring precipitates and inclusion of well discharge precipitates. Gallium isotope analysis of hydrothermally altered rock and hydrothermal minerals from deep wells at Rotokawa and Ohaaki-Broadlands geothermal systems. In these altered samples, $\mathrm{Ga}^{3+}$ may be sequestered in the hydrothermally altered silicate minerals. These further analyses will help to better characterise the gallium isotope composition of the hydrothermal systems.

- Repeat analyses of samples that were limited by gallium concentration and volume of sample.

- Ga isotope analysis of $\mathrm{Ga}^{3+}$ bound to sulfide and oxygen ligands in primary sulfide minerals (and supergene alteration minerals) in the hydrothermal ore deposit at Tsumeb, Namibia.

- Investigation of the gallium bonding environment in the geothermal sulfide precipitates using synchrotron EXAFS and XANES absorption spectroscopy, and correlating the gallium isotopic composition to its bonding environment in the hot spring precipitates.

\subsection{Future work}

Further studies should be made on the speciation, solubility and stability of various hydrothermal related gallium complexes (i.e. hydroxides, sulfides, sulfides etc.) at high temperatures to elucidate what effect ligand exchange processes occurring during the transport of deep fluid from reservoir to surface will have on the gallium isotope ratio. There will be a leaching of gallium isotopes from the host rock into geothermal fluid based on the ligand composition of the fluid as it is transported from the geothermal reservoir to the surface.

The flashing of a super-heated fluid to steam and liquid phases may also induce a mass dependent fractionation of gallium isotope. Further analysis of gallium isotopes should be made on coupled steam condensate and brine solutions from geothermal well sites.

There are a number of investigations that would complement this reconnaissance study on the isotopes of gallium in hydrothermal systems. The following sections outline those that would be of most benefit to better understand processes that may result in a fractionation of gallium isotopes that occur in hydrothermal systems.

\subsubsection{Gallium in the other phases of hydrothermal systems}

Gallium was detected the vapour phase of the hydrothermal well samples. This is of great interest as there could be a fractionation of gallium isotopes associated with the flashing (boiling) process. Unfortunately, the gas condensate samples did not contain enough gallium to analyse the isotopic ratio. Therefore it would be a key step for further research in this field to collect larger volumes 
of the steam condensate and analyse these for gallium isotopes. Further sampling and isotopic analysis of other aspects of the hydrothermal systems would also be beneficial for the understanding of the behaviour of gallium isotopes through the whole system. A gallium isotope analysis should be made of hydrothermally altered rock and hydrothermal minerals from deep wells at Rotokawa and Ohaaki-Broadlands geothermal systems. In these altered samples, $\mathrm{Ga}^{3+}$ may be sequestered in the hydrothermally altered silicate minerals. In addition, unaltered, fresh rocks (rhyolites, dacites, etc.) in the TVZ as well as basement greywackes, need to be analysed for the bulk gallium concentration and gallium isotopic composition. These further analyses will help to better characterise the gallium isotope composition of the hydrothermal systems.

\subsubsection{Speciation of gallium in hydrothermal fluids}

Geologically relevant complexes of gallium have been critically reviewed by Wood and Samson (2006). In general, there is little information on the speciation and stability of gallium in natural aqueous solutions, especially at elevated temperature and pressures such as those found in hydrothermal systems. There have been a number of studies conducted on the hydroxide complexes of gallium at temperatures relevant to hydrothermal systems (i.e. up to $300^{\circ} \mathrm{C}$; Benezeth et al., 1997; Diakonov et al., 1997; Wood and Samson, 2006). It is interesting to note that unhydrolised $\mathrm{Ga}^{3+}$ would not play a significant role in hydrothermal mass transfer of gallium (Wood and Samson, 2006). Hydroxide complexes have been predicted to be the most important forms of transport for gallium, however, there is some evidence that suggests fluoride complexes will be important where the activity of fluoride is relatively high (e.g. greisen formation). At temperatures below $300^{\circ} \mathrm{C}$, chloride complexes are not expected to play a significant role in the mass transfer of gallium. Wood and Samson (2006) suggest that under special conditions, the presence of sulfate complexes of gallium may play limited roles in the hydrothermal mass transfer of gallium. This warrants further investigation with regards to this study as there is a significant presence of sulfide minerals in the environments sampled, in particular those of Tsumeb and Kipushi mines. The role (if any) of reduced sulfur (e.g. HS ${ }^{-}$) in gallium transport in hydrothermal environments is unknown.

\subsubsection{Fine structure of gallium-sulfide/gallium-silica complexes}

Ga has only one nominal oxidation state (i.e. $\mathrm{Ga}^{3+}$ ). Therefore, redox reactions should not affect the gallium isotope ratio. However, the bonding environment of gallium will play a significant role in the fractionation of gallium isotopes. Extended X-ray Absorption Fine Structure (EXAFS) and X-Ray Absorption Near Edge Structure (XANES) measurements can be used to determine the bonding environment of $\mathrm{Ga}$, and such measurements can be made at the Australian Synchrotron facility in Melbourne. The isotopic composition of the gallium in the sulfide 
precipitates of Rotokawa is most likely related to the gallium bonding environment. Insight into this could be obtained using x-ray absorption spectroscopy.

Silicic acid, $\mathrm{Si}(\mathrm{OH})_{4}$, and sulfides are important components of hydrothermal waters, particularly hydrothermal waters in which aqueous silica and sulfide are saturated (Lovelock, 1995; Junqing et al., 2000), such as in the Wairakei hydrothermal field (Lovelock, 1995). Aqueous aluminium/iron (III) silicate complexes can enhance mobility of $\mathrm{Fe}$ and $\mathrm{Al}$ in aquatic systems (Olsen and O’Melia, 1973; Doelsch et al., 2000; Exley and Birchall, 1993). Gallium and aluminium are both located in the third column of the period table, and therefore exhibit similar chemical and geochemical properties (Baes and Mesmer, 1976). It is known that gallium forms stable complexes with silicate species (Pokrovski et al., 2002). Knowledge of gallium coordination and local atomic environment in their hydroxide, silicate and sulfide complexes is not well studied and necessary for understanding the mobility of gallium and formation of galliumcontaining minerals, and the role of aqueous silica and sulfide in these processes.

X-ray absorption fine structure (EXAFS) is a direct in situ method that provides quantitative information at the atomic scale about local structural environment (i.e. ligand identity and number, and inter-atomic distance). Gallium can be studied using EXAFS spectroscopy at concentrations less than one millimolar using third generation synchrotron light sources. Therefore, EXAFS spectroscopy would allow accurate results for Ga-silica and Ga-sulfide interactions and can be used for understanding the behaviour of gallium in hydrothermal waters.

\subsubsection{Addition of thallium isotope measurements}

It is interesting to note that in the samples that have so far been collected, thallium (Tl) is also concentrated into sulphide minerals. $\mathrm{Tl}$ is also has two stable isotopes, ${ }^{203} \mathrm{Tl}$ and ${ }^{205} \mathrm{Tl}$, and have been shown to fractionate substantially, despite their heavy masses. This provides an ideal opportunity to extend the work as a method for precise measurement of $\mathrm{Tl}$ isotopes as well, using MC-ICPMS methodology already established. The addition of TI isotopic data for the already collected samples would add significantly to the understanding of geothermal/hydrothermal processes that are occurring in association with sulfides, thus complementing the gallium isotope analysis. Thallium has two oxidation states in aqueous systems (i.e. $\mathrm{Tl}^{+}$and $\mathrm{Tl}^{3+}$ ) and hence, significant redox mediated isotope fractionations should occur in natural systems but have never been observed. 


\section{REFERENCES}

Albarède, F., 2003, Geochemistry, an Introduction. Cambridge University Press.

Albarède, F., and Beard, B., 2004, Analytical methods for non-traditional isotopes: Reviews in Mineralogy and Geochemistry, v. 55, p. 113-152.

Aston, F. W., 1935, The isotopic constitution and atomic weights of Hafnium, Thorium, Rhodium, Titanium, Zirconium, Calcium, Gallium, Silver, Carbon, Nickel, Cadmium, Iron and Indium, In: Proceedings of the Royal Society of London. Series A - Mathematical and Physical Sciences, v. 149, no. 867, p. 396-405.

Baes Jr., C.F., and Mesmer, R.E., 1986. The Hydrolysis of Cations. Krieger Publishing Company, Malabar, Florida. 489 pp.

Benézéth, P., Diakonov, I. I., Pokrovski, G. S., Dandurand, J.-L., Schott, J., and Khodakovsky, I. L., 1997, Gallium speciation in aqueous solution. Experimental study and modelling: Part 2. Solubility of $\alpha-\mathrm{GaOOH}$ in acidic solutions from 150 to $250^{\circ} \mathrm{C}$ and hydrolysis constants of gallium (III) to $300^{\circ} \mathrm{C}$ : Geochimica et Cosmochimica Acta, v. 61, no. 7, p. 1345-1357.

Crump, M. E., 1995, A new source of gallium - geotheraml muds: PACRIM 1995 Congress.

De Groot, P. A., 2009, Handbook of stable isotope analytical techniques, v. 2, Elsevier.

De Laeter, J. R., 1972, The isotopic composition and elemental abundance of gallium in meteorites and in terrestrial samples: Geochimica et Cosmochimica Acta, v. 36, no. 7, p. 735-743.

Dembinski, Q., Herdzik, I., Skwara, W., Bulska, E., and Wysocka, A. I., 2006, Isotope effects of gallium in cation exchange chromatography: Nukleonika, v. 15, no., 4, p. 217-220.

Denisova, N. E., and Tsvetkova, E. V., 1961, Analysis of aluminium-antimony-gallium alloys: Zavodskaya Laboratoriya, v. 27, p, 656.

Diakonov, I. I., Pokrovski, G. S., Bénézeth, P., Schott, J., Dandurand, J.-L., and Escalier, J., 1997, Gallium speciation in aqueous solution. Experimental study and modelling: Part 1. Thermodynamic properties of $\mathrm{Ga}(\mathrm{OH}) 4-$ to $300^{\circ} \mathrm{C}$ : Geochimica et Cosmochimica Acta, v. 61, no. 7, p. 1333-1343.

Doelsch E., Rose J., Masion A., Bottero J.Y., Nahon D., and Bertch P. M. , 2000, Speciation and crystal chemistry of iron (III) chloride hydrolyzed in the presence of $\mathrm{SiO} 4$ ligands. 1. An Fe K-edge EXAFS study: Langmuir v. 16, p. 4726-4731.

Ehrlich, S., Butler, I., Halicz, L., Rickard, D., Oldroyd, A., and Matthews, A., 2004, Experimental study of the copper isotope fractionation between aqueous $\mathrm{Cu}$ (II) and covellite, CuS: Chemical Geology, v. 209, p. 259-269.

Ellis, A., J., and Mahon, W., A., 1977, Chemistry and Geothermal Systems: Academic Press, New York, San Francisco, London.

Exley C. and Birchall J. D., 1993, A mechanism of hydroxyaluminosilicate formation: Polyhedron, v. 12, p. 1007-1017.

Gillieson, A. H., 1969, S.C.C. Reference standards: Canadian Spectroscopy, v. 13, 144.

Goldman, M., Nief, G., and Roth, E., 1956, Influence de la temperature sur la separation isotopique sous l'effet du courant dans le gallium fondu: Comptes rendus Hebdomadairs des seances de l'Academie des sciences, v. 243, p. 1414-1416.

Graham, S., Pearson, N., Jackson, S., Griffin, W., and O'Reilly, S.Y., 2004, Tracing Cu and Fe from source to porphyry: in situ determination of $\mathrm{Cu}$ and $\mathrm{Fe}$ isotope ratios in sulfides from the Grasberg Cu-Au deposit: Chemical Geology, v. 207, p. 147-169. 
Gramlich, J. W., and Machlan, L. A., 1985, Isotopic variations in commercial high-purity gallium: Analytical Chemistry, v. 57, no. 8, p. 1788-1790.

Inghram, M. G., Hess, D. C., Jr., Brown, H. S., and Goldberg, E., 1948, On the Isotopic Composition of Meteoritic and Terrestrial Gallium: Physical Review, v. 74, no. 3, p. 343344.

John, D. A., 2001, Miocene and Early Pliocene Epithermal Gold-Silver Deposits in the Northern Great Basin, Western United States: Characteristics, Distribution, and Relationship to Magmatism: Economic Geology, v. 96, no. 8, p. 1827-1853.

Junqing, H., Bin, D., Kaibin, T., Qingyi, L., Rongrong, J., and Yitai, Q., 2001, Hydrothermal preparation and characterization of nanocrystalline: Silver gallium sulfides: Solid State Sciences, v. 3, no. 3, p. 275-278.

Kloo, L., Rosdahl, J., and Taylor, M. J., 2002, The nature of subvalent gallium and indium in aqueous media: Polyhedron, v. 21, no. 5-6, p. 519-524.

Korkisch, J., 1988, CRC Handbook of Ion Exchange Resins: Their application to inorganic analytical chemistry, Boca Raton, Florida, CRC Press, 301 p.

Korkisch, J., and Hazan, I., 1965, Anion-exchange separations in hydrobromic acid-organic solven media: Analytical Chemistry, v. 37, p. 707.

Korkisch, J., Steffan, I., Nonaka, J., and Arrhenius, G., 1979, Chemical analysis of manganese nodules: Part 5. Determination of Gallium after Anion-Exchange Separation: Analytica Chimica Acta, v. 109, no. 1, p. 181-185.

Kraus, K. A., Nelson, F., and Smith, G. W., 1954, Anion-Exchange Studies. Absorbability of a number of metals in Hydrochloric Acid Solutions: Journal of Physical Chemistry, v. 58, p. 11-17.

Krupp, R., E., and Seward, T., M., 1987, The Rotokawa geothermal system, New Zealand: An active epithermal gold-depositing environment: Economic Geology, v.82, p. 1109-1129.

Krupp, R. E., and Seward, T., M., 1990, Transport and deposition of metals in the Rotokawa geothermal system, New Zealand: Mineralium Deposita, v. 25, p. 73-81.

Lovelock, B., 1995. Deviations in silica geothermometry at Wairakei: World Geothermal Congress, v. 2, p. 983-988.

Machlan, L. A., and Gramlich, J. W., 1988, Isotopic fractionation of gallium on an ionexchange column: Analytical Chemistry, v. 60, no. 1, p. 37-39.

Machlan, L. A., Gramlich, J. W., Powell, L. J., and Lambert, G. M., 1986, Absolute isotopic abundance ratio and atomic weight of a reference sample of gallium: Journal of Research of the National Bureau of Standards, v. 91, no. 6.

Maréchal, C. N., Telouk, P., and Albarède, F., 1999, Precise analysis of copper and zinc isotopic compositions by plasma-source mass spectrometry: Chemical Geology, v. 156, p. 251-273.

May, T. W., and Weidmeyer, R. H., 1998, A table of polyatomic interferences in ICPMS: Atomic Spectroscopy: v. 19, no. 5, p. 150-155.

McKibben, M. A., and Williams, A. E., 1989, Metal speciation and solubility in saline hydrothermal fluids; an empirical approach based on geothermal brine data: Economic Geology, v. 84, no. 7, p. 1996-2007.

Miner, F. J., and De Grazio, R. P., Ion-exchange separation and volumetric determination of gallium in plutonium-gallium alloys: Analytical Chemistry, v. 37, p. 1071.

Morris, D. F. C., and Brewer, F. M., 1954, The occurrence of gallium in blende: Geochimica et Cosmochimica Acta, v. 5, no. 3, p. 134-141. 
Morris, D. F. C., and M. E. Chambers, M., 1960, The determination of gallium in rocks by neutron-activation analysis: Talanta, v. 5, no. 3-4, p. 147-153.

Nadezhina, L. S., 1962, Determination of small amounts of gallium: Zhurnal Analiticheskoi Khimii, v. 17, no. 3, p 383.

Neif, G., and Roth, E., 1954, Sur un phenomene de separation d'isotopes provoque par passage de courant electric dans un metal fondu: Comptes rendus de l'Academie des Sciences, v. 239 , p. $162-164$.

Neirinckx, R. D., and van der Merwe, M. J., 1971, Production of iron-free and carrier-free gallium-67: Radiochemical and Radioanalytical Letters, v. 7, p. 31-35.

Olsen, L. L., and O'Melia, C. R., 1973, The interaction of Fe(II) with $\mathrm{Si}(\mathrm{OH})$ : Journal of Inorganic Nuclear Chemistry, v. 35, p. 1977-1985.

Pesch, R., 2001, Interferences Workshop version 2.5, Thermo Finnigan, Bremen, Germany.

Pokrovski, G. S., Schott, J., Hazemann, J.-L., Farges, F., and Pokrovsky, O. S., 2002, An X-ray absorption fine structure and nuclear magnetic resonance spectroscopy study of galliumsilica complexes in aqueous solution: Geochimica et Cosmochimica Acta, v. 66, no. 24, p. 4203-4222.

Rouxel, O., Fouquet, Y., and Ludden, J.N., 2004, Copper isotope systematics of the Lucky Strike, Rainbow, and Logatchev sea-floor hydrothermal fields on the Mid-Atlantic Ridge: Economic Geology, v. 99, p. 585-600.

Rytuba, J.J., John, D.A., Foster, A., Ludington, S.D., and Kotlyar, B., 2003, Hydrothermal enrichment of gallium in zones of advanced argillic alteration-examples from the Paradise Peak and McDermitt ore deposits, Nevada: U.S. Geological Survey Bulletin 2209-C, 16 pp.

Saito, T., 1984, Selected data on ion exchange separation in radioanalytical chemistry, Pure and Applied Chemistry, v. 56, no. 4, p. 523-539.

Shaw, D. M., 1957, The geochemistry of gallium, indium, thallium — a review: Physics and Chemistry of the Earth, v. 2, no. 0, p. 164-211.

Strelow, F. W. E., 1980a, Quantitative separation of gallium from uranium, cobalt, aluminium and many other elements by cation-exchange chromatography in mixtures of hydrochloric or hydrobromic acid with acetone: Analytica Chimica Acta, v. 113, no. 2, p. 323-329.

Strelow, F. W. E., 1980b, Quantitative separation of gallium from zinc, copper, indium, iron(III) and other elements by cation-exchange chromatography in hydrobromic acidacetone medium: Talanta, v. 27, no. 3, p. 231-236.

Strelow, F. W. E., and van der Walt, T. N., 1987, Separation of trace amounts of indium, gallium and aluminium from each other by cation-exchange chromatography on AG50-X4 resin: Talanta, v. 34, no. 10, p. 895-897.

Strelow, F. W. E., and Victor, A. H., 1972, Quantitative separation of aluminium, gallium, indium, and thallium by cation-exchange chromatography in hydrochloric acid-acetone: Talanta, v. 19, p. 1019.

Strelow, F. W. E., Wienert, C. H. S. W., and van der Walt, T. N., 1974, Selective separation of indium from zinc, lead, gallium and many other elements by cation-exchange chromatography in hydrohalic acid - acetone medium: Talanta, v. 21, no. 11, p. 1183-1191.

Stulzaft, O., Maziere, B., and Ly, S., 1980, Gallium determination in biological samples: Journal of Radioanalytical Chemistry, v. 55, no. 2, p. 291.

Tan, S. H., and Horlick, G., 1986, Background spectral features in inductively coupled plasma mass spectrometry: Applied Spectroscopy, v. 40, p. 445-460. 
Ullrich, M. K., 2012, Sulfur redox chemistry governs diurnal antimony and arsenic cycles at Champagne Pool, Waiotapu, New Zealand, Masters Thesis, Universitat Bayreuth.

Uzumasa, Y., and Nasu, Y., 1960. Chemical investigations of hot springs in Japan: LVII. Gallium in hotsprings: Nippon Kagaku Zasshi, v. 81, p. 732.

van der Walt, T. N., and Strelow, F. W. E., 1983, Quantitative separation of gallium from elements by cation-exchange chromatography: Analytical Chemistry, v. 55, no. 2, p. 212216.

Weissberg, B. G., Browne, P. R. L., and Seward, T.M., 1979, Ore metals in active geothermal systems. In: Barnes, H.L. (Ed.), Geochemistry of Hydrothermal Ore Deposits, 2nd edition. John-Wiley and Sons, New York, p. 738-780.

White, W. M., 2013, Geochemistry. Wiley-Blackwell.

White, W. M., Albarède, F., and Telouk, P., 2000, High-precision analysis of Pb isotope ratios by multi-collector ICPMS: Chemical Geology, v. 167, p. 257-270.

Wood, S. A., and Samson, I. M., 2006, The aqueous geochemistry of gallium, germanium, indium and scandium: Ore Geology Reviews, v. 28, no. 1, p. 57-102.

Zweidinger, R. A., Barnett, L., and Pitt, C. G., 1973, Fluorimetric determination of gallium in biological materials at nanogram levels: Analytical Chemistry, v. 45, p. 1563. 


\section{APPENDIX}

\begin{tabular}{|c|c|c|c|c|c|}
\hline Resin & $\begin{array}{l}\text { Length } \\
(\mathrm{cm})\end{array}$ & Eluents & $\begin{array}{l}\text { Volume of } \\
\text { Eluates }\end{array}$ & $\begin{array}{l}\text { Elements present in } \\
\text { gallium eluate }\end{array}$ & $\begin{array}{l}\text { Ga recovered } \\
(\%)\end{array}$ \\
\hline AG50W-X4, 100-200 & 1 & $\begin{array}{l}8 \mathrm{M} \mathrm{HCl} \\
2.5 \mathrm{M} \mathrm{HCl}^{*}\end{array}$ & $\begin{array}{l}30 \mathrm{ml} \\
10 \mathrm{ml}\end{array}$ & $\mathrm{Mn}, \mathrm{Fe}, \mathrm{Zn} *$ & $7.36 \%$ \\
\hline AG50W-X4, 200-400 & 3 & $\begin{array}{l}8 \mathrm{M} \mathrm{HCl} \\
2.5 \mathrm{M} \mathrm{HCl}^{*}\end{array}$ & $\begin{array}{r}15 \mathrm{ml} \\
5 \mathrm{ml}\end{array}$ & $\mathrm{Mn}, \mathrm{Fe}, \mathrm{Zn} *$ & $85 \%$ \\
\hline AG50W-X4, 200-400 & 5 & $\begin{array}{l}8 \mathrm{M} \mathrm{HCl}+0.001 \% \mathrm{Nal} \\
8 \mathrm{M} \mathrm{HCl} \\
2.5 \mathrm{M} \mathrm{HCl}^{*}\end{array}$ & $\begin{array}{l}10 \mathrm{ml} \\
10 \mathrm{ml} \\
10 \mathrm{ml}\end{array}$ & $\begin{array}{l}\mathrm{Na}, \mathrm{Zn}, \mathrm{Fe}, \mathrm{V}, \mathrm{Cr}, \\
\mathrm{Mn}^{*}\end{array}$ & $5.65 \%$ \\
\hline AG 50W-X4, 200-400 & 4.5 & $\begin{array}{l}0.5 \mathrm{M} \mathrm{HBr} \text { in } 65 \% \text { Acetone } \\
0.2 \mathrm{M} \mathrm{HBr} \text { in } 80 \% \text { Acetone } \\
2.5 \mathrm{M} \mathrm{HCl}^{*}\end{array}$ & $\begin{array}{r}10 \mathrm{ml} \\
5 \mathrm{ml} \\
5 \mathrm{ml}\end{array}$ & Tl, V, Cr, Mn, Zn, Fe* & $85.68 \%$ \\
\hline AG1-X8, 100-200 & 7 & $\begin{array}{l}4 \mathrm{M} \mathrm{HCl}+\text { conc } \mathrm{TiCl} 3 \\
6 \mathrm{M} \mathrm{HCl} \\
2 \mathrm{M} \mathrm{HNO}^{*}\end{array}$ & $\begin{array}{l}25 \mathrm{ml} \\
20 \mathrm{ml} \\
50 \mathrm{ml}\end{array}$ & $\mathrm{Mn}, \mathrm{Fe}, \mathrm{Zn} *$ & $83.09 \%$ \\
\hline AG50W-X4, 200-400 & 4.5 & $\begin{array}{l}8 \mathrm{M} \mathrm{HCl}+0.001 \% \mathrm{TiCl} 3 \\
8 \mathrm{M} \mathrm{HCl} \\
2.5 \mathrm{M} \mathrm{HCl}^{*}\end{array}$ & $\begin{array}{l}15 \mathrm{ml} \\
15 \mathrm{ml} \\
15 \mathrm{ml}\end{array}$ & $\mathrm{Sb}, \mathrm{Tl}, \mathrm{Cr}, \mathrm{Mn}, \mathrm{Fe}, \mathrm{Zn}$ & $68.57 \%$ \\
\hline AG50W-X4, 200-400 & 15 & $\begin{array}{l}8 \mathrm{M} \mathrm{HCl}+0.001 \% \mathrm{TiCl} 3 \\
8 \mathrm{M} \mathrm{HCl}+\operatorname{tr} . \mathrm{HF} \\
2.5 \mathrm{M} \mathrm{HCl}^{*}\end{array}$ & $\begin{array}{r}60 \mathrm{ml} \\
120 \mathrm{ml} \\
40 \mathrm{ml}\end{array}$ & $\mathrm{V}, \mathrm{Mn}, \mathrm{Fe}, \mathrm{Zn}$ & $0 \%$ \\
\hline AG50W-X12, 100-200 & 15 & $\begin{array}{l}8 \mathrm{M} \mathrm{HCl}+0.3 \% \mathrm{TiCl} 3 \\
8 \mathrm{M} \mathrm{HCl} \\
2.5 \mathrm{M} \mathrm{HCl}^{*}\end{array}$ & $\begin{array}{r}90 \mathrm{ml} \\
100 \mathrm{ml} \\
40 \mathrm{ml}\end{array}$ & $\begin{array}{l}\mathrm{Tl}, \mathrm{Sb}, \mathrm{Sn}, \mathrm{V}, \mathrm{Cr}, \mathrm{Mn}, \\
\mathrm{Fe}\end{array}$ & $52.10 \%$ \\
\hline AG50W-X4, 200-400 & 15 & $\begin{array}{l}8 \mathrm{M} \mathrm{HCl}+0.3 \% \mathrm{TiCl} 3 \\
8 \mathrm{M} \mathrm{HCl}^{*} \\
2.5 \mathrm{M} \mathrm{HCl}^{*}\end{array}$ & $\begin{array}{r}90 \mathrm{ml} \\
100 \mathrm{ml} \\
40 \mathrm{ml}\end{array}$ & $\mathrm{Tl}, \mathrm{Ag}, \mathrm{V}, \mathrm{Cr}, \mathrm{Mn}, \mathrm{Fe}$ & $93.23 \%$ \\
\hline AG50W-X8, 100-200 & 15 & $\begin{array}{l}8 \mathrm{M} \mathrm{HCl}+0.3 \% \mathrm{TiCl} \\
8 \mathrm{M} \mathrm{HCl} \\
2.5 \mathrm{M} \mathrm{HCl}^{*}\end{array}$ & $\begin{array}{r}90 \mathrm{ml} \\
100 \mathrm{ml} \\
40 \mathrm{ml}\end{array}$ & $\mathrm{V}, \mathrm{Cr}, \mathrm{Mn}, \mathrm{Fe}$ & $99.47 \%$ \\
\hline AG50W-X8, 200-400 & 15 & $\begin{array}{l}8 \mathrm{M} \mathrm{HCl}+0.3 \% \mathrm{TiCl} 3 \\
8 \mathrm{M} \mathrm{HCl} \\
2.5 \mathrm{M} \mathrm{HCl}^{*}\end{array}$ & $\begin{array}{r}90 \mathrm{ml} \\
100 \mathrm{ml} \\
40 \mathrm{ml}\end{array}$ & $\mathrm{V}, \mathrm{Mn}, \mathrm{Fe}, \mathrm{Sb}$ & $0.04 \%$ \\
\hline AG50W-X8, 100-200 & 1.5 & $\begin{array}{l}8 \mathrm{M} \mathrm{HCl}+0.3 \% \mathrm{TiCl} 3 \\
8 \mathrm{M} \mathrm{HCl}^{*} \\
2.5 \mathrm{M} \mathrm{HCl}^{*}\end{array}$ & $\begin{array}{l}40 \mathrm{ml} \\
50 \mathrm{ml} \\
20 \mathrm{ml}\end{array}$ & $\mathrm{Sb}, \mathrm{Fe}, \mathrm{Zn}$ & $6.44 \%$ \\
\hline AG50W-X8, 100-200 & 1.5 & $\begin{array}{l}8 \mathrm{M} \mathrm{HCl}+0.3 \% \mathrm{TiCl} 3 \\
8 \mathrm{M} \mathrm{HCl} \\
2.5 \mathrm{M} \mathrm{HCl}^{*}\end{array}$ & $\begin{array}{r}90 \mathrm{ml} \\
100 \mathrm{ml} \\
40 \mathrm{ml}\end{array}$ & $\mathrm{Ag}, \mathrm{Fe}, \mathrm{Sb}$ & $98.84 \%$ \\
\hline
\end{tabular}




\begin{tabular}{|c|c|c|c|c|c|}
\hline Resin & $\begin{array}{l}\text { Length } \\
\text { (cm) }\end{array}$ & Eluents & $\begin{array}{l}\text { Volume of } \\
\text { Eluates }\end{array}$ & $\begin{array}{l}\text { Elements present in } \\
\text { gallium eluate }\end{array}$ & $\begin{array}{l}\text { Ga recovered } \\
\text { (\%) }\end{array}$ \\
\hline AG50W-X8, 100-200 & 3 & $\begin{array}{l}8 \mathrm{M} \mathrm{HCl}+0.3 \% \mathrm{TiCl} 3 \\
8 \mathrm{M} \mathrm{HCl} \\
2.5 \mathrm{M} \mathrm{HCl}^{*}\end{array}$ & $\begin{array}{l}40 \mathrm{ml} \\
50 \mathrm{ml} \\
20 \mathrm{ml}\end{array}$ & $\mathrm{Ag}, \mathrm{Sb}, \mathrm{V}, \mathrm{Mn}, \mathrm{Fe}$ & $47.35 \%$ \\
\hline AG50W-X8, 100-200 & 3 & $\begin{array}{l}8 \mathrm{M} \mathrm{HCl}+0.3 \% \mathrm{TiCl} 3 \\
8 \mathrm{M} \mathrm{HCl} \\
2.5 \mathrm{M} \mathrm{HCl}^{*}\end{array}$ & $\begin{array}{r}90 \mathrm{ml} \\
100 \mathrm{ml} \\
40 \mathrm{ml}\end{array}$ & $\mathrm{Sb}, \mathrm{V}, \mathrm{Mn}, \mathrm{Fe}$ & $95.83 \%$ \\
\hline AG50W-X8, 100-200 & 6 & $\begin{array}{l}8 \mathrm{M} \mathrm{HCl}+0.3 \% \mathrm{TiCl} 3 \\
8 \mathrm{M} \mathrm{HCl} \\
2.5 \mathrm{M} \mathrm{HCl}^{*}\end{array}$ & $\begin{array}{r}120 \mathrm{ml} \\
150 \mathrm{ml} \\
40 \mathrm{ml}\end{array}$ & $\mathrm{V}, \mathrm{Cr}, \mathrm{Mn}, \mathrm{Fe}$ & $63.38 \%$ \\
\hline AG50W-X8, 100-200 & 6 & $\begin{array}{l}8 \mathrm{M} \mathrm{HCl}+0.3 \% \mathrm{TiCl} 3 \\
8 \mathrm{M} \mathrm{HCl} \\
2.5 \mathrm{M} \mathrm{HCl}^{*}\end{array}$ & $\begin{array}{r}90 \mathrm{ml} \\
100 \mathrm{ml} \\
40 \mathrm{ml}\end{array}$ & $\mathrm{V}, \mathrm{Cr}, \mathrm{Mn}, \mathrm{Fe}$ & $63.84 \%$ \\
\hline AG50W-X12, 100-200 & 15 & $\begin{array}{l}8 \mathrm{M} \mathrm{HCl}+0.3 \% \mathrm{TiCl} 3 \\
8 \mathrm{M} \mathrm{HCl} \\
2.5 \mathrm{M} \mathrm{HCl}^{*}\end{array}$ & $\begin{array}{r}90 \mathrm{ml} \\
100 \mathrm{ml} \\
40 \mathrm{ml}\end{array}$ & $\begin{array}{l}\mathrm{Ag}, \mathrm{Sn}, \mathrm{Hg}, \mathrm{Tl}, \mathrm{Mg}, \\
\mathrm{Al}, \mathrm{Sc}, \mathrm{Ti}, \mathrm{Cr}, \mathrm{Fe}, \mathrm{Ni}, \\
\mathrm{Cu}, \mathrm{Zn}\end{array}$ & $54.16 \%$ \\
\hline AG50W-X8, 100-200 & 15 & $\begin{array}{l}8 \mathrm{M} \mathrm{HCl}+0.3 \% \mathrm{TiCl} 3 \\
8 \mathrm{M} \mathrm{HCl} \\
2.5 \mathrm{M} \mathrm{HCl}^{*}\end{array}$ & $\begin{array}{r}90 \mathrm{ml} \\
100 \mathrm{ml} \\
40 \mathrm{ml}\end{array}$ & $\begin{array}{l}\mathrm{Sn}, \mathrm{Hg}, \mathrm{Tl}, \mathrm{Mg}, \mathrm{Al} \text {, } \\
\mathrm{Sc}, \mathrm{Ti}, \mathrm{Cr}, \mathrm{Fe}, \mathrm{Ni}, \mathrm{Cu} \text {, } \\
\mathrm{Zn}, \mathrm{As}\end{array}$ & $99.30 \%$ \\
\hline AG50W-X4, 200-400 & 15 & $\begin{array}{l}8 \mathrm{M} \mathrm{HCl}+0.3 \% \mathrm{TiCl} 3 \\
8 \mathrm{M} \mathrm{HCl} \\
2.5 \mathrm{M} \mathrm{HCl}^{*}\end{array}$ & $\begin{array}{r}90 \mathrm{ml} \\
100 \mathrm{ml} \\
40 \mathrm{ml}\end{array}$ & $\begin{array}{l}\mathrm{Ag}, \mathrm{Sn}, \mathrm{Mg}, \mathrm{Al}, \mathrm{Mn} \text {, } \\
\mathrm{Ti}, \mathrm{Cr}, \mathrm{Fe}, \mathrm{Ni}, \mathrm{Cu}, \mathrm{Zn} \text {, } \\
\text { As }\end{array}$ & $75.89 \%$ \\
\hline AG50W-X4, 50-100 & 15 & $\begin{array}{l}8 \mathrm{M} \mathrm{HCl}+0.3 \% \mathrm{TiCl} 3 \\
8 \mathrm{M} \mathrm{HCl} \\
2.5 \mathrm{M} \mathrm{HCl}^{*}\end{array}$ & $\begin{array}{r}90 \mathrm{ml} \\
100 \mathrm{ml} \\
40 \mathrm{ml}\end{array}$ & $\begin{array}{l}\mathrm{Ag}, \mathrm{Sn}, \mathrm{Hg}, \mathrm{Tl}, \mathrm{Al}, \mathrm{Sc}, \\
\mathrm{Ti}, \mathrm{V}, \mathrm{Cr}, \mathrm{Mn}, \mathrm{Fe}, \mathrm{Co}, \\
\mathrm{Ni}, \mathrm{Cu}, \mathrm{Zn}, \mathrm{As}\end{array}$ & $65.96 \%$ \\
\hline AG50W-X8, 200-400 & 15 & $\begin{array}{l}8 \mathrm{M} \mathrm{HCl}+0.3 \% \mathrm{TiCl} 3 \\
8 \mathrm{M} \mathrm{HCl} \\
2.5 \mathrm{M} \mathrm{HCl}^{*}\end{array}$ & $\begin{array}{r}90 \mathrm{ml} \\
100 \mathrm{ml} \\
40 \mathrm{ml}\end{array}$ & $\begin{array}{l}\mathrm{Bi}, \mathrm{Mg}, \mathrm{Al}, \mathrm{Sc}, \mathrm{Ti}, \mathrm{Cr} \\
\mathrm{Fe}, \mathrm{Ni}, \mathrm{As}, \mathrm{Zn}\end{array}$ & $95.70 \%$ \\
\hline
\end{tabular}

